\title{
POTENCIALIDADE DO SISTEMA DE COLHEITA SEM QUEIMA DA CANA-DE-AÇÚCAR PARA O SEQÜESTRO DE CARBONO
}

\author{
DINAILSON CORRÊA DE CAMPOS
}

\begin{abstract}
Tese apresentada à Escola Superior de Agricultura “Luiz de Queiroz", Universidade de São Paulo, para obtenção do título de Doutor em Agronomia, Área de Concentração: Microbiologia Agrícola
\end{abstract}

P I R A C I C A B A

Estado de São Paulo - Brasil

Maio - 2003 


\title{
POTENCIALIDADE DO SISTEMA DE COLHEITA SEM QUEIMA DA CANA-DE-AÇÚCAR PARA O SEQUËSTRO DE CARBONO
}

\section{DINAILSON CORRÊA DE CAMPOS}

Licenciado em Ciências

\author{
Orientador: Prof. Dr. CARLOS CLEMENTE CERRI
}

\begin{abstract}
Tese apresentada à Escola Superior de Agricultura
"Luiz de Queiroz", Universidade de São Paulo, para obtenção do título de Doutor em Agronomia, Área de Concentração: Microbiologia Agrícola
\end{abstract}

\author{
P I R A C I C A B A
}

Estado de São Paulo - Brasil

Maio - 2003 


\title{
Dados I nternacionais de Catalogação na Publicação (CI P) DIVISÃO DE BI BLI OTECA E DOCUMENTAÇÃO - ESALQ/ USP
}

\author{
Campos, Dinailson Corrêa de \\ Potencialidade do sistema de colheita sem queima da \\ cana-de-açúcar para o seqüestro de carbono / Dinailson \\ Corrêa de Campos. - - Piracicaba, 2003. \\ 103 p. : il. \\ Tese (doutorado) - Escola Superior de Agricultura Luiz de \\ Queiroz, 2003. \\ Bibliografia. \\ 1. Cana-de-açúcar 2. Carbono 3. Colheita mecânica 4. \\ Palhada I. Título
}

CDD 633.61 
Ofereço este trabalho

à minfra esposa goceli

e aos meus filfos Laura e Augusto

pelas muitas horas distantes, pôr serem fonte de energia

e porto seguro ao longo da caminfada e motivo maior do me u viver

Dedico este trabalfo

Aos meus paisg oão e Lusia

e aos meus irmãos

Dinae l, Dioné ia e Diovana

Pe la convivência familiar

que me permitiuser o que sou

"...uma coisa é você achar que está no caminfo certo, outra é achar que seu caminho é o único..."

Paulo Coelho 


\section{AGRADECIMENTOS}

Ao término de mais esta etapa da minha vida, gostaria de expressar os meus mais sinceros agradecimentos a todos que colaboraram para que o presente trabalho fosse realizado:

- Ao Prof. Dr. Carlos Clemente Cerri, pela orientação, amizade e incentivo na realização e condução deste trabalho;

- Ao Dr. Christian Leon Feller do IRD, um agradecimento especial pela co-orientação, amizade e incentivo na realização e condução deste trabalho;

- Ao CPG em Microbiologia Agrícola da Escola Superior de Agricultura "Luiz de Queiroz" - ESALQ/USP, pela possibilidade de realizar o curso e pelos ensinamentos recebidos;

- Ao Centro de Energia Nuclear na Agricultura (CENA/USP) pela oportunidade da realização deste trabalho;

- À Dra. Brigitte Feigel e a Dra. Marisa Piccolo, pelo auxílio dos trabalhos no Laboratório de Biogeoquímica Ambiental do CENA/USP;

- Ao Dr. Martial Bernoux do IRD pelo apoio e ensinamentos;

- Aos amigos do Laboratório de Biogeoquímica Ambiental do CENA, Sandra, Lílian, Dagmar, Luiz Hiroshi, Mara e Robertinho (em memória), pela amizade e apoio técnico, sem os quais não teria sido possível a realização deste trabalho;

- Ao estagiário Gleison de Souza, que muito auxiliou na condução deste trabalho;

- Ao companheiro de trabalhos Dr. Edgar Fernando de Luca, com quem desenvolvi este trabalho de doutoramento. A companheira e amiga Ecóloga Marilda Zanoni Mariotti Abbas pelo grande apoio em várias etapas do trabalho e da vida; 
- Aos amigos da sala de alunos da pós-graduação do Laboratório de Biogeoquímica Ambiental: Marcos Siqueira (Chiquitiba), Christiane Teixeira, Solismar Paiva Venzke (PV), Gabor Szakács, Mariana Pavei, Silvana Fernandes, Maria da Conceição, Marcelo, Karine, Janaína, Norberto, Caio, Cristiano e Viviane pelo convívio amigo, saudável e pelas longas discussões científicas e filosóficas;

- Ao grande amigo Dr. Luiz Humberto Gomes pela amizade e incentivo em mais esta jornada;

- Aos Profs. Drs. Luiz Gonzaga do Prado Filho e Gerd Sparovek e a Prof. Dra. Marisa Piccolo que participaram da minha qualificação, pelas sugestões e ajuda na elaboração deste trabalho;

- A Fundação de Amparo à Pesquisa do Estado de São Paulo - FAPESP, pela concessão da bolsa de estudo e pelo financiamento da pesquisa;

- Ao Centro de Tecnologia COPERSUCAR, particularmente aos Eng. Agrônomos Célio Manequini e Jorge Donzelli, pela cooperação científica;

- As empresas: Usina São Martinho, particularmente a Mário Gandini, e aos engenheiros Borba e Marcelo Bento; Usina Da Pedra, particularmente a Marco Bidóia, pela colaboração e disponibilização das áreas de estudo;

- A Ligiana, bibliotecária da Economia pela revisão da tese;

- Aos amigos encontrados pelos caminhos da vida que com seu apoio e incentivo contribuíram para a realização de mais esse trabalho: Silene, Ana, Marina, Juliana, Lia, Van, Xirobutá, Déia, Lucas, Keila, Polé, enfim...

- A muitas outras pessoas que direta ou indiretamente contribuíram para a realização da mais esse trabalho: 


\section{SUMÁRIO}

Página

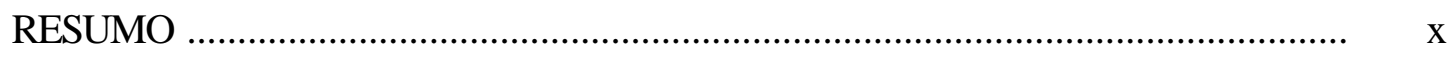

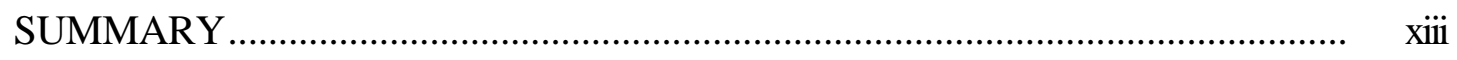

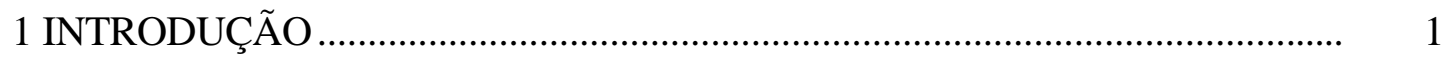

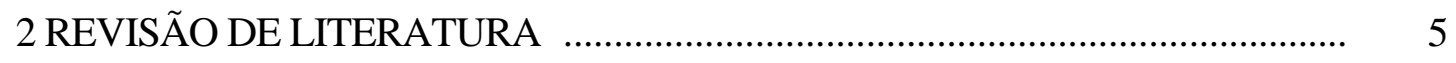

2.1 Colheita mecanizada da cana crua e deposição de palhada ................................ 5

2.2 Decomposição da palhada junto ao solo .......................................................... 6

2.3 Emissão de gases do efeito estufa ........................................................................ 8

3 QUANTIDADE E QUALIDADE DA PALHADA REMANESCENTE ENTRE 3 E 5 ANOS NO SISTEMA DE COLHEITA SEM QUEIMA DA CANA-DE-AÇÚCAR .......................................................................... 12

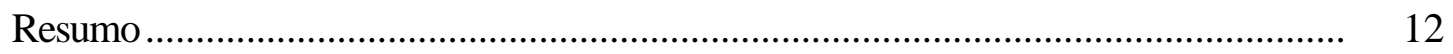

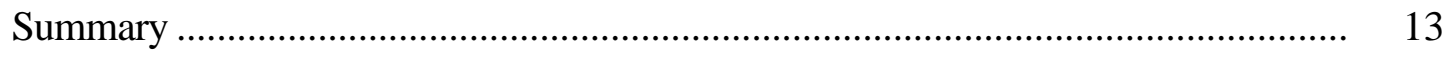

3.1 Introdução ............................................................................................. 14

3.2 Material e métodos........................................................................................ 17

3.2.1 Caracterização das áreas de estudos .............................................................. 17

3.2.2 Situações estudadas .................................................................................. 19

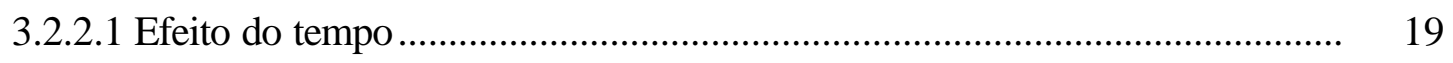

3.2.2.2 Efeito das diferentes quantidades de palhada.............................................. 19

3.2.2.3 Efeito das diferentes variedades de cana-de-açúcar...................................... 19 
3.2.3 Amostragem e caracterização da palhada ................................................... 20

3.2.3.1 Fracionamento físico da palhada remanescente …........................................ 20

3.2.3.2 Determinação das concentrações e estoque de carbono e nitrogênio nas frações

3.2.4 Delineamento experimental................................................................. 21

3.3 Resultados e discussão ................................................................................... 22

3.3.1 Produtividade e restituição da palhada............................................................... 22

3.3.2 Estoques de massa seca e carbono na palhada ................................................ 24

3.3.2.1 Efeito da quantidade de palhada depositada e do tempo de deposição sobre a acumulação da palhada

3.3.2.2 Carbono estocado em função da variedade da cana-de-açúcar.

3.3.3 Qualidade da palhada

3.3.3.1 Efeito da quantidade e do tempo de deposição sobre a qualidade da palhada

3.3.3.2 Efeito da variedade da cana-de-açúcar

3.3.3.3 Efeito do tempo sobre a razão $\mathrm{C} / \mathrm{N}$

3.4 Conclusões

4 DECOMPOSIÇÃO ANUAL DA PALHADA DA CANA-DE-AÇÚCAR

Resumo.

Summary

4.1 Introdução

4.2 Material e métodos

4.2.1 Amostragem da palhada 
4.2.2 Fracionamento físico da palhada remanescente e determinação das concentrações e estoques de carbono e nitrogênio nas frações ......................................... 42

4.3 Resultados e discussão .................................................................................... 44

4.3.1 Variação intra-anual do remanescente de matéria seca e carbono na palhada.. $\quad 44$

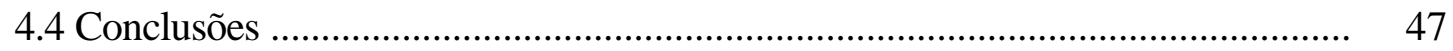

5 CARACTERIZAÇÃO MORFOLÓGICA, QUÍMICA E BIOQUÍMICA DE CAMADAS COM DIFERENTES IDADES DE PALHADA REMANESCENTE DE CANA-DE-AÇÚCAR ............................................... 49

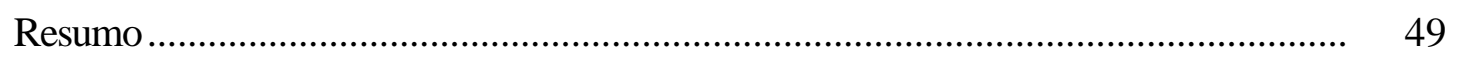

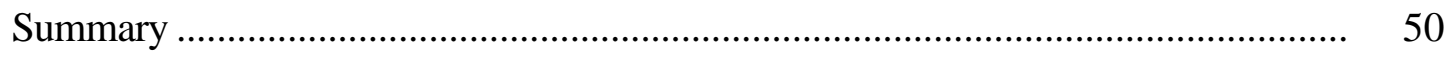

5.1 Introdução ......................................................................................... 51

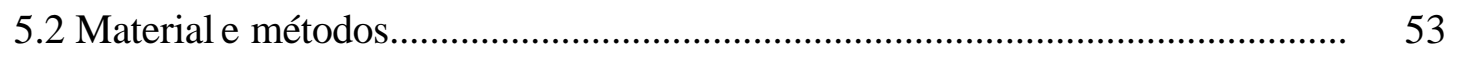

5.2.1 Caracterização da palhada .................................................................... 53

5.2.2 Preparo e análise de amostras.................................................................... 53

5.3 Resultados e discussão ............................................................................... 58

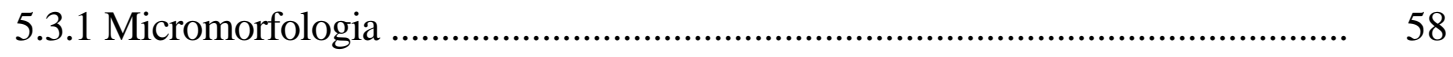

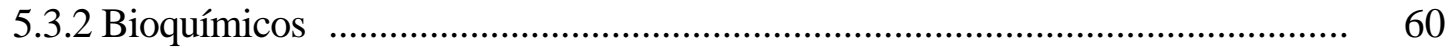

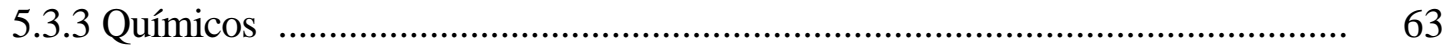

5.3.4 Efeito da decomposição sobre a qualidade da palhada no solo ......................... 64

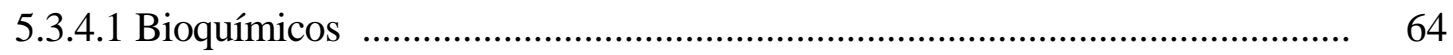

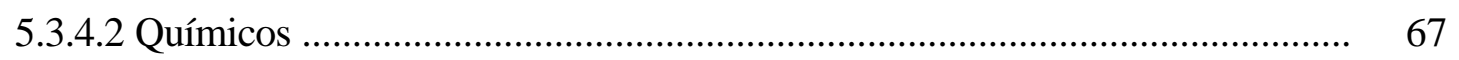

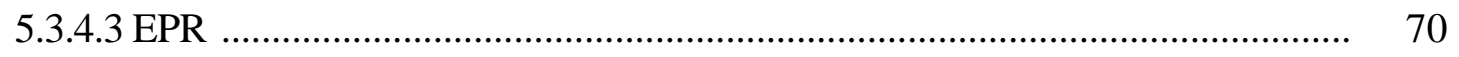

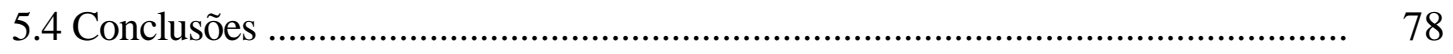


6 COLHEITA DE CANA-DE-AÇÚCAR SEM A QUEIMA PRÉVIA DO CANAVIAL, E A EMISSÃO DOS GASES DO EFEITO ESTUFA............................. 80

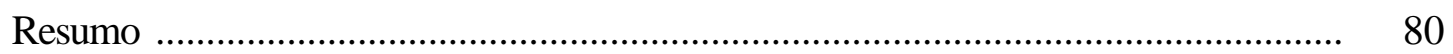

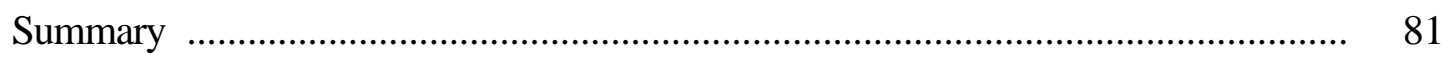

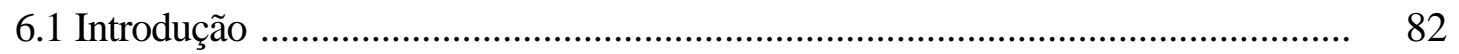

6.2 Material e métodos ..................................................................................... 83

6.2.1 Áreas de estudos .................................................................................. 83

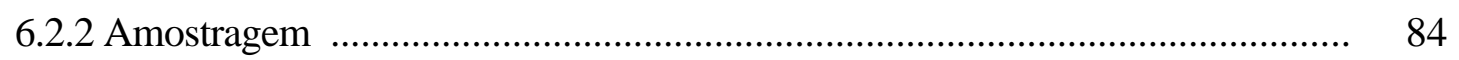

6.2.2.1 Amostragem dos gases do solo e da palhada ............................................ 84

6.2.2.2 Amostragem da palhada ....................................................................... 86

6.3 Resultados e discussão ............................................................................... 86

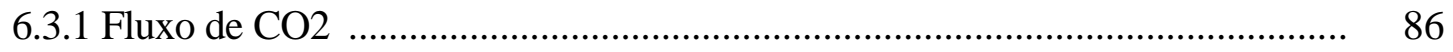

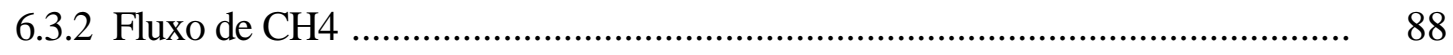

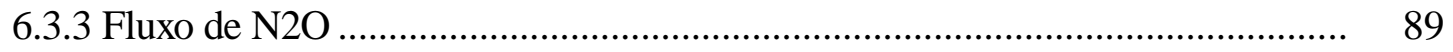

6.4 Balanço do carbono em equivalente de C-CO2 …............................................. 91

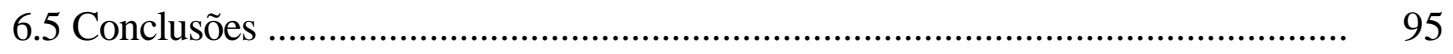

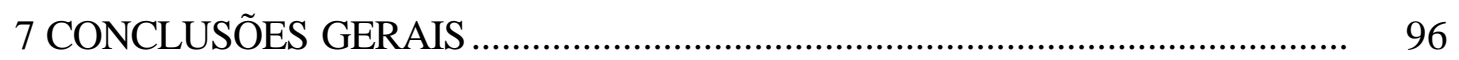

REFERÊNCIAS BIBLIOGRÁFICAS ........................................................... 98 


\title{
POTENCIALIDADE DO SISTEMA DE COLHEITA SEM QUEIMA DA CANA- DE-AÇÚCAR PARA O SEQUESTRO DO CARBONO
}

\author{
Autor: DINAILSON CORRÊA DE CAMPOS \\ Orientador: Prof. Dr. CARLOS CLEMENTE CERRI
}

\section{RESUMO}

$\mathrm{O}$ presente trabalho foi conduzido em áreas experimentais da COPERSUCAR, uma sobre Latossolo Vermelho (EMBRAPA 1999) na Usina São Martinho e outra sobre um Neossolo Quartzarênico na Usina Da Pedra, região de Ribeirão Preto (SP). O objetivo foi analisar a influência da palhada depositada sobre o solo na dinâmica do carbono no agrossistema cana-de-açúcar, uma vez que atualmente buscam-se alternativas para a diminuição da emissão de carbono para o ambiente. Estudou-se o efeito da acumulação da palhada ao longo do tempo (3, 4 e 5 anos) e da deposição de diferentes quantidades de palhada sobre a acumulação de carbono no sistema, bem como da distribuição granulométrica dessa palhada. Acompanhourse o comportamento intra-anual da palhada, através de medidas ao longo de um ano em áreas experimentais. Analisou-se a composição química e bioquímica da palhada remanescente ao longo do tempo e a influência da colheita sem queima na emissão de gases do efeito estufa. Os levantamentos de campo foram desenvolvidos ao longo dos anos de 1998, 1999 e 2000. Durante o período estudado, observourse que a produtividade média de cana-de-açúcar sob manejo com queima foi cerca de $5 \%$ maior do que sob manejo sem queima (101 e $95 \mathrm{Mgha}^{-1}$ ano $^{-1}$ para o Latossolo e de 88 e 85 $\mathrm{Mgha}^{-1}$ ano $^{-1}$ para o Neossolo). Ocorreu uma deposição média anual da palhada da ordem de $13,9 \mathrm{Mg} \mathrm{ha}^{-1}$ para as áreas sobre Latossolo e $12,8 \mathrm{Mg} \mathrm{ha}^{-11}$ para as áreas sobre o Neossolo. Após quatro anos de manejo sem queima observou-se a formação de uma camada de palhada, com diferentes níveis de decomposição. Nessa palhada foi possível distinguir visualmente, três camadas diferentes de acordo com o grau de decomposição: 
uma camada nova, mais recente; uma camada velha, entre um ano e dois anos após a deposição e uma camada muito velha, com pelo menos dois anos. Nos tecidos vegetais das camadas velha e muito velha foi observada diminuição da celulose, pequeno aumento de lignina e diminuição da razão $\mathrm{C} / \mathrm{N}$. A composição granulométrica da palhada demonstrou que a maior parte desta se encontra na fração $>4 \mathrm{~mm}$, com valores superiores a $50 \%$ nesta fração, e que a razão $\mathrm{C} / \mathrm{N}$ decresceu com a diminuição do tamanho das frações. A massa de matéria seca acumulada na palhada após quatro anos foi de 4,5 $\mathrm{Mg} \mathrm{ha}^{-1}$, ou 1,1 $\mathrm{Mg} \mathrm{ha}^{-1}$ ano $^{-1}$ para o Latossolo e de 3,6 $\mathrm{Mg} \mathrm{ha}^{-1}$, ou 0,9 $\mathrm{Mg} \mathrm{ha}^{-}$ 1 ano $^{-1}$ no Neossolo. Os fatores solo e variedade de cana não influenciaram a decomposição da palhada, mas houve um efeito positivo da quantidade depositada ao solo sobre a quantidade acumulada ao longo dos anos, tanto para o Latossolo como para o Neossolo. Um total de $1,5 \mathrm{MgC} \mathrm{ha}^{-1}$ ano $^{-1}$ foram estocados no compartimento palhada $\left(0,5 \mathrm{MgC} \mathrm{ha}^{-1} \mathrm{ano}^{-1}\right)$ e solo $\left(1 \mathrm{Mg} \mathrm{C} \mathrm{ha}^{-1} \mathrm{ano}^{-1}\right)$. As emissões de gases ocorridas durante a queimada no manejo com queima da cana-de-açúcar foram calculadas a partir de dados da literatura. Foi mostrado que durante a queimada ocorreu a emissão de uma importante quantidade de $\mathrm{N}_{2} \mathrm{O}$, expressada em $\mathrm{CCO}_{2}\left(4,3 \mathrm{tC}-\mathrm{CO}_{2}\right.$ ha $^{-1}$ ano $\left.{ }^{-1}\right)$ e esse é um dos gases mais efetivos do efeito estufa. Os fluxos de gases na superfície do solo foram medidos ao longo de um ano nos manejos com e sem queima no Latossolo. O manejo com queima mostrou menor emissão de $\mathrm{CO}_{2}$ e fixação de $\mathrm{CH}_{4}$ em comparação com o manejo sem queima, essas diferenças estão relacionadas a presença da palhada sobre o solo. Quanto ao $\mathrm{N}_{2} \mathrm{O}$, não houve diferença significativa nas emissões nos dois tipos de manejos estudados. Considerando todos os compartimentos de estoque de carbono (planta, palhada e solo) e de fluxos de gases do efeito estufa, foi estabelecido um balanço do carbono em equivalente de $\mathrm{CCO}_{2}$ emitido ou seqüestrado pelo manejo sem queima, em comparação ao manejo com queima. $\mathrm{O}$ resultado para o Latossolo, num período de 3 anos, mostrou uma mitigação de cerca de $5 \mathrm{Mg} \mathrm{C}-\mathrm{CO}_{2} \mathrm{ha}^{-1}$ ano $^{-1}$. 


\title{
CARBON SEQUESTRATION POTENCIALITY OF SUGARCANE HARVESTING WITHOUT BURNING
}

\author{
Author: DINAILSON CORRÊA DE CAMPOS \\ Advisor: Prof. Dr. CARLOS CLEMENTE CERRI
}

\section{SUMMARY}

The present work was led in experimental areas installed by COPERSUCAR, in clay soil - Hapludox (Usina São Martinho) and sandy soil Quartzipsamment (Usina da Pedra) in the area of Ribeirão Preto (SP). The objective was to analyze the influence of the deposited trash on the soil surface in relation to the dynamics of carbon in the sugarcane agrosystem since now alternatives are urged to decrease the emission of atmospheric carbon. The effect of the accumulation of trash was studied along the time (3, 4 and 5 years) and deposition of different amounts due to the accumulation of carbon in the system, as well as the granulometric distribution of it. The intra-annual behavior of trash was accompanied through measures along one year in experimental areas. The chemical and biochemical composition of the remaining trash was analyzed along the time and the influence of the crop without burning, due to the the imput of the greenhouse gas emission. That studies were developed along the years of 1998, 1999 and 2000. During the studied period, we found an average productivity of sugarcane by burning (88-101 $\mathrm{Mg} \mathrm{ha}^{-1} \mathrm{ano}^{-1}$ ) was $5 \%$ larger than without burning (85-95 $\mathrm{Mgha}^{-1} \mathrm{ano}^{-1}$ ) for the Hapludox and the Quartzpisament respectively. The trash deposited in an order of $13,9 \mathrm{Mg} \mathrm{ha}^{-1} \mathrm{ano}^{-1}$ for the areas on Hapludox and 12,8 $\mathrm{Mg} \mathrm{ha}^{-}$ ${ }^{1}$ ano $^{-1}$ for the Quartzpisament. After four years without burning a formation of a new humus horizon it was observed (trash), constituted of vegetable residues with different decomposition levels. In this horizon we distinguished, visually, three different layers: a new layer, more recent; an older layer, between one year and two years after the deposition and the oldest layer, with at least three years. The vegetable fabrics of two 
oldest layers were altered particularly by fungus with decrease of cellulose, a small lignin increase and a decrease of the $\mathrm{C} / \mathrm{N}$ ratio. The fractionation of the trash demonstrated that most of it belonged to the fraction $>4 \mathrm{~mm}$, with superior values of $50 \%$ in this fraction, and that the $\mathrm{C} / \mathrm{N}$ ratio decreased with the decrease of the size of the fractions. The mass of accumulated dry matter in the trash after four years was 4,5 $\mathrm{Mgha}^{-1}$, and 1,1 Mg ha ${ }^{-1}$ for 1 year on Hapludox and 3,6 $\mathrm{Mghave}^{-1}$ (4 years), and 0,9 $\mathrm{Mgha}^{-1}$ (1 year) on Quartzpisament. The soil factors and cane variety didn't influence the decomposition of the trash. But there was a positive effect for the amount deposited on the soil surface in relation to the accumulated amount along the years, for both soil types. A total of $1,5 \mathrm{Mg} \mathrm{Cha}^{-1}$ year $^{-1}$ they were storage in the trash $\left(0,5 \mathrm{Mg} \mathrm{Cha}^{-1}\right.$ ano $^{-}$ $\left.{ }^{1}\right)$ and soil $\left(1 \mathrm{MgC} \mathrm{ha}^{-1} \mathrm{ano}^{-1}\right)$ compartment. The emissions of gases happened during burning of the trash before the cut of the sugar-cane they were calculated by data of literature. It was shown that the emission of $\mathrm{N}_{2} \mathrm{O}$ during the burning liberated an important amount of this greenhouse gas, expressed in $\mathrm{C}^{-} \mathrm{CO}_{2}\left(4,3 \mathrm{tC}-\mathrm{CO}_{2}\right.$ have-1 year1). The flows of gases on the soil surface were measured along one year with burning and without it burning on Hapludox. It was shown that the management without burning provoked a larger emission of $\mathrm{CO}_{2}$ and $\mathrm{CH}_{4}$ than the management with burning due to gas fixation. According to $\mathrm{N}_{2} \mathrm{O}$, there was no difference on the emissions for the two management system. Due to the carbon stock compartments (plants, trash and soil) and the flows of the greenhouse gases, we established a balance of carbon in equivalent of emitted $\mathrm{C}-\mathrm{CO}_{2}$ or sequestrated kidnapped by the management without burning, in comparison with the traditional burning system. The final result for Hapludox, in a period of 3 years, revealed a mitigation of $5 \mathrm{MgC}-\mathrm{CO}_{2} \mathrm{ha}^{-1}$ year ${ }^{-1}$. 


\section{INTRODUÇÃO}

O Brasil é o maior produtor mundial de cana-de-açúcar, com uma produção na safra 2001-2002 superior a 335 milhões de toneladas em aproximadamente 5 milhões de hectares cultivados, sendo que $50 \%$ dessa área localiza-se no Estado de São Paulo e possibilitou uma produção superior a 176 milhões de toneladas (UNICA, 2003).

A queimada do canavial, usada para facilitar o corte manual da cana-de-açúcar, libera para a atmosfera grande quantidade dos gases $\mathrm{CO}_{2}, \mathrm{~N}_{2} \mathrm{O}$ e $\mathrm{CH}_{4}$. A elevação das concentrações desses gases na atmosfera aumenta o efeito estufa, constituindo um dos principais problemas ambientais atuais.

A extinção da queima de resíduos agrícolas, configura uma alternativa bastante viável para o processo chamado de "mitigação", no qual é evitada a emissão de carbono para o ambiente.

A cana-de-açúcar é responsável por cerca de $98 \%$ das emissões de gases provenientes da queima de resíduos agrícolas no Brasil (Lima, 1999). Entretanto o balanço entre a emissão de $\mathrm{CO}_{2}$ durante as queimadas e a retirada de $\mathrm{CO}_{2}$ do ambiente, pelo processo fotossintético é nulo, uma vez que a cultura reabsorve o equivalente ao $\mathrm{CO}_{2}$ emitido (Silva, 1996).

A adoção do manejo da colheita sem a queima prévia do canavial torna positivo o balanço do $\mathrm{CO}_{2}$, uma vez que o carbono que seria emitido imediatamente durante a queimada, pode permanecer no sistema, e ser incorporado ao solo.

A utilização da cana-de-açúcar como mitigador de carbono, ainda demanda estudos para analisar a aplicabilidade e a viabilidade, representaria uma alternativa econômica para os produtores.

O poder público estadual também criou leis com finalidade de eliminar gradativamente a prática da colheita com a queimada do canavial, no Estado de São 
Paulo. O Decreto de Lei Estadual nீ 47.700 de 11 de março de 2003, regulamenta a Lei $n^{0} 11.241$, de 19 de setembro de 2002, que dispõe sobre a eliminação gradativa da queima da palha da cana-de-açúcar e dá providências correlatas (São Paulo, 2003), é de grande interesse agrícola e ecológico, estabelece prazos, procedimentos, regras e proibições que visam regulamentar as queimadas em práticas agrícolas.

Devido a possibilidade do uso de máquinas colhedoras em algumas regiões do estado, facilitada pela topografia, e a adoção da lei estadual, é cada vez maior a área onde a colheita é feita mecanicamente e sem queima prévia do canavial.

Com a colheita mecanizada a palhada, formada pela palha seca, ponteiros e folhas verdes (Oliveira et al., 1999), pode permanecer depositada sobre o solo e agir de maneira positiva na proteção, conservação e recuperação dos solos.

A quantidade de palhada depositada depende de algumas condições específicas tais como estágio da cultura e eficiência da colhedora. A deposição média anual é da ordem de $15 \mathrm{Mg}$ ( 1 megagrama $=10^{6}$ gramas $=1$ tonelada $)$ de massa de palhada seca por hectare, que forma uma camada de cerca de 10-12 cm centímetros de espessura.

Com a cobertura podem ser criadas condições favoráveis para o estabelecimento de um microclima nessas áreas, pois não ocorrem mudanças bruscas na temperatura e na umidade do solo. Essa condição pode favorecer o estabelecimento de uma comunidade biológica que atuará na decomposição da palhada, permitindo o reaproveitamento dos nutrientes.

A decomposição da palhada pode ocasionar aumento no teor de matéria orgânica no solo (MOS) (Luca, 2002), já que parte do material decomposto pode ser incorporado ao solo, possibilitando aumento da agregação, da capacidade de troca de cátions (CTC) e, aumento do poder tampão do solo, o que é importante para solos quimicamente adubados (Primavesi, 1987) e ainda, com o aumento do teor de MOS, pode ocorrer diminuição do uso de adubação química.

São poucos os estudos relacionados à decomposição da palhada da cana-deaçúcar e, com o aumento de áreas onde o canavial é cortado sem a queima prévia, mais estudos se fazem necessários para medir todas as mudanças ambientas que poderão ocorrer com a adoção desta prática. 
Diante disso, podemos considerar a seguinte questão: A adoção do sistema de colheita sem a queima prévia do canavial e a utilização de colheita mecanizada, possibilitará a acumulação de palhada sobre o solo, permitindo que parte do carbono que seria liberado durante a queimada permaneça no sistema e seja incorporado a MOS ?

Para responder a esta questão, essa tese teve como objetivo comparar o balanço do carbono nos dois sistemas de colheita da cana-de-açúcar (com e sem queima prévia do canavial); avaliar a influência do manejo da palhada deixada sobre o solo após a colheita mecanizada e sem queima do canavial no tocante a deposição de diferentes quantidades de palhada, bem como de diferentes variedades de cana-de-açúcar; acompanhar a decomposição e acumulação da palhada ao longo do tempo e o efeito da acumulação da palhada sobre a dinâmica do carbono no sistema, bem como sobre a emissão de gases do efeito estufa para a atmosfera.

Os estudos foram realizados em ensaios agronômicos, referentes aos sistemas de colheita com e sem a queima prévia do canavial, pré-instalados pela COPERSUCAR sobre Latossolo Vermelho (Usina São Martinho, Pradópolis-SP) e Neossolo Quartzarênico (Usina Da Pedra, Serrana-SP), que ficam localizadas na região nordeste do Estado de São Paulo. Os ensaios foram instalados em 1995, com o plantio da cana, e as coletas foram realizadas em 1998, 1999 e 2000.

A definição dos locais que apresentassem as situações propostas levou em consideração que fossem áreas localizadas em uma região na qual a cultura da cana-deaçúcar fosse representativa e que a colheita sem a queima prévia do canavial viesse sendo empregada, assim como a colheita tradicional, permitindo comparações entre os dois sistemas de colheita em áreas na mesma região.

Como resultado desses estudos, foi elaborada essa tese que é composta de 7 capítulos, dos quais quatro são trabalhos científicos cujos títulos e objetivos de cada um, são apresentados a seguir:

Capítulo 1 - "Introdução"

Capítulo 2 - "Revisão de literatura" 
Capítulo 3 - "Quantidade e qualidade da palhada remanescente entre 3 e 5 anos no sistema de colheita sem queima da cana-de-açúcar".

Capítulo elaborado na forma de artigo científico, onde se avaliou a influência do tempo de colheita sem queima, da variedade de cana-de-açúcar e do manejo da palhada da cana-de-açúcar referente às diferentes quantidades de palhada (totalidade, 1/3, 2/3 e o dobro de palhada) deixada sobre o solo após a colheita, sobre a decomposição e acumulação da matéria orgânica na palhada.

Capítulo 4 - "Decomposição anual da palhada da cana-de-açúcar".

Capítulo elaborado na forma de artigo científico, onde se acompanhou durante um ano, através da variação do peso seco da palhada e dos estoques de carbono, a decomposição da palhada deixada sobre o solo após a colheita da cana-de-açúcar.

Capítulo 5 - "Caracterização morfológica e bioquímica das diferentes camadas da palhada remanescente da cana-de-açúcar".

Capítulo elaborado na forma de artigo científico, onde se buscou caracterizar através de estudos microscópicos, químicos e bioquímicos as camadas de palhada que se formam com diferentes níveis de decomposição.

Capítulo 6 - "Colheita de cana-de-açúcar sem a queima prévia do canavial, e a emissão dos gases do efeito estufa".

Capítulo elaborado na forma de artigo científico, onde se analisou e comparou durante um ano, as emissões dos gases do efeito estufa nos dois sistemas de colheita, com e sem a queima prévia do canavial e se fez um balanço do carbono no sistema.

Capítulo 7 - "Conclusões Gerais" 


\section{REVISÃO DE LITERATURA}

\subsection{Colheita mecanizada da cana crua e deposição de palhada}

Com a prática da colheita sem a queima prévia do canavial e utilizando-se máquinas para esse fim, grande quantidade de palhada pode ser depositada sobre o solo, formando uma camada de alguns centímetros de espessura $(10-12 \mathrm{~cm})$.

Levantamentos realizados anteriormente mostraram que a quantidade de palhada depositada varia dependendo das características da área estudada. Ripoli et al. (1990) utilizando dados obtidos por vários autores encontraram que para uma produção

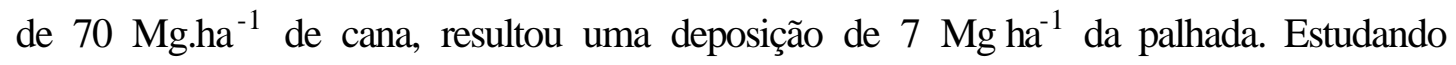
diferentes variedades, idades das plantas e local da cultura, Page et al. (1986) encontraram deposições de 22,8 $\mathrm{Mg} \mathrm{ha}^{-1}$, $13.4 \mathrm{Mg} \mathrm{ha}^{-1}$ e $6 \mathrm{Mg} \mathrm{ha}^{-1}$.

Abramo Filho et al. (1993) avaliando a palhada depositada após o terceiro corte mecanizado do canavial, encontraram $15 \mathrm{Mg} \mathrm{ha}^{-1}$ de massa seca de palhada, formando uma camada de 8 a $10 \mathrm{~cm}$ de espessura possibilitando uma alteração da temperatura de 5 ${ }^{0} \mathrm{C}$ na superfície do solo abaixo da palhada em comparação com a temperatura ambiente.

Considerando-se que a colheita mecanizada da cana-de-açúcar pode gerar em média 11\% da biomassa produzida em resíduos (Crutzen \& Andrea, 1990), a quantidade de palhada que poderá ser depositada sobre o solo, vai depender de uma série de fatores, entre os quais, a eficiência da máquina que está realizando a colheita, no que se refere à ventilação e limpeza do equipamento, a eficiência do operador em acertar o desponte e às condições de manejo do canavial, principalmente no que se refere a variedade da cana-de-açúcar cultivada, que implica em diferentes produções de biomassa total do canavial (Abramo Filho et al, 1993). 
Com a cobertura do solo ocorre diminuição ra erosão, pois a palhada impede a ação direta dos ventos e o transporte de partículas (erosão eólica) e também, protege o solo da erosão de impacto e a laminar causadas pelas chuvas, ajudando a conservar solos (Sallaway, 1979; Page et al, 1986; Furlani Neto et al.1997; Sparovek, 1997).

Devido a formação da camada de palhada pode ocorrer a formação de um microclima, já que não ocorrem mudanças bruscas na temperatura e na umidade do solo, possibilitando assim, a formação de uma comunidade biológica, principalmente de fungos, que atuará na decomposição dessa palhada, e estabelecerá uma simbiose mais próxima da encontrada em áreas de mata nativa.

A cobertura do solo pela palhada, também ajuda no controle de ervas daninhas, possibilitando, assim, a diminuição do uso de herbicidas, e a diminuição ou mesmo supressão do uso desse produto, que representa um risco potencial ao ambiente, poderá, ainda, acarretar um ganho econômico para o produtor.

Outra importante contribuição da implementação deste sistema, pode funcionar como um mitigador de carbono, contribuindo para a redução do efeito estufa, uma vez que o carbono que seria liberado durante a queimada permanece na palhada e pode ser incorporado a MOS. Estudos realizados por Lal et al. (1997) encontraram que o manejo de resíduos, associado às técnicas de manejo e conservação do solo, seriam responsáveis por uma mitigação do $\mathrm{CO}_{2}$ atmosférico da ordem de $3,2 \mathrm{Pg}^{2}$ ano $^{-1}\left(1\right.$ petagrama $\left.=10^{15} \mathrm{~g}\right)$.

Essa matéria orgânica que fica depositada sobre o solo é um importante reservatório de nutrientes que através da decomposição podem ser disponibilizados para as plantas, desta forma contribuiriam para a recuperação da fertilidade do solo.

\subsection{Decomposição da palhada no solo}

A deposição e a manutenção de palhada sobre a superfície do solo é apontada como uma técnica de manejo que contribui para a conservação do solo (Furlani Neto et al., 1994), contudo, em relação às práticas agronômicas ainda pode causar alguns problemas relacionados ao manejo da cultura.

Dentre os principais problemas, destacam-se as dificuldades encontradas durante as operações de cultivo e adubação da soca (Aude et al., 1993; Barbosa, 1997), a 
baixa taxa líquida de mineralização do nitrogênio no período de um ano agrícola (Ng Kee Kwong \& Deville, 1987; Rípoli et al., 1991; Trivelin et al., 1995), a dificuldade de execução de controle seletivo de plantas daninhas e, o aumento das populações de pragas que se abrigam e multiplicam sob a palhada, além de diminuição do rendimento por problemas de brotação da nova planta após o corte.

A decomposição da palhada depende das condições ambientais, tais como disponibilidade hídrica, e de oxigênio, e também da composição química do substrato (razão C/N, teores de celulose, hemicelulose, lignina e polifenóis) Oliveira et al., 1999, influenciando, desta forma a taxa de decomposição e a dinâmica do carbono.

Os tecidos vegetais podem ser fracionados em celulose, hemicelulose, lignina, proteína, materiais hidrossolúveis e materiais éter-solúveis (Abramo Filho, 1995). A palhada contém principalmente matérias celulósicas (celulose + hemicelulose $=69,71$ $\%)$ e lignina $(19,71 \%)$. A velocidade da decomposição da celulose e hemicelulose é bem maior do que a da lignina, sendo que esta última, juntamente com o $\mathrm{N}$ são apontados como agentes controladores da taxa de decomposição de substratos vegetais (Melillo et al., 1982; Sanger et al., 1996).

A razão $\mathrm{C} / \mathrm{N}$, que é um parâmetro indicador do potencial húmico dos resíduos orgânicos no solo (Robin, 1997), no caso da palhada, é de aproximadamente 80:1, enfatizando que tanto o carbono como o nitrogênio são muito importantes na decomposição (Lynch, 1986). Quando a razão C/N atinge 17/1, ocorre uma igualdade entre a quantidade de nitrogênio imobilizado e a quantidade mineralizada.

Segundo Galvão et al. (1991) a quantidade inicial de nitrogênio está entre os fatores que mais influenciam a velocidade de decomposição do material orgânico, mas também que as diferenças nas composições da matéria orgânica de compostos como a lignina por exemplo, vão influenciar a velocidade da decomposição, quanto maior o teor desta substância, mais demorada será a decomposição.

A incorporação da palhada poderia causar a falta de nitrogênio durante a decomposição da mesma, contudo, a medida que a palhada é mantida sobre a superfície do solo, ou superficialmente incorporada (Stuble-mulch), não provoca a falta de $\mathrm{N}$ no solo para o crescimento da planta, neste caso, o efeito desfavorável da palhada ocorre 
somente pela ação das fitotoxinas liberadas no início da decomposição (Abramo Filho, 1995).

Primavesi (1987), sugeriu que não se deve plantar quando a palhada tiver sido recém aplicada ou deixada sobre o solo, deve-se esperar pela chuva abundante para permitir que os produtos liberados no início da decomposição possam ser lixiviados, não comprometendo, assim, o desenvolvimento da planta.

\subsection{Emissão de gases do efeito estufa}

O aumento das emissões dos gases do efeito estufa é um dos principais problemas ambientais atuais. A causa principal é o aumento das concentrações de gases como Gás Carbônico $\left(\mathrm{CO}_{2}\right)$, Óxido Nitroso $\left(\mathrm{N}_{2} \mathrm{O}\right)$ e Metano $\left(\mathrm{CH}_{4}\right)$, que são provenientes da queima de combustíveis fósseis, do deflorestamento e da queima de resíduos agrícolas.

Algumas alternativas para diminuir esse problema podem ser discutidas. A diminuição do uso e/ou substituição de combustíveis fósseis é uma delas, porém, encontra resistências da maioria dos países. Outra alternativa é cessão do desflorestamento nas áreas tropicais, contudo isso também será de difícil implantação, visto que nessas áreas é que existem as fronteiras agrícolas que estão sendo intensivamente exploradas.

A alternativa mais viável é a não queima dos resíduos agrícolas, que poderiam contribuir significativamente para a diminuição da emissão dos gases do efeito estufa para a atmosfera e também possibilitaria o seqüestro de carbono na área agrícola.

Nesse sentido, a cana-de-açúcar representa um potencial mitigador das emissões de gases, uma vez que com o manejo de colheita sem a queima prévia do canavial, o carbono que seria emitido durante a queimada, fica retido na palhada e no solo, permitindo que a cultura que ocupa cerca de 5 milhões de hectares no Brasil, possa desempenhar papel importante na busca pela diminuição do efeito estufa.

Lima et al. (1999) relataram que existe muita incerteza nas estimativas das emissões de gases provenientes de atividades agrícolas no país, e que isso seria decorrente de vários fatores, entre os quais a ausência de medições de fluxos de gases 
em diferentes sistemas de produção e a falta de informações detalhadas sobre os parâmetros requeridos nas estimativas das emissões.

Sugerem ainda, que uma série de estudos sobre o fluxo de gases atmosféricos deveriam ser realizados sob diferentes condições climáticas e fisiográficas do país, a fim de se obter fatores de emissões específicos a cada atividade agrícola, já que não se dispõe de dados de pesquisa suficientes para a adoção de fatores de emissões de gases para as diferentes ecorregiões do país, bem como esse levantamento permitiria se estimar o potencial de absorção desses gases em agroecossistemas.

A produção de resíduos agrícolas nos países em desenvolvimento é grande e estima-se que cerca de $40 \%$ do que é produzido anualmente $(425 \mathrm{Tg}$ de biomassa seca $=$ $10^{12}$ gramas) sejam queimado no campo (Jallow, 1995). Segundo o Intergovernmental Panel on Climate Change - IPCC (1995) os resíduos da cana-de-açúcar representam cerca de $11 \%$ da produção mundial de resíduos agrícolas, e a queima desses resíduos é responsável por uma liberação substancial de $\mathrm{CO}_{2}$.

Segundo o levantamento realizado por Lima et al (1999), do total de emissões de gases gerados pela queima de resíduos agrícolas, no ano de 1994, a queima de canade-açúcar foi responsável por cerca de 97,5 \% dessa emissão.

Esse levantamento indicou ainda que houve um aumento de cerca de $15 \%$ nas emissões estimadas dos gases $\mathrm{CO}$ e $\mathrm{CH}_{4}$ e de $14 \%$ nas emissões de $\mathrm{N}_{2} \mathrm{O}$ e $\mathrm{NO}_{\mathrm{x}}$. Desta forma, a diminuição/supressão da prática de colheita com a queima prévia do canavial, contribuiria em muito para a diminuição da liberação desses gases do efeito estufa.

Cabe salientar que a liberação de $\mathrm{CO}_{2}$ durante a queimada do canavial, não é considerada como uma emissão líquida de carbono, uma vez que durante o ciclo fotossintético seguinte, ocorrerá absorção de $\mathrm{CO}_{2}$ atmosférico, que segundo Silva (1996) é da ordem de $15 \mathrm{Mg} \mathrm{CO}_{2} \mathrm{ha}^{-1} \mathrm{ano}^{-1}$.

Contudo, durante a queimada, outros gases como $\mathrm{N}_{2} \mathrm{O}, \mathrm{NOx}, \mathrm{CO}$ e $\mathrm{CH}_{4}$, são liberados e, a taxa de emissão depende do tipo de biomassa e das condições da queima.

Ainda, segundo o IPCC (1995), estimativas médias globais de emissões dos gases de efeito estufa associados à queima de biomassa, são: $26 \mathrm{Tg}$ de $\mathrm{NO}_{\text {x.ano }}{ }^{-1}$; 0,8 Tg de $\mathrm{N}_{2} \mathrm{O}$ ano $^{-1} ; 40 \mathrm{Tg}$ de $\mathrm{CH}_{4}$ ano $^{-1}$ e $500 \mathrm{Tg}$ de $\mathrm{CO}$ ano ${ }^{-1}$. Essas emissões equivalem a 
9,7; 8,9 e 10,7 \% do $\mathrm{NO}_{\mathrm{x}}, \mathrm{N}_{2} \mathrm{O}$ e $\mathrm{CH}_{4}$, respectivamente, provenientes de todas as atividades humanas (8,96 $\mathrm{Tg} \mathrm{N}_{2} \mathrm{O}, 375 \mathrm{Tg} \mathrm{CH}_{4}$ e 82,5 $\mathrm{Tg}_{\mathrm{Nox}}$ ano $^{-1}$, respectivamente).

Deve-se levar em consideração a eficiência dos gases para a ocorrência do efeito estufa, sendo que, por molécula, o $\mathrm{CH}_{4}$ é 32 vezes e o $\mathrm{N}_{2} \mathrm{O}$ é aproximadamente 150 vezes mais efetivo na retenção da radiação de onda longa (radiação térmica) do que o $\mathrm{CO}_{2}$ (Bowden, 1990).

A estimativa da emissão dos gases provenientes da queima de resíduos agrícolas baseia-se no carbono total liberado, que é uma função da biomassa queimada e da fração oxidada e do carbono contido na biomassa e depois aplica-se o fator de conversão para os gases de interesse.

Para o cálculo do carbono total liberado aplica-se uma fórmula:

$$
\mathrm{MC}=\mathrm{P} \times \mathrm{R} \times \operatorname{Rs} \times \operatorname{Re} \times \mathrm{Rq} \times \mathrm{Tc}
$$

onde:

$\mathrm{MC}=$ massa total do carbono;

$\mathrm{P}=$ produção vegetal anual, em giga-gramas $(\mathrm{Gg})\left(10^{9}\right.$ gramas $)$;

$\mathrm{R}$ = relação resíduo/produção;

Rs = conteúdo de matéria seca do resíduo;

$\mathrm{Re}=$ proporção de resíduos expostos à queima;

$\mathrm{Rq}=$ fração oxidada de resíduos durante a queima;

Tc = conteúdo de carbono nos resíduos.

A massa total de nitrogênio ( $\mathrm{MN}$ ) produzida durante a queimada é obtida multiplicando-se a massa MC pela razão N/C. As quantidades de $\mathrm{CO}, \mathrm{CH}_{4}, \mathrm{~N}_{2} \mathrm{O}$ e $\mathrm{NO}_{\mathrm{x}}$ são estimadas à partir da multiplicação das taxas de emissão e fatores de conversão para cada gás, pelas massas MC ou MN, caso o gás seja composto de carbono ou nitrogênio, respectivamente.

Para o cálculo da emissão de gases devido à queimada utilizou-se os dados fornecidos por Lima et al. (1999), onde consta que a eficiência da queimada é da ordem 
de $79 \%$. A tabela 1 apresenta as taxas de emissões dos gases e os fatores de conversão para se calcular o equivalente em $\mathrm{C}-\mathrm{CO}_{2}$ de emissão dos gases.

Tabela 1. Taxas de emissão de gases liberados durante a queima de resíduos agrícolas e fatores de conversão para o cálculo das emissões, segundo IPCC

\begin{tabular}{ccc}
\hline Gases do efeito & Taxas de Emissão & Fatores de Conversão \\
\hline $\mathrm{CO}$ & $0,030(\mathrm{C})$ & $28 / 12$ \\
$\mathrm{CH}_{4}$ & $0,005(\mathrm{C})$ & $16 / 12$ \\
$\mathrm{~N}_{2} \mathrm{O}$ & $0,007(\mathrm{~N})$ & $44 / 28$ \\
\hline
\end{tabular}

Fonte: Lima et al. (1999)

Como as taxas de emissões se encontram em unidades de carbono (C) ou nitrogênio $(\mathrm{N})$, é necessário se empregar fatores de conversão, que consideram o peso molecular dos gases emitidos. A emissão desses gases é calculada como segue:

Emissão de $\mathrm{CO}=$ carbono liberado $\mathrm{x}$ taxa de emissão $\mathrm{x}$ fator de conversão;

Emissão de $\mathrm{CH}_{4}=$ carbono liberado $\mathrm{x}$ taxa de emissão $\mathrm{x}$ fator de conversão;

Emissão de $\mathrm{N}_{2} \mathrm{O}=$ carbono liberado $\mathrm{x}$ razão $\mathrm{N} / \mathrm{C} \times$ taxa de emissão $\mathrm{x}$ fator de conversão.

Diferentes fatores de emissão de gases relacionados à queima de resíduos da cana-de-açúcar têm sido registrados na literatura, assim como Lima et al. (1999) optout se por utilizar os fatores de emissão sugeridos pelo IPCC (1996), em função da ausência de fatores específicos para as condições brasileiras, com bases experimentais de campo. 


\section{QUANTIDADE E QUALIDADE DA PALHADA REMANESCENTE ENTRE 3 E 5 ANOS NO SISTEM A DE COLHEITA SEM QUEIMA DA CANA-DE- AÇÚCAR}

\section{Resumo}

No manejo sem queima, onde a colheita é realizada geralmente por máquinas colhedoras de cana-de-açúcar, a parte foliar (cerca de $14 \mathrm{Mg} \mathrm{ha}^{-1} \mathrm{ano}^{-1}$ em matéria seca ou 6,5 $\mathrm{Mg} \mathrm{C} \mathrm{ha}^{-1} \mathrm{ano}^{-1}$ ) pode ser depositada anualmente sobre o solo e se decompor naturalmente. As condições ambientais (umidade, temperatura), a quantidade de palhada depositada e a constituição dessa palhada, interferem diretamente no processo de decomposição, agindo sobre a acumulação da palhada ao longo do tempo. Com o objetivo de avaliar a influência do tipo de solo, do tempo de colheita sem queima, da variedade de cana-de-açúcar e da quantidade de palhada deixada sobre o solo após a colheita, sobre a decomposição e acumulação da matéria orgânica na palhada, estudout se o manejo sem queima da cana-de-açúcar em áreas experimentais localizadas na região nordeste do Estado de São Paulo, sobre Latossolo Vermelho, e Neossolo Quartzarênico. Os levantamentos de dados demonstraram que a produtividade da cana-de-açúcar foi $5 \%$ menor no sistema sem queima, com cerca de $95 \mathrm{Mgha}^{-1}$, enquanto que, no sistema com queima, o valor foi aproximadamente $101 \mathrm{Mgha}^{-1}$. A deposição média da palhada foi equivalente a cerca de $15 \%$ da produtividade com um valor médio de 13,9 $\mathrm{Mg} \mathrm{MS} \mathrm{ha-}$ ${ }^{1}$ ano $^{-1}$. Após três anos de acompanhamento do experimento, pode-se constatar que ocorreu uma estabilização no estoque da palhada, do carbono e do nitrogênio, com valores entre 3,5 - 4,5 $\mathrm{Mg} \mathrm{MS} \mathrm{ha}^{-1} ; 1350$ - $1600 \mathrm{KgCha}^{-1}$ e 21 - $22 \mathrm{Kg} \mathrm{N}^{-1}$, respectivamente para as áreas sobre Latossolo e Neossolo. A variedade da cana-deaçúcar e as diferentes quantidades de palhada depositadas, não influenciaram a 
acumulação de palhada e de carbono no sistema sem queima. Comparando diferentes variedades e tipos de solos, também não foram encontradas diferenças no processo de acumulação de palhada e de carbono. A distribuição granulométrica da palhada não foi influenciada pela de palhada depositada, pelo tempo de implantação do sistema e pela variedade de cana cultivada.

\section{Summary}

The objective of the work was to evaluate the influence of the soil type, the time of crop of without burning, the sugarcane variety and the management of the sugarcane trash regarding the different amounts of trash (totality, 1/3, 2/3 and the trash double) left on the soil after the crop of the same, about the decomposition and accumulation of the organic matter in the trash. For so much we studied the influence of the deposition of the trash, the decomposition of that trash and the effect of the accumulation of this on the soil surface. The study areas are located in the northeast area of the São Paulo State, one on a clay soil (Latossolo Vermelho), and another on a sandy soil (Neossolo Quartzarênico). The increasing of data demonstrated that the productivity

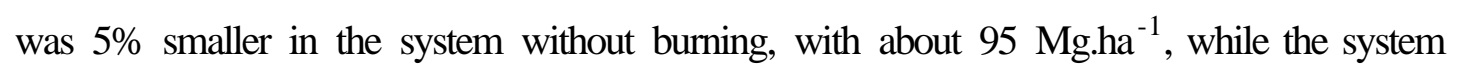

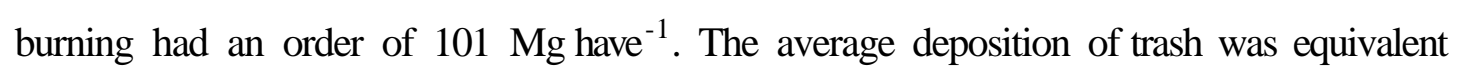
to $15 \%$ of the productivity with an average value of $13,9 \mathrm{Mg} \mathrm{MS} \mathrm{ha}^{-1}$.ano ${ }^{-1}$. After three years occurred a stabilization on trash carbon and nitrogen stock, with values between 3,5 - 4,5 Mg MS ha ${ }^{-1} 1350$ - $1600 \mathrm{Kg} \mathrm{Cha}^{-1}$ and 21 - $22 \mathrm{Kg} \mathrm{N} \mathrm{ha}^{-1}$, respectively for the areas on Latossolo Vermelhoo and Neossolo Quartzarênico. When we analyzed the same soil type, we didn't observed any influence of the sugarcane variety nor of the different amounts of deposited trash on the soil surface, nor on the trash and carbon stocks. Comparing different varieties and soil types, we did not observed any differences in the process of trash and carbon accumulation. The fractionation of the trash fractions was not influenced by the factor amount of deposited trash, for the time of the system implantation, nor for the variety of cultivated cane. 


\subsection{Introdução}

A colheita da cana-de-açúcar manejada sem a queima, condiciona o uso de máquinas colhedoras, pois a grande quantidade de biomassa foliar diminui a eficiência da colheita manual e pode aumentar a incidência de acidentes (Rípoli et al., 1995) e o custo da colheita manual subiria muito, tornando essa prática inviável (Sparovek et al., 1997).

Com a colheita mecanizada e sem a queima do canavial a palhada, formada pela palha seca, ponteiros e folhas verdes pode permanecer depositada sobre o solo (Oliveira et al., 1999). Segundo Abramo Filho et al. (1993) um hectare de cana-de-açúcar, com produção média de $100 \mathrm{Mgha}^{-1}(1$ megagrama $=1$ tonelada $)$ de colmos, resulta aproximadamente $15 \mathrm{Mg}$ de massa seca de palhada por hectare, que pode ser depositada anualmente sobre o solo.

A deposição e manutenção da palhada sobre a superfície do solo são apontadas como técnicas de manejo que contribuem para a conservação do mesmo (Furlani Neto et al., 1994), pois possibilitará diminuição na erosão, já que impede a ação direta dos ventos e o transporte de partículas (erosão eólica) e também, protege o solo da erosão causada pelas chuvas (de impacto e laminar), ajudando a conservar solos (Sallaway, 1979; Page et al, 1986).

A decomposição da palhada pode ocasionar aumento no teor de matéria orgânica no solo (MOS) (Luca, 2002), pois parte do material decomposto pode ser incorporado ao solo, possibilitando aumento da agregação, da capacidade de troca de cátions (CTC) e aumento do poder tampão do solo, o que é importante para solos quimicamente adubados (Primavesi, 1987) e ainda, com o aumento do teor de MOS, pode ocorrer diminuição do uso de adubação química.

Com a cobertura podem ser criadas condições favoráveis para o estabelecimento de um microclima nessas áreas, uma vez que não ocorrem mudanças bruscas na temperatura e na umidade do solo. Essa condição pode favorecer o estabelecimento de uma comunidade biológica que atuará na decomposição da palhada, permitindo o reaproveitamento dos nutrientes. 
A cobertura do solo pela palhada, também controla as ervas daninhas, possibilitando, assim, a diminuição do uso de herbicidas, o que é importante pois esse produto representa um risco potencial ao ambiente, e a diminuição do uso desse produto acarretará um ganho econômico para o produtor.

Alguns aspectos negativos devem ser considerados, principalmente em relação às práticas agronômicas, visto que a palhada depositada sobre o solo pode causar alguns problemas relacionados ao manejo da cultura.

Dentre os principais problemas, destacam-se as dificuldades encontradas durante as operações de cultivo e adubação da soca (Aude et al., 1993; Barbosa, 1997), a baixa taxa líquida de mineralização do nitrogênio no período de um ano agrícola $(\mathrm{Ng}$ Kee Kwong \& Deville, 1987; Rípoli et al., 1991; Trivelin et al., 1995), a dificuldade de execução de controle seletivo de plantas daninhas e, o aumento das populações de pragas que se abrigam e multiplicam sob a palhada, além de diminuição do rendimento por problemas de brotação da nova planta após o corte.

A decomposição da palhada vai influenciar diretamente esses problemas, e está ligada diretamente às condições ambientais, tais como disponibilidade hídrica, e de oxigênio, além de estar ligada também a composição química do substrato $(\mathrm{C} / \mathrm{N}$, teores de celulose, hemicelulose, lignina e polifenóis), (Oliveira et al., 1999), influenciando, desta forma a taxa de decomposição e a dinâmica do carbono.

Os tecidos vegetais podem ser fracionados em celulose, hemicelulose lignina, proteína, materiais hidrossolúveis e materiais éter-solúveis (Abramo Filho 1995). A palhada contém mais matérias celulósicas (celulose + hemicelulose $=69,71 \%$ ) e lignina (19,71\%). A velocidade da decomposição da celulose e hemicelulose é bem maior do que a da lignina, sendo que esta última, juntamente com o $\mathrm{N}$ são apontados como agentes controladores da taxa de decomposição de substratos vegetais (Melillo et al., 1982; Sanger et al., 1998).

A razão $\mathrm{C} / \mathrm{N}$, que é um parâmetro indicador do potencial húmico dos resíduos orgânicos no solo (Robin, 1997), no caso da palhada, é de aproximadamente 80:1, enfatizando que tanto o carbono como o nitrogênio são muito importantes na 
decomposição (Lynch, 1986). Quando a razão C/N atinge 17/1, ocorre uma igualdade entre a quantidade de nitrogênio imobilizado e a quantidade mineralizada.

Segundo Galvão et al. (1991) a quantidade inicial de nitrogênio está entre os fatores que mais influenciam a velocidade de decomposição do material orgânico, mas também que as diferenças nas composições da matéria orgânica de compostos como a lignina por exemplo, vão influenciar a velocidade da decomposição. Quanto maior o teor de lignina, mais demorada será a decomposição.

É importante salientar que são poucos os estudos relacionados à decomposição da palhada da cana-de-açúcar e, com o aumento de áreas onde o canavial é cortado sem a queima prévia, mais estudos se fazem necessários para medir todas as mudanças ambientas que poderão ocorrer com a adoção desta prática.

Diante disso, podemos considerar a seguinte questão: A adoção do sistema de colheita sem a queima prévia do canavial e a utilização de colheita mecanizada, possibilitará a acumulação de palhada sobre o solo, permitindo que parte do carbono que seria liberado durante a queimada permaneça no sistema e seja incorporado a MOS?

Para responder a essa questão propusemos a realização desse estudo, que teve como objetivo avaliar a influência do manejo da palhada deixada sobre o solo após a colheita mecanizada e sem queima do canavial no tocante a deposição de diferentes quantidades de palhada, bem como de diferentes variedades de cana-de-açúcar; acompanhar a decomposição e acumulação da palhada ao longo do tempo e o efeito da acumulação da palhada sobre a dinâmica do carbono no sistema,

Os estudos foram realizados em ensaios agronômicos, referentes aos sistemas de colheita com e sem a queima prévia do canavial, pré-instalados pela COPERSUCAR. Os ensaios foram instalados em 1995, com o plantio da cana, e as coletas foram realizadas em 1998, 1999 e 2000, uma semana antes da colheita de cada ano.

A definição dos locais que apresentassem as situações propostas levou em consideração que fossem áreas localizadas em uma região na qual a cultura da cana-deaçúcar fosse representativa e que a colheita sem a queima prévia do canavial viesse sendo empregada, assim como a colheita tradicional, permitindo comparações entre os dois sistemas de colheita em áreas na mesma região. 


\subsection{Material e métodos}

\subsubsection{Caracterização das áreas de estudos}

As áreas de estudos estão localizadas na região nordeste do Estado de São Paulo e segundo a classificação de Köppen apresentam clima Aw: tropical com verão chuvoso e inverno seco (precipitação do mês mais seco $<30 \mathrm{~mm}$, temperatura média do mês mais quente $>22^{\circ} \mathrm{C}$ e do mês mais frio $>18^{\circ} \mathrm{C}$ ).

Foram selecionadas duas áreas experimentais de cana-de-açúcar implantadas pela COPERSUCAR, uma na Usina São Martinho e outra na Usina Da Pedra.

A Usina São Martinho (Latossolo Vermelho) localiza-se no município de Pradópolis - SP (21 $\left.22^{\prime} \mathrm{S}, 48^{\circ} 03^{\prime} \mathrm{O}\right)$, Altitude aproximada de $620 \mathrm{~m}$. Ocupa a província geomorfológica denominada de "Cuestas Basálticas". O clima segundo Köppen, é o Aw: tropical com verão chuvoso e inverno seco, com temperatura do mês mais frio superior a $18{ }^{0} \mathrm{C}$. A precipitação média anual é de $1560 \mathrm{~mm}$ e a temperatura média anual é de $22,9^{\circ} \mathrm{C}$.

A Usina Da Pedra: (Neossolo Quartzarênico) localiza-se no município de Serrana - SP (21 $\left.11^{\circ} \mathrm{S}, 47^{\circ} 35^{\prime} \mathrm{O}\right)$, Altitude aproximada de $620 \mathrm{~m}$. A precipitação média anual é de $1549 \mathrm{~mm}$ e a temperatura média anual é de $22,9^{\circ} \mathrm{C}$.

Esses experimentos foram instalados no ano de 1995. A variedade de cana-deaçúcar cultivada na Usina São Martinho era a SP 80-185, enquanto que na Usina Da Pedra era a RB 7851-48. Os tratos culturais utilizados para a implantação dos experimentos foram os mesmos utilizados comumente com gradagem pesada (grade aradora por 2 ou 3 vezes) para eliminação da soqueira anterior; grade intermediária (destorroamento), subsolagem e grade niveladora ou de acabamento.

A localização das usinas e as parcelas referentes ao experimentos com e sem queima, estão representados nas figuras 1 e 2 . 


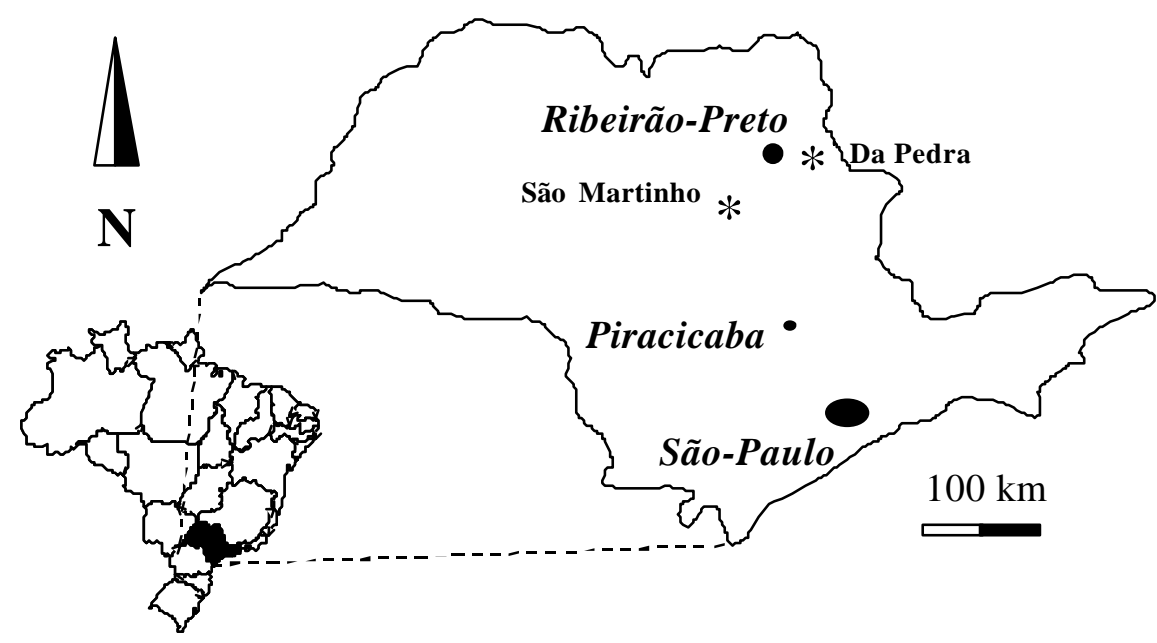

Figura 1 - Localização em ampla escala das regiões estudadas.

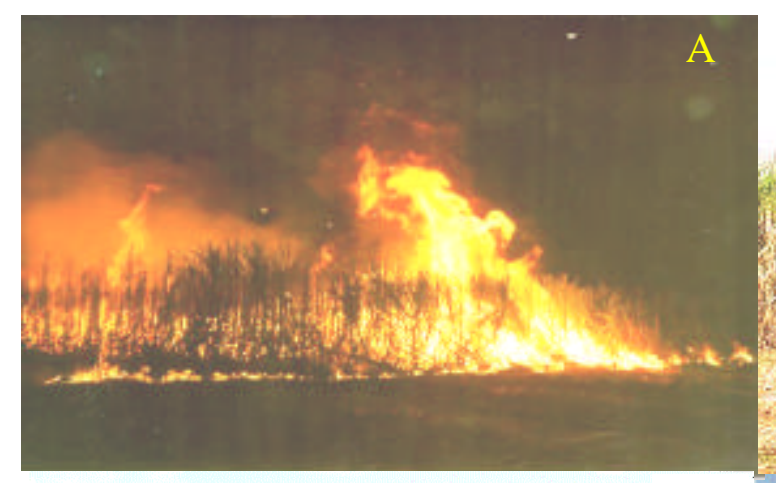

C

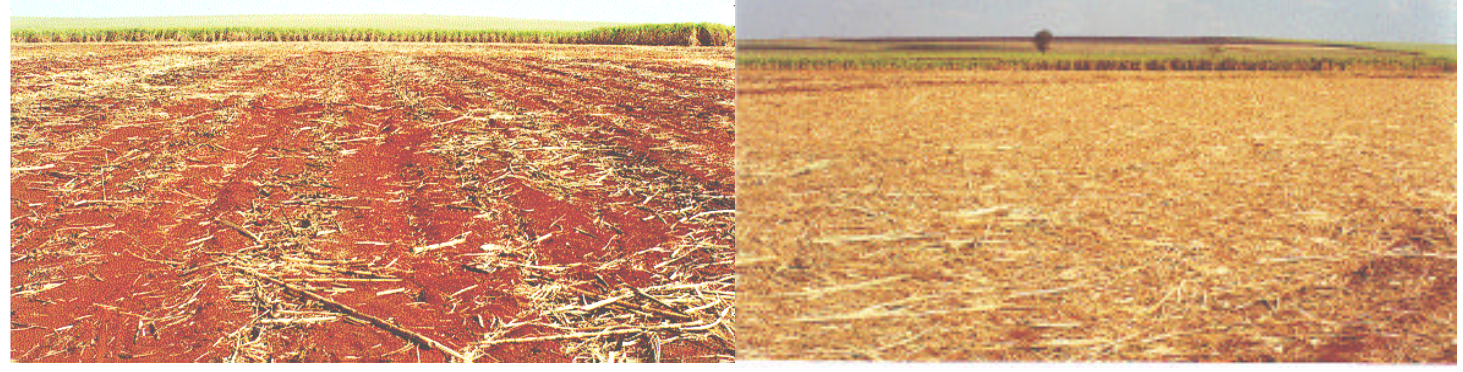

Figura 2 - Sistemas de colheita com e sem queima e áreas de estudos na Usina São Martinho. A) Queimada do canavial; B) Corte mecanizada de área não queimada,; C) Aspecto visual da parcela colhida após a queimada e D) Aspecto visual da parcela colhida mecanicamente sem a queimada do canavial. 


\subsubsection{Situações estudadas}

Para responder a questão formulada inicialmente, se a colheita mecanizada sem a queima prévia do canavial e com deposição da palhada sobre o solo possibilitará a acumulação de carbono no sistema, foram coletadas amostras da palhada para estudar o efeito do tempo de implantação do sistemas de colheita sem queima, do efeito do manejo da palhada remanescente em relação a diferentes quantidades de palhada depositada e da variedade da cana-de-açúcar.

\subsubsection{Efeito do tempo}

O estudo da acumulação da palhada depositada sobre o solo, foi realizado na área sobre Latossolo Vermelho (LV) durante os anos de 1998, 1999 e 2000 utilizando-se as parcelas referentes a totalidade de palhada depositada, no experimento de Quantidade (Q) (LV Q Sq 3,4 e 5); e na área sobre Neossolo Quartzarênico (NQ Q Sq 4 ) também no experimento de diferentes Quantidades, nas parcelas referentes a totalidade de palhada depositada.

\subsubsection{Efeito das diferentes quantidades de palhada}

Para o estudo da influência da quantidade da palhada depositada, as amostras foram coletadas em LV Q Sq 3,4 e 5 nos ano de 1998, 1999 e 2000, e em NQ Q Sq 4 no ano de 1999.

Os experimentos foram divididos em parcelas com diferentes quantidades de palhada deixadas sobre o solo (totalidade da palhada; 2/3; 1/3; o dobro da palhada e parcelas onde não era depositada palhada). Para cada tratamento existiam 6 parcelas, sendo que as parcelas referentes ao dobro recebiam a palhada das parcelas onde não havia deposição.

\subsubsection{Efeito das diferentes variedades de cana-de-açúcar}

O estudo referentes ao efeitos de diferentes variedades de cana-de-açúcar sobre acumulação da matéria orgânica, foi realizado numa área localizada sobre um Latossolo Vermelho e que contava com 4 anos de colheita sem queima da cana-de-açúcar. Essa 
área chamada de banco expositivo, mantida pela Usina São Martinho, onde estavam plantadas 36 variedades diferentes de cana-de-açúcar e, cada variedade possuía uma parcela formada por 10 linhas de plantio por 20 metros de comprimento.

Foram escolhidas 4 variedades cujo critério foi aquela de maior área plantada pela usina SP 80-1816 e outras 3 escolhidas pelo aspecto visual quanto à produção e deposição de palhada, muita palha RB 82-5335, média quantidade de palha RB 83-5486 e pouca quantidade de palha RB 85-5453. Foram coletadas 10 amostras por variedade.

\subsubsection{Amostragem da palhada}

As amostragens foram realizadas uma semana antes do corte dos canaviais. Para tanto foi utilizado um molde retangular medindo $0,5 \mathrm{~m}$ de largura $\mathrm{x} 0,75 \mathrm{~m}$ de comprimento $\left(0,325 \mathrm{~m}^{2}\right)$. Desta forma amostrou-se toda a palha correspondente à metade da entrelinha, uma vez que a distância entre as linhas de plantio da cana-de-açúcar é de 1,50 m. Assim, a amostragem ficou padronizada, obtendo valores mais representativos das áreas estudadas.

\subsubsection{Fracionamento físico da palhada remanescente}

Através da utilização de peneiras de diferentes diâmetros, foram obtidas 6 frações do material remanescente: > 4; 4-2; 2-1; 1-0,5;0,5-0,2 e <0,2mm

Cada fração obtida foi pesada e calculada a porcentagem daquela fração em relação ao peso total da amostra. Nessas frações é que foram analisados os teores de carbono e nitrogênio o que possibilitou a obtenção dos estoques de carbono e nitrogênio em cada fração dos restos culturais.

\subsubsection{Determinação das concentrações e estoque de carbono e nitrogênio nas frações}

As amostras separadas em diferentes frações foram moídas e analisadas por combustão a seco no equipamento Leco $\mathrm{CN}$ 2000, onde foram obtidos os teores de carbono e nitrogênio em cada uma das frações. 
Com os valores das concentrações procedeu-se o cálculo dos estoques, multiplicando a concentração do elemento pelo peso de matéria seca correspondente à fração.

\subsubsection{Delineame nto experimental}

O dimensionamento padronizado de parcelas para os experimentos está descrito a seguir:

Para o experimento que compara os sistemas de cultivo, o delineamento experimental é o de blocos ao acaso e consta de seis repetições, com parcelas formadas por 22 linhas de plantio com $70 \mathrm{~m}$ de comprimento e área útil formada pelas 10 linhas centrais de plantio das parcelas e cada linha com $50 \mathrm{~m}$ de comprimento.

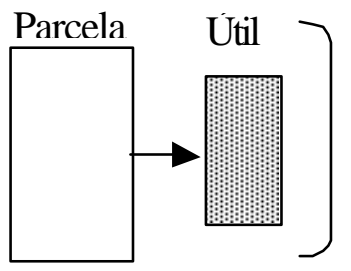

Parcela total $=22$ linhas de plantio por $70 \mathrm{~m}$ de comprimento, Parcela útil $=10$ linhas de plantio por $50 \mathrm{~m}$ de comprimento, Bordadura $=6$ linhas de plantio em cada lado, $10 \mathrm{~m}$ à frente e $10 \mathrm{~m}$ no fundo da parcela útil

Para o estudo do efeito da quantidade dos restos culturais, o delineamento também é o de blocos ao acaso e as parcelas são em número de 5 por tratamento; tratamentos são: totalidade, 2/3, 1/3 e o dobro dos restos culturais deixados sobro o solo. Cada parcela é compostas por 10 linhas de plantio por 10 metros de comprimento, sendo a área útil formada pelas 5 linhas centrais de cada parcela e pelos 10 metros de comprimento.

Parcela referente ao estudo das diferentes quantidades de resíduos culturais deixados sobre o solo, na parte externa, a área total, formada por 10 linhas de plantio e 10 metros de comprimento, na parte interna, a área útil, 5 linhas de plantio por 10 metros de comprimento.

$$
\begin{aligned}
& \text { Parcela } \\
& \begin{array}{|l}
\text { Util } \\
\square
\end{array} \begin{array}{l}
\begin{array}{l}
\text { Parcela total }=10 \text { linhas de plantio por } 10 \mathrm{~m} \text { de comprimento, } \\
\text { Parcela útil }=5 \text { linhas de plantio por } 10 \mathrm{~m} \text { de comprimento, } \\
\text { Bordadura }=6 \text { linhas de plantio em cada lado, } 10 \mathrm{~m} \text { à frente } \\
\text { e } 10 \mathrm{~m} \text { no fundo da parcela útil }
\end{array}
\end{array}
\end{aligned}
$$


Para o estudo do efeito da variedade da cana-de-açúcar, foram utilizadas parcelas de uma área experimental pertencente à Usina São Martinho, onde cada parcela representava uma variedade e era composta por 10 linhas de plantio cada uma com 20 metros de comprimento, sendo a área útil formada pelas 6 linhas centrais de cada parcela e pelos 10 metros centrais de comprimento.

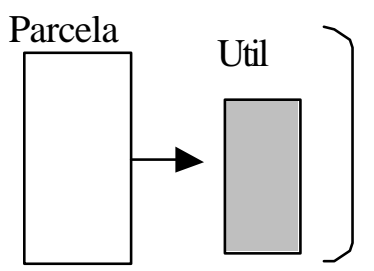

Parcela total $=10$ linhas de plantio por $20 \mathrm{~m}$ de comprimento, Parcela útil $=6$ linhas de plantio por $10 \mathrm{~m}$ de comprimento.

\subsection{Resultados e discussão}

\subsubsection{Produtividade e restituição da palhada}

As informações sobre a produtividade da cana-de-açúcar das áreas localizadas nas duas usinas (tabela 1 ) foram fornecidos pela COPERSUCAR. ${ }^{1}$

Tabela 1. Produtividade de cana-de-açúcar.

\begin{tabular}{ccccccc}
\hline \multirow{2}{*}{ Áreas } & \multicolumn{7}{c}{ Rendimento } \\
\cline { 2 - 7 } & 1996 & 1997 & 1998 & 1999 & 2000 & Média \\
\hline & 115 & 106 & 103 & 96 & 85 & 101 \\
LV Cq $^{*}$ & 104 & 114 & 99 & 82 & 78 & 95 \\
LV Sq & 133 & 107 & 75 & 37 & nd & 88 \\
NQ Cq & 133 & 68 & 43 & nd & 85 \\
NQ Sq & 132 & 96 & &
\end{tabular}

Fonte: COPERSUCAR (2000)

* LV = Latossolo Vermelhoo; $\mathrm{NQ}=$ Neossolo quartzarênico; $\mathrm{Cq}=$ Com queima; $\mathrm{Sq}=$ Sem queima

Os resultados da produtividade referem-se à cana-de-açúcar produzida (colhida + perdas na colheita). A produção é um pouco maior no sistema de colheita com queima 
${ }^{1}$ COPERSUCAR. Relatório final do projeto Cana-Crua safra 99/00 RT n 961, 2000. e corte manual da cana-de-açúcar, exceção feita no ano de 1997 para LVSq e, no ano de 1999 para NQSq, quando a produtividade no sistema sem queima foi maior. As diferenças são de 6 e $3 \mathrm{Mgha}^{-1}$ para LV e NQ, respectivamente. Esse rendimento menor pode estar relacionado com problemas de rebrota da cana-de-açúcar já que nestas áreas grade quantidade de palhada fica sobre o solo, ou ainda, pela imobilização de nitrogênio da adubação e de outros nutrientes na palhada.

Apesar de serem variedades diferentes de cana-de-açúcar, a produtividade é praticamente a mesma para as duas situações quando se comparam os sistemas com e sem queima, inclusive quando analisamos a diminuição da produtividade ao longo do tempo, a queda é mais acentuada no sistema sem queima.

Quando comparados os dois solos, nota-se que a produtividade é maior em NQ apenas na primeira colheita, enquanto que nas demais é menor do que em LV. Na área NQ4, após 4 ciclos de cultivo, foi necessária a reforma do canavial, já que a produtividade estava muito baixa, 43 e $37 \mathrm{Mgha}^{-1}$ respectivamente para o sistema com queima e sem queima. Essa reforma, que empregou a técnica do cultivo mínimo, inviabilizou a continuidade dos estudos inicialmente previsto.

A tabela 2 mostra as quantidades de palhada depositadas sobre os solos nas áreas experimentais localizadas nas áreas LVSq e NQSq.

Tabela 2. Restituição anual da palhada sobre o solo, nas áreas estudadas.

\begin{tabular}{crrrrrr}
\hline \multirow{2}{*}{ Áreas } & \multicolumn{7}{c}{ Massa seca de palhada } \\
\cline { 2 - 7 } & 1996 & 1997 & 1998 & 1999 & 2000 & Média \\
\hline \multirow{2}{*}{ LVSq } & 15,7 & 12,8 & 11,3 & 14,5 & 15,2 & 13,8 \\
NQSq & 10,5 & 16,8 & 11,4 & nd & nd & 12,9 \\
\hline
\end{tabular}

Fonte: COPERSUCAR (2000) 
Nos anos de 1999 e 2000, não foram feitos os levantamentos da restituição dos resíduos culturais na área NQSq, por conta da reforma efetuada na mesma.

Os valores variaram de 12,8 até $15,7 \mathrm{Mg} \mathrm{ha}^{-1}$.ano ${ }^{-1}$ para LVSq e de 10,5 até 16,8 $\mathrm{Mg} \mathrm{ha}^{-1} \cdot \mathrm{ano}^{-1}$ para NQSq com médias de 13,8 e $12,9 \mathrm{Mg} \mathrm{ha}^{-1} \cdot$ ano $^{-1}$ respectivamente.

A produção média anual de palhada foi equivalente a cerca de $15 \%$ da produtividade da área, o que está de acordo com Lima et al (1999).

O total de palhada depositada até o ano de 1998 foi similar para as duas áreas (39,8 e 38,7 $\mathrm{Mgha}^{-1}$ ), apesar de serem variedades de cana-de-açúcar diferentes, e de uma produtividade neste período ter sido 5\% maio na área localizada sobre LVSq.

\subsubsection{Estoques de massa seca e carbono na palhada}

Neste item serão apresentados e discutidos os resultados referentes ao acúmulo de palhada remanescente antes das colheitas (variações inter-anuais), bem como a distribuição granulométrica da palhada no tocante às concentrações e estoque de $\mathrm{C}$ e ao estoque de massa seca.

\subsubsection{Efeito da quantidade de palhada depositada e do tempo de deposição sobre a acumulação da palhada}

Na tabela 3 e figura 2 são apresentados os estoques de palhada depositada e remanescente sobre o solo, bem como a porcentagem remanescente em relação à quantidade de material depositado ao longo de três anos.

Para as situações LVSq 3, LVSq 4 e LVSq 5, as quantidades de palhada remanescente sobre o solo no tratamento totalidade da palhada, foram respectivamente 5,97; 4,46 e 5,59 $\mathrm{Mg} \mathrm{ha}^{-1}$, indicando que após 3 anos de sistema ocorre uma estabilização no estoque de palhada sobre o solo.

A porcentagem de palhada remanescente em relação a porcentagem total de palhada depositada, decresceu com o tempo (Tabela 3 comparação LVSq3, Sq4, Sq5), mesmo essa área tendo recebido na colheita de 1998 cerca de $11,3 \mathrm{Mg} \mathrm{ha}^{-1}$ de palhada e no ano de 1999 mais $14,5 \mathrm{Mg} \mathrm{ha}^{-1}$, totalizando uma decomposição da ordem de $90 \%$ da 
palhada depositada. Cabe ressaltar que em 1998 foi o ano que ocorreu a menor deposição de palhada com cerca de $11 \mathrm{Mgha}^{-1}$ e, essa menor deposição deve ter contribuído para uma diminuição do remanescente em LVSq 4 em relação aos estoques encontrados nos outros anos.

Tabela 3. Massa seca de palhada remanescente antes das colheitas nos tratamentos de diferentes quantidades de palhada.

\begin{tabular}{|c|c|c|c|c|c|c|}
\hline \multirow{3}{*}{$\begin{array}{l}\text { Tratamentos } \\
\text { Quantidades }\end{array}$} & \multicolumn{3}{|c|}{ Massa seca de palhada total } & \multicolumn{3}{|c|}{ Carbono Total } \\
\hline & \multirow{2}{*}{ Depositada } & \multicolumn{2}{|c|}{ Remanescente } & Depositado & \multicolumn{2}{|c|}{ Remanescente } \\
\hline & & $\mathrm{Mg} \mathrm{ha}^{-1}$ & $\%$ & \multicolumn{2}{|c|}{$\mathrm{Mg} \mathrm{ha}^{-1}$} & $\%$ \\
\hline & \multicolumn{6}{|c|}{ LV Q Sq 3 (1998) } \\
\hline $1 / 3$ & 9,5 & $2,94 \mathrm{a}^{*}$ & 31 & 4,12 & 1,25 & 30 \\
\hline $2 / 3$ & 19,1 & $4,32 \mathrm{ab}$ & 23 & 8,29 & 1,84 & 22 \\
\hline $3 / 3$ & 28,5 & $5,97 \mathrm{~b}$ & 21 & 12,37 & 2,55 & 21 \\
\hline $6 / 3$ & \multicolumn{4}{|c|}{ LV Q Sq 4 (1999) } & & nd \\
\hline $1 / 3$ & 13,3 & $2,29 \mathrm{a}$ & 17 & 5,77 & 0,82 & 14 \\
\hline $2 / 3$ & 26,7 & $3,51 \mathrm{~b}$ & 13 & 11,58 & 1,26 & 11 \\
\hline $3 / 3$ & 39,8 & $4,46 \mathrm{~b}$ & 11 & 17,27 & 1,61 & 9 \\
\hline $6 / 3$ & 79,6 & $5,64 \mathrm{bc}$ & 7 & 35,54 & 2,02 & 6 \\
\hline & \multicolumn{6}{|c|}{ LV Q Sq 5 (2000) } \\
\hline $1 / 3$ & 18,1 & $3,25 \mathrm{a}$ & 18 & 7,85 & 1,39 & 18 \\
\hline $2 / 3$ & 36,4 & $5,36 \mathrm{ab}$ & 15 & 15,79 & 2,28 & 14 \\
\hline $3 / 3$ & 54,3 & $5,59 \mathrm{ab}$ & 10 & 23,56 & 2,36 & 10 \\
\hline $6 / 3$ & 108,6 & $6,73 \mathrm{bc}$ & 6 & 47,12 & 2,88 & 6 \\
\hline \multicolumn{7}{|c|}{ NQ Q Sq 4 (1999) } \\
\hline $1 / 3$ & 12,9 & $2,25 \mathrm{a}$ & 17 & & 0,85 & \\
\hline $2 / 3$ & 25,8 & $3,13 \mathrm{ab}$ & 12 & & 1,18 & \\
\hline $3 / 3$ & 38,7 & $3,58 \mathrm{bc}$ & 9 & & 1,35 & \\
\hline $6 / 3$ & 77,4 & $5,15 \mathrm{c}$ & 7 & & 1,94 & \\
\hline
\end{tabular}

N ota: L etras iguais indicam que não houve diferença estatisticamente significativa

LV: L atossolo Vermelho; Q: Quantidades; Sq: Sistema sem queima 


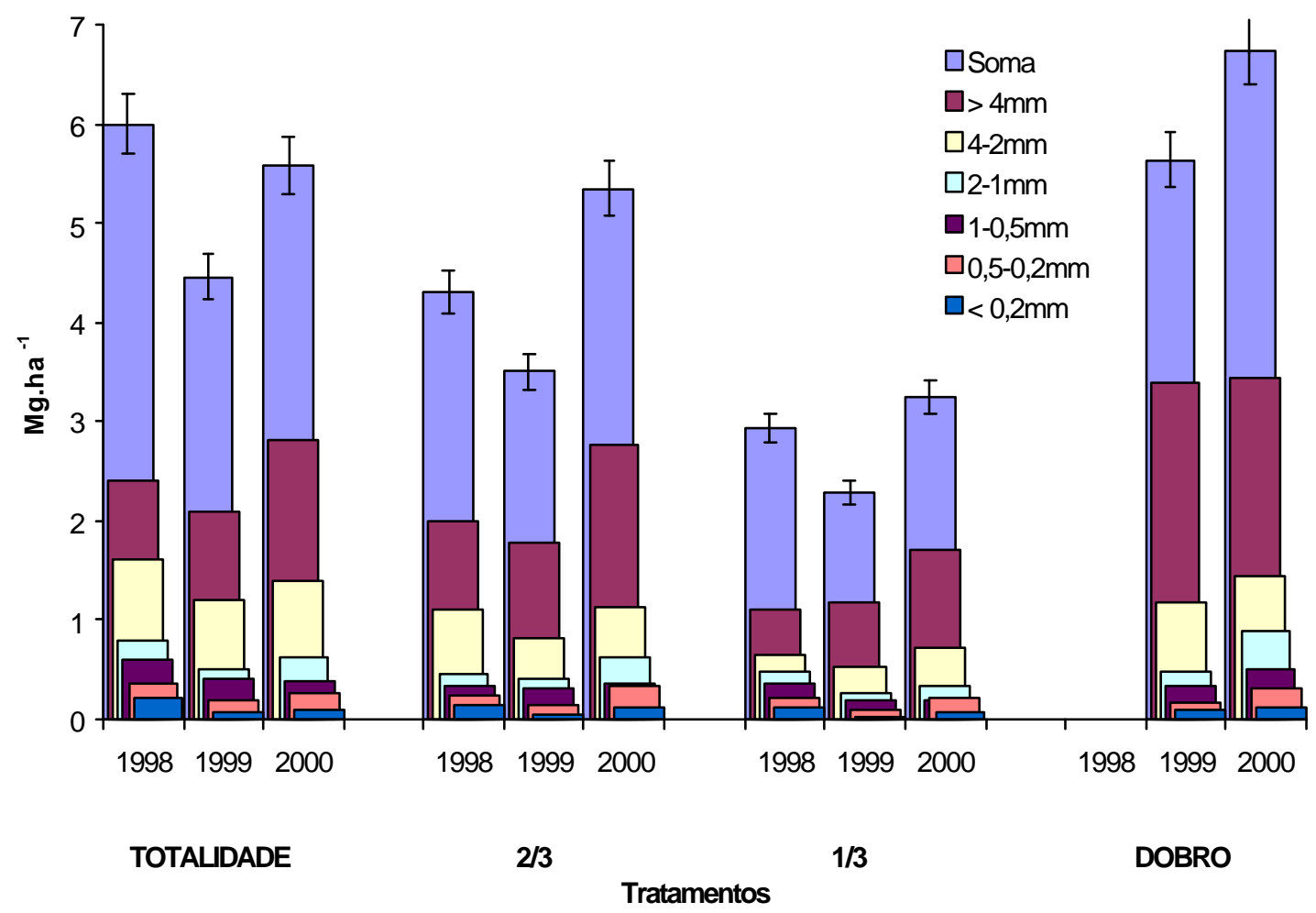

Figura 2 - Remanescentes de palhada em megagramas por hectare em LV Q ao longo dos três anos de estudos.

Entre os tratamentos é mantida mesma característica encontrada na palhada do ano anterior, com diferença estatisticamente significativa apenas no tratamento com 1/3 de palhada. Mesmo o tratamento com o dobro de palhada, não apresentou diferença em relação ao tratamento com a totalidade da palhada. Há uma tendência geral a uma diminuição da estocagem com a diminuição das restituições, também para NQ Q Sq4.

A comparação entre LVQSq4 e NQQSq4 mostra que a acumulação de palhada é a mesma para as duas áreas em cada um dos tratamentos. Como os totais de palhada depositada foi similar para as duas áreas, observamos que não houve feito do tipo de solo sobre a decomposição da palhada. 


\subsubsection{Carbono estocado em função da variedade da cana-de-açúcar}

As figuras 3 e 4 mostram que não existe diferença estatisticamente significativa em relação aos estoques de massa seca (MS) e de carbono (C) da palhada remanescente entre as quatro variedades estudadas, sendo que os estoques de MS variaram entre 6,5 e 7,4 $\mathrm{Mgha}^{-1}$, e de $\mathrm{C}$ entre 2,3 e 2,7 $\mathrm{MgC} \mathrm{ha}^{-1}$. Entre as frações também não houve diferenças, e os maiores estoques de MS e de $\mathrm{C}$ foram encontrados nas frações $>4 \mathrm{~mm}$ com cerca de $50 \%$ do total para MS e C.

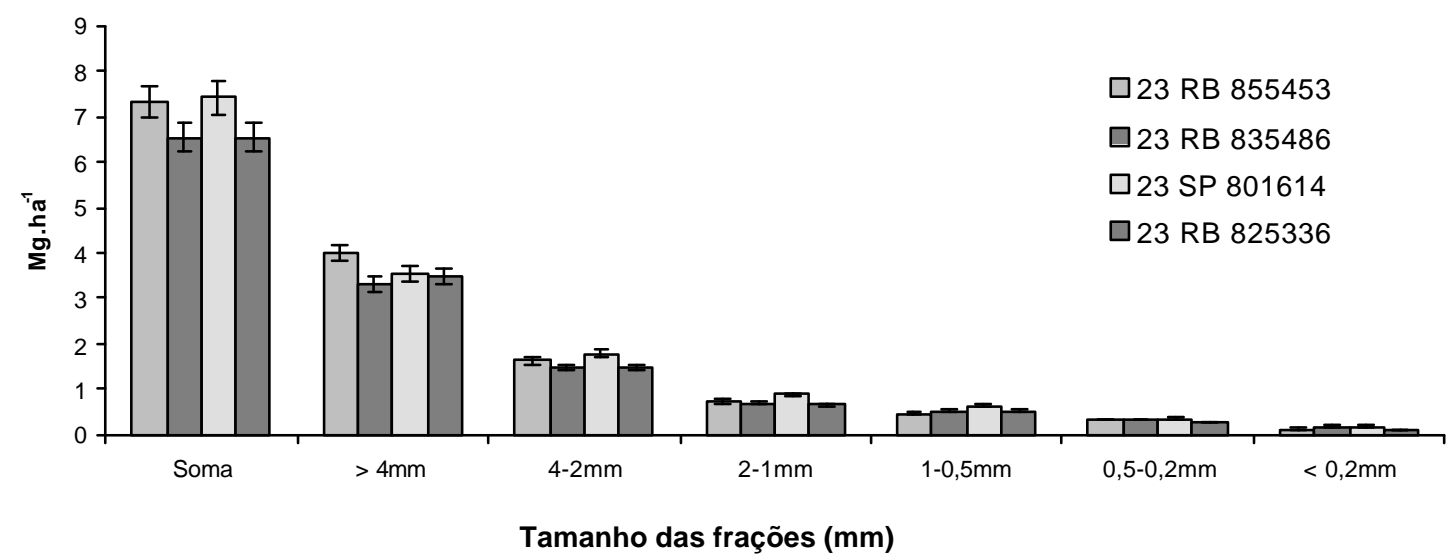

Figura 3 - Remanescente de palhada em Megagramas por hectare de quatro variedades de cana-de-açúcar.

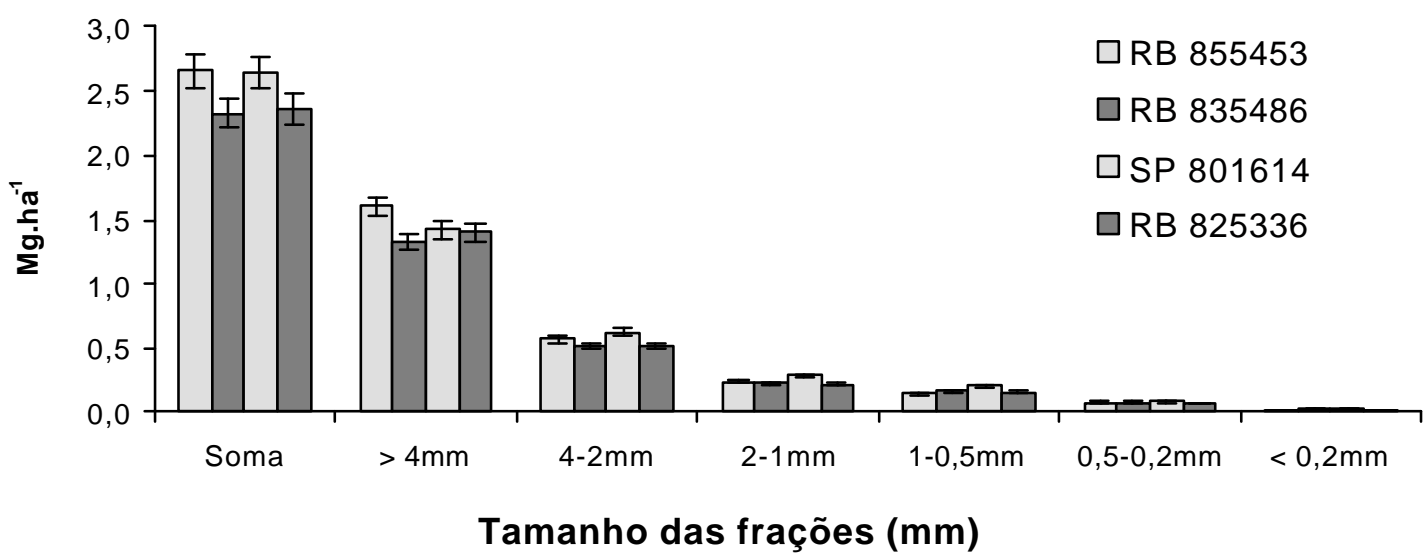

Figura 4 - Estoque de carbono total e nas frações das quatro variedades de cana-deaçúcar estudadas. 
Ainda analisando o efeito da variedade da cana-de-açúcar cultivada, sobre a deposição e acumulação da palhada, na Tabela 4 estão demonstradas as quantidades de palhada remanescentes nas parcelas dos tratamentos onde era deixada a totalidade da palhada, nas áreas experimentais LVSq 4 e NQSq 4, cujas variedades eram a a SP 80185 e a RB 7851-48, respectivamente, porcentagem remanescente do total de palhada depositado, e os estoques de carbono e nitrogênio na palhada.

Tabela 4. Massa seca de palhada remanescente sobre o solo e estoques de Carbono e Nitrogênio na palhada.

\begin{tabular}{|c|c|c|c|c|c|}
\hline \multirow[t]{3}{*}{ Sistema } & \multicolumn{3}{|c|}{ Massa seca de palhada } & \multicolumn{2}{|c|}{ Estoque de $\mathrm{C}$ e $\mathrm{N}$ na palhada } \\
\hline & Média & Coef. Var & Remanescente & Carbono & Nitrogênio \\
\hline & $\mathrm{Mgha}^{-1}$ & \multicolumn{2}{|c|}{$\%$} & \multicolumn{2}{|c|}{$\mathrm{kg} \mathrm{ha}^{+1}$} \\
\hline LV Sq 4 & $4,50 \pm 0,70 a$ & 16 & 11 & $1608 \mathrm{~A}$ & $31,8 a$ \\
\hline NQ Sq 4 & $3,55 \pm 0,39 a$ & 11 & 9 & $1355 \mathrm{~A}$ & $20,9 a$ \\
\hline
\end{tabular}

Nota: Letras iguais entre os sistemas significam que não houve diferença estatisticamente significativa $(\mathrm{p}<0,05)$.

Pode-se observar que a acumulação da palhada ao longo do tempo é semelhante para as duas áreas estudadas, pois não encontramos diferença estatisticamente significativa em relação ao remanescente da palhada, com 4,50 $\mathrm{Mgha}^{-1}$ para a área LVSq 4 e 3,55 $\mathrm{Mgha}^{-1}$ para a área NQSq 4. As taxas de decomposição da palhada são próximas com cerca de $89 \%$ e $91 \%$ respectivamente para LV e NQ $(11 \%$ e $9 \%$ remanescente de toda a palhada depositada).

Os estoques de carbono e nitrogênio na palhada, foram um pouco maiores na área LVSq 4, apresentando $1608 \mathrm{kgC} \mathrm{ha}^{-1}$ e $31,8 \mathrm{~kg} \mathrm{Nha}^{-1}$; contra $1355 \mathrm{~kg} \mathrm{Cha}^{-1} \mathrm{e}$ $20,9 \mathrm{~kg} \mathrm{~N} \mathrm{ha}^{-1}$ na área NQSq 4.

$\mathrm{Na}$ Tabela 5 estão apresentados os resultados referentes ao fracionamento da palhada, no tocante a porcentagem de cada fração em relação a amostra total, bem como os teores e estoques de carbono e nitrogênio em cada fração e a razão $\mathrm{C} / \mathrm{N}$.

Pode-se notar que entre 70 e $80 \%$ da palhada encontra-se nas frações $>2 \mathrm{~mm}$, e que em torno de $5 \%$ se encontra na fração $<0,5 \mathrm{~mm}$. 
As concentrações de carbono são maiores nas frações $>4 \mathrm{~mm}(>400 \mathrm{~g} / \mathrm{KgMS})$ e diminuem nas frações menores que $0,5 \mathrm{~mm}(<150 \mathrm{~g} / \mathrm{KgMS})$. Essas concentrações mais baixas devem ter sido provocadas pelo processo de decomposição, como também por contaminação de solo nessas frações da palhada.

Tabela 5. Massa seca de palhada remanescente, porcentagem da fração em relação ao peso total da amostra, concentrações e estoques de carbono e nitrogênio e razão $\mathrm{C} / \mathrm{N}$ nas frações da palhada.

\begin{tabular}{|c|c|c|c|c|c|c|c|c|c|c|}
\hline \multirow[t]{3}{*}{ Frações } & \multicolumn{3}{|c|}{ Massa seca de palhada } & \multicolumn{3}{|c|}{ Concentração } & \multicolumn{4}{|c|}{ Estoque na palhada } \\
\hline & \multicolumn{2}{|c|}{ Média } & Reman. & $\mathrm{C}$ & $\mathrm{N}$ & $\mathrm{C} / \mathrm{N}$ & \multicolumn{2}{|c|}{$\mathrm{C}$} & \multicolumn{2}{|c|}{$\mathrm{N}$} \\
\hline & \multicolumn{2}{|c|}{$\mathrm{Mg} \mathrm{ha}^{-1} \%$} & $\%$ & \multicolumn{2}{|c|}{$\mathrm{g} \mathrm{kg}^{-1} \mathrm{MS}$} & & $\mathrm{kg} \mathrm{ha}^{-1}$ & $\%$ & $\mathrm{~kg} \mathrm{ha}$ & $\%$ \\
\hline \multicolumn{11}{|c|}{ LVSq 4} \\
\hline$>4 \mathrm{~mm}$ & 2,10 & 47 & & 400,2 & 6,0 & 67 & 838,5 & 52 & 12,6 & 40 \\
\hline $42 \mathrm{~mm}$ & 1,21 & 27 & & 347,8 & 7,4 & 47 & 420,4 & 26 & 9,4 & 30 \\
\hline $2-1 \mathrm{~mm}$ & 0,51 & 11 & & 324,9 & 8,5 & 38 & 166,7 & 10 & 4,3 & 14 \\
\hline $1-0,5 \mathrm{~mm}$ & 0,40 & 9 & & 312,4 & 8,6 & 36 & 125,3 & 8 & 3,6 & 11 \\
\hline $0,5-0,2 \mathrm{~mm}$ & 0,20 & 4 & & 231,7 & 7,2 & 32 & 46,8 & 3 & 1,4 & 4 \\
\hline$<0,2 \mathrm{~mm}$ & 0,08 & 2 & & 132,4 & 5,3 & 25 & 10,0 & 1 & 0,4 & 1 \\
\hline Soma & 4,50 & 100 & 11 & & & & 1607,7 & 100 & 31,8 & 100 \\
\hline \multicolumn{11}{|c|}{ NQSq 4} \\
\hline$>4 \mathrm{~mm}$ & 2,05 & 57 & & 421,6 & 5,3 & 86 & 863,4 & 64 & 10,6 & 51 \\
\hline $42 \mathrm{~mm}$ & 0,83 & 23 & & 376,4 & 7,1 & 53 & 311,7 & 23 & 5,9 & 28 \\
\hline $2-1 \mathrm{~mm}$ & 0,28 & 8 & & 341,0 & 7,5 & 45 & 96,1 & 7 & 2,1 & 10 \\
\hline $1-0,5 \mathrm{~mm}$ & 0,22 & 6 & & 266,9 & 6,5 & 42 & 60,1 & 4,4 & 1,4 & 7 \\
\hline $0,5-0,2 \mathrm{~mm}$ & 0,13 & 4 & & 154,5 & 4,6 & 34 & 20,1 & 1,4 & 0,6 & 3 \\
\hline$<0,2 \mathrm{~mm}$ & 0,04 & 1 & & 81,0 & 5,3 & 16 & 3,5 & 0,2 & 0,2 & 1 \\
\hline Soma & 3,55 & 100 & 9 & & & & 1354,9 & 100 & 20,9 & 100 \\
\hline
\end{tabular}

As concentrações de nitrogênio não seguem o mesmo padrão das concentrações de carbono, já que as concentrações foram maiores nas frações 1-0,5mm, 21mm, $42 \mathrm{~mm}$ e 
$>4 \mathrm{~mm} \quad\left(8,6 \mathrm{~g} \mathrm{~N} \mathrm{~kg}^{-1} \mathrm{MS} ; \quad 8,5 \mathrm{~g} \mathrm{~N} \mathrm{~kg}^{-1} \mathrm{MS} ; \quad 7,4 \mathrm{~g} \mathrm{~N} \mathrm{~kg}^{-1} \mathrm{MS} \quad\right.$ e $\quad 6,0 \mathrm{~g} \mathrm{~N} \mathrm{~kg}^{-1} \mathrm{MS}$ respectivamente) para LVSq 4, mas não diferiram significativamente entre si.

Para a área NQSq 4 as concentrações de $\mathrm{N}$ foram mais baixas do que em LVSq 4. Isso pode ter ocorrido pelo efeito das variedades de cana-de-açúcar diferentes entre as duas situações ou uma menor absorção de $\mathrm{N}$ em NQ, já que rendimento médio da canade-açúcar nesta área foi menor.

Para as duas situações a razão $\mathrm{C} / \mathrm{N}$ diminuiu com o tamanho das frações de 67 a $86(>4 \mathrm{~mm})$ até 25 a $16(<0,2 \mathrm{~mm})$.

$\mathrm{Na}$ figura 5 observam-se as relações entre o total depositado e o remanescente, onde confirmamos que apesar de serem variedades diferentes de cana-de-açúcar, o comportamento do estoque da palhada é similar.
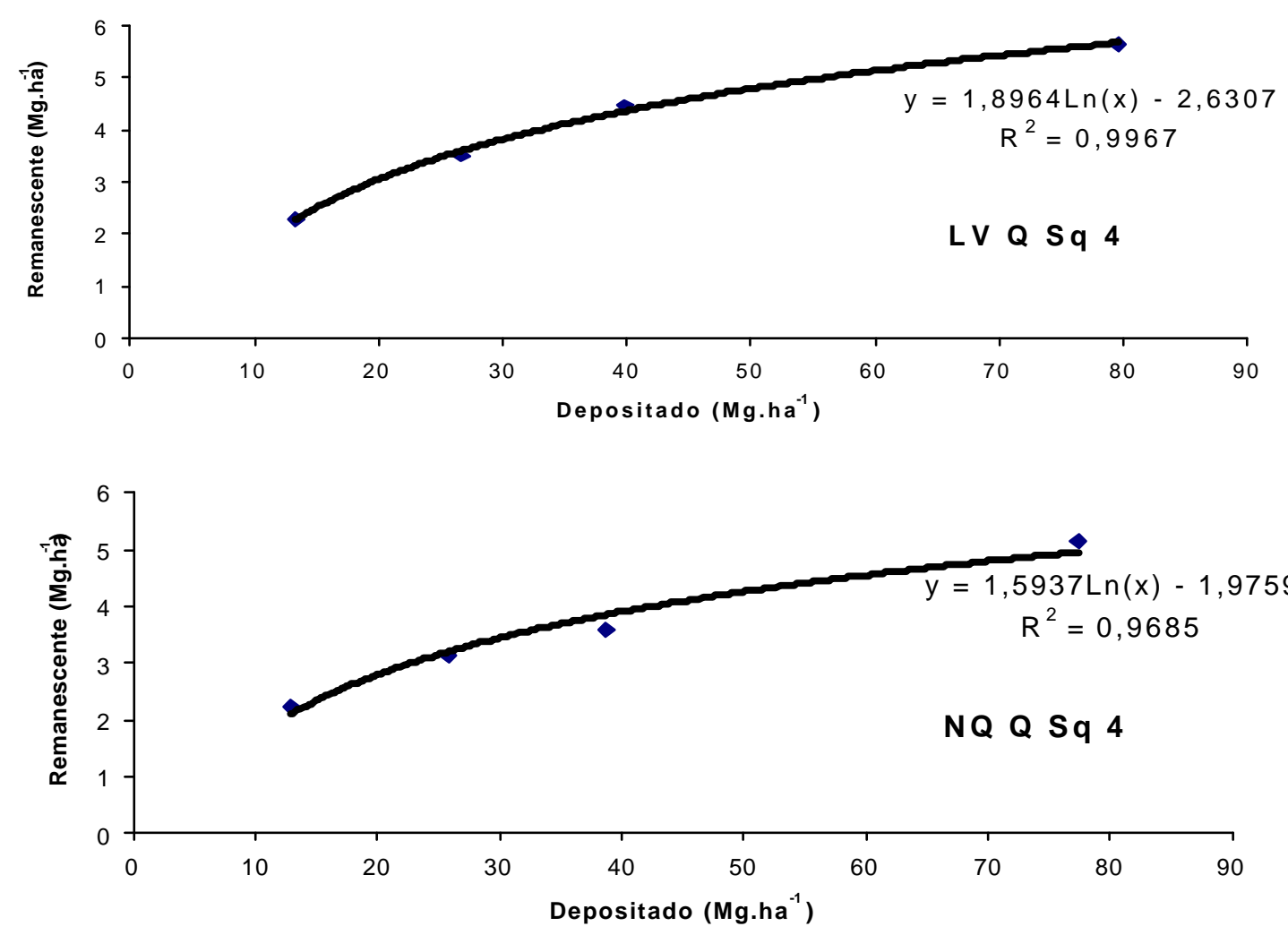

Figura 5 - Relação entre o total de palhada depositada e o remanescente após 4 anos para LVQSq e NQQSq. 


\subsubsection{Qualidade da palhada}

A qualidade da palhada será estudada considerando a distribuição granulométrica dessa palhada nas diferentes situações estudadas.

\subsubsection{Efeito da quantidade de palhada depositada e do tempo sobre o fracionamento granulométrico}

Na figura 6, que é referente às porcentagens encontradas na área LV Q Sq 5, cuja palhada foi coletada no ano de 2000, pode-se observar que não ocorreu diferenças estatisticamente significativas nas porcentagens de cada fração entre os tratamentos estudados. Isso indica que a quantidade de material depositado não interfere na distribuição da palhada nas diferentes frações.

A maior porcentagem foi encontrada na fração $>4 \mathrm{~mm}$, com valores em torno de $50 \%$. Essa porcentagem diminui menos de $5 \%$ para as frações $<0,5 \mathrm{~mm}$. A somatória das frações $0,5-0,2 \mathrm{~mm}$ e $<0,2 \mathrm{~mm}$ representam menos que $10 \%$ do peso total.

Por outro lado, a fração $<0,2 \mathrm{~mm}$ foi contaminada pelo solo (observação visual). Então, dependendo do parâmetro a ser analisado, essas frações podem ser descartadas.

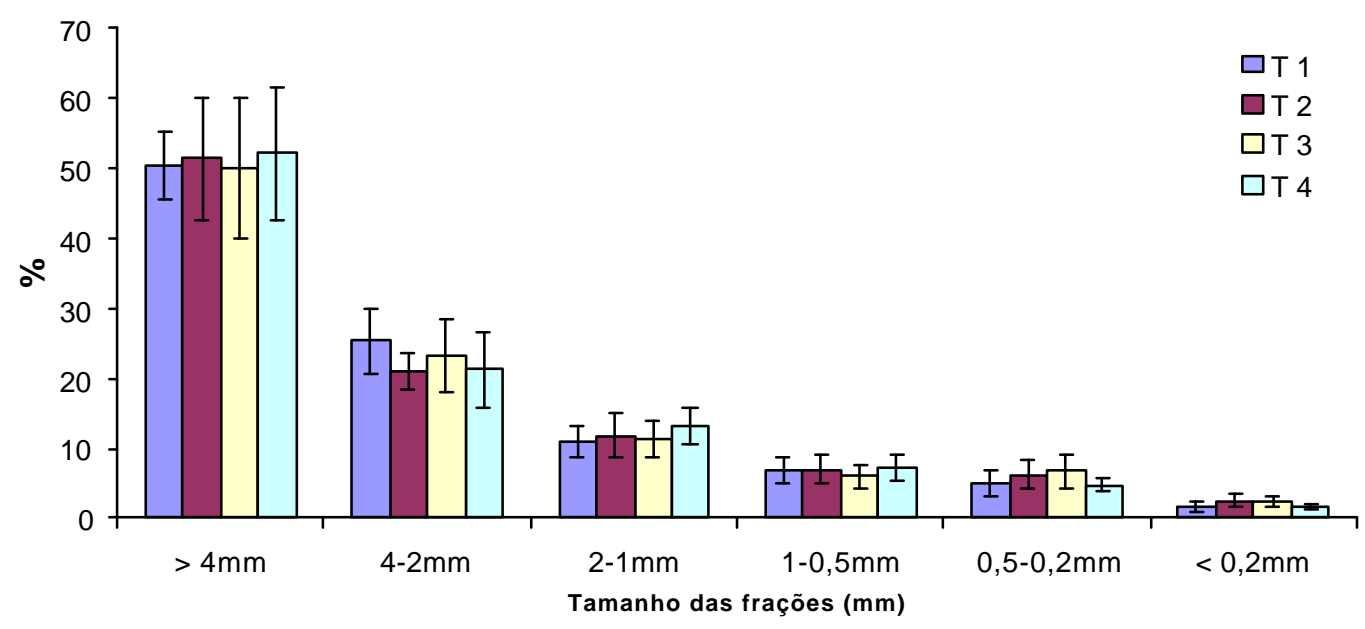

Figura 6 - Porcentagem das frações em relação ao peso total das amostras na área LV Q Sq 5 , onde $\mathrm{T} 1=3 / 3 . \mathrm{T} 2=2 / 3 ; \mathrm{T} 3=1 / 3$ e $\mathrm{T} 4=6 / 3$ da palhada depositada. 
$\mathrm{Na}$ figura 7 estão apresentados os valores referentes ao experimento com diferentes quantidades de palhada depositada sobre o solo na área LV Q Sq. Onde podem ser encontradas as porcentagens de cada fração ao longo dos 3 anos de estudos. Pode-se notar que as mesmas proporções encontradas entre as frações para LV Q Sq no ano de 2000, ocorreram nos anos anteriores, indicando que ao longo desse período, essas proporções não se alteram significativamente, com exceção do tratamento $1 / 3$ no ano de 1998.

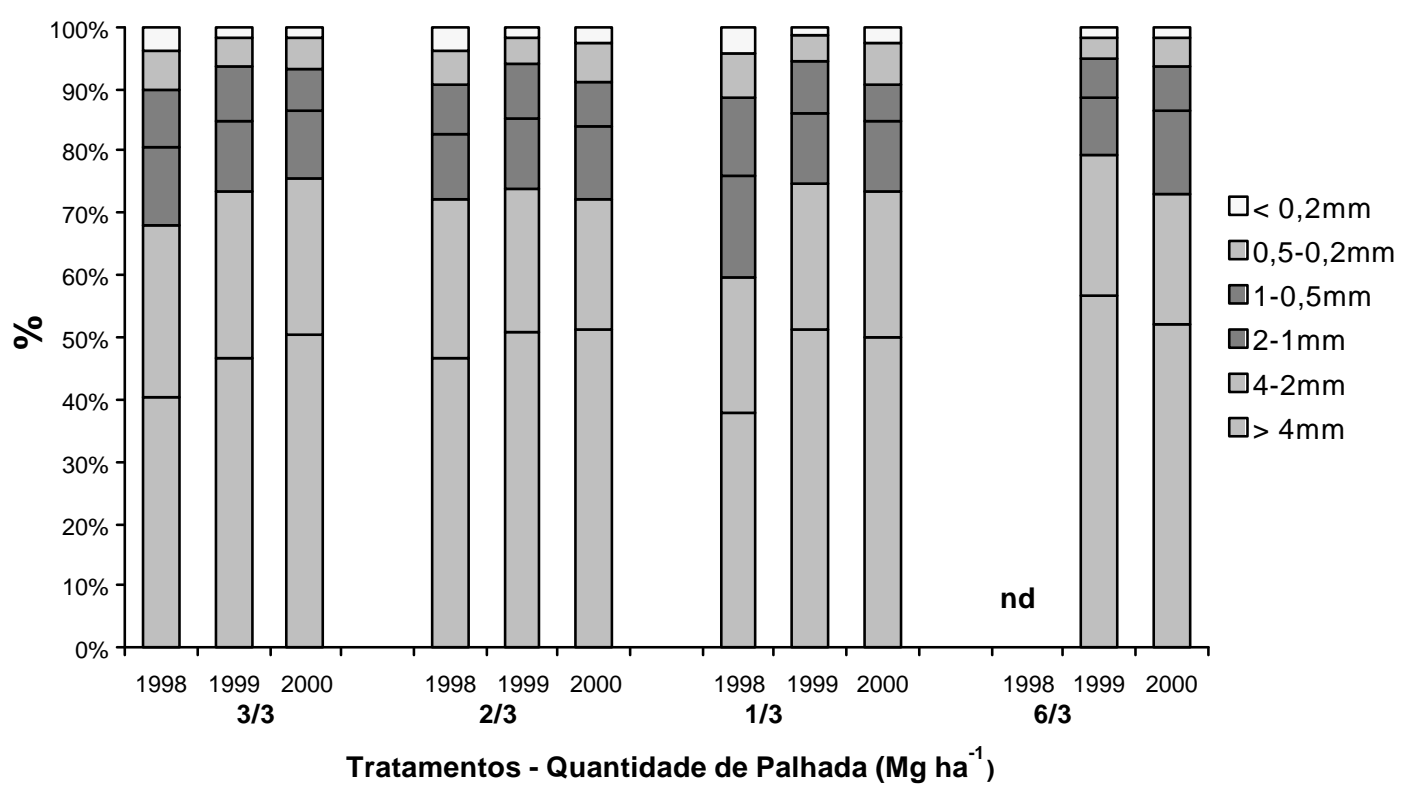

Figura 7 - Porcentagem das frações no LV Q ao longo de três anos ( Sq 3, Sq 4 e Sq 5).

Independente da quantidade de palhada depositada sobre o solo, a distribuição entre as frações foi similar para todas situações.

Pode-se notar que ocorreu um pequeno aumento da porcentagem de palhada na fração > $4 \mathrm{~mm}$ em detrimento às frações menores. Esse aumento é mais evidenciado entre LV Q Sq 5 e LV Q Sq 3, entretanto não diferem estatisticamente. 


\subsubsection{Efeito da variedade da cana-de-açúcar}

A figura 8 mostra que entre as variedades não ocorreu diferenças estatisticamente significativas na distribuição da palhada nas diferentes frações analisadas, com exceção da comparação SP 801816 com RB 855453.

Os valores mais elevados foram encontrados nas frações $>4 \mathrm{~mm}$, variando entre 48 e $55 \%$ e diminuindo nas frações menores, entre 22 e $24 \%$ nas frações 42 mm, até menos que $10 \%$ nas frações $<0,5 \mathrm{~mm}$.

Para a variedade SP 801816 encontrou-se valores menores apenas na fração $>4 \mathrm{~mm}$ com cerca de 48\%, sendo inclusive diferente estatisticamente das demais variedades. Nas outras frações ocorreram diferenças na fração 1-0,5 mm onde a variedade RB 855453, apresentou valor mais baixo que as variedades SP 801816 e RB 835486, entretanto, a porcentagem dessas frações em relação ao total da amostra representa menos do que $10 \%$.

Desta forma, exceto na variedade SP 801816, não ocorreu efeito da variedade sobre a distribuição da palhada nas diferentes frações, indicando que o comportamento da palhada é bastante parecido entres as principais variedades cultivadas.

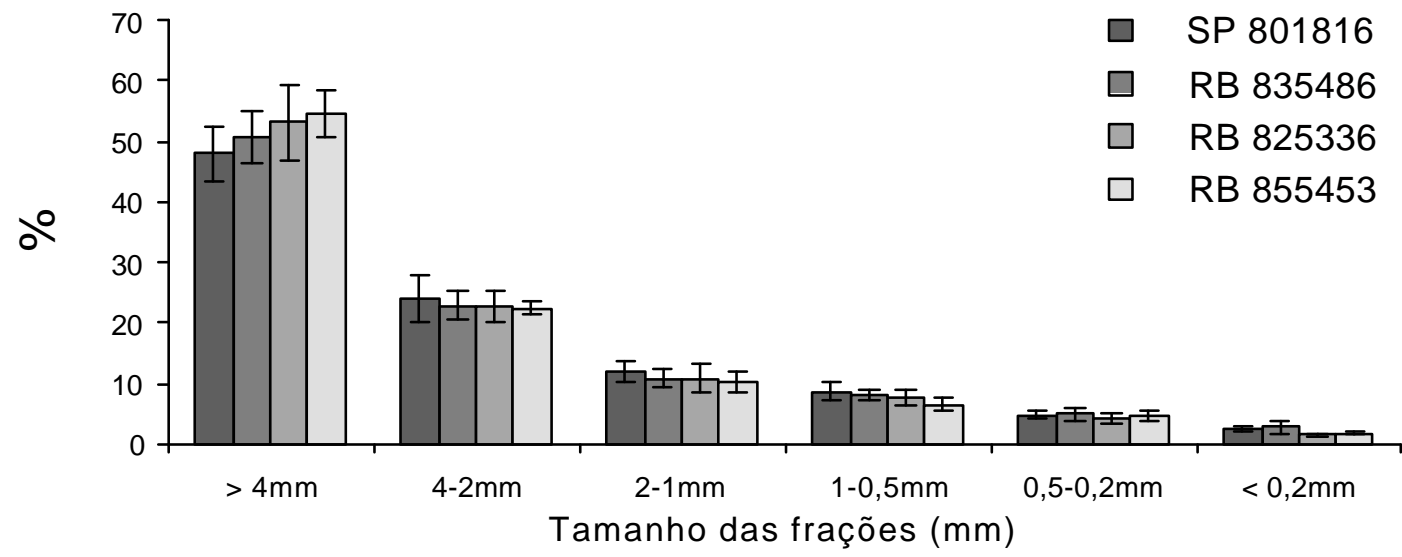

Figura 8 - Porcentagem das frações em diferentes variedades de cana-de-açúcar. 
A figura 9 apresenta a distribuição granulométrica da palhada nas áreas experimentais das usina São Martinho e Da Pedra, com as variedades SP 80-185 e RB 7851-48 respectivamente, e mostra a participação (\%) de cada fração no peso total de palhada.

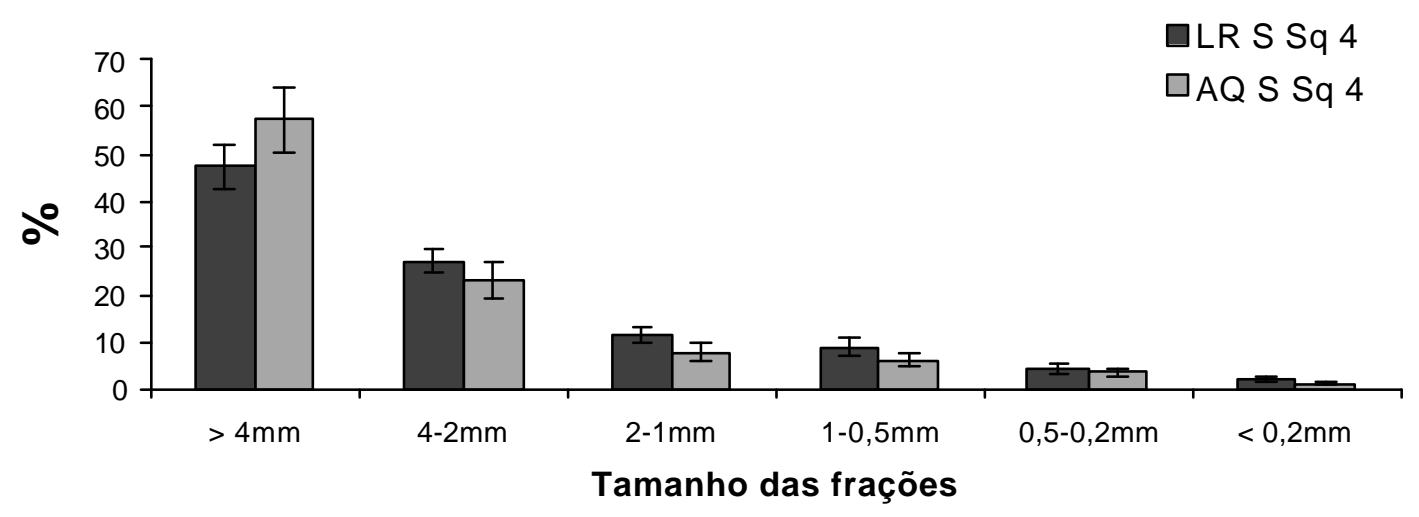

Figura 9 - Porcentagem das frações em relação ao peso total.

A fração > $4 \mathrm{~mm}$ representa a participação mais elevada, com valores de $57 \%$ e $47 \%$, respectivamente para as áreas NQ Q Sq 4 e LV Q Sq 4, essa distribuição é similar a encontrada para as outras variedades estudadas, sendo que é mais elevada para a área NQ apenas nesta fração. A porcentagem diminuiu nas frações menores, passando para $23 \%$ e $27 \%$ na fração entre 4 e 2 mm, até menos que 5\% para as frações menores que $0,5 \mathrm{~mm}$, como nas demais variedades.

\subsubsection{Efeito do tempo sobre a razão $\mathrm{C} / \mathrm{N}$}

A razão $\mathrm{C} / \mathrm{N}$ foi determinada nas amostras fracionadas das palhadas remanescentes coletadas nos anos de 1999 e 2000.

Pode-se observar na figura 10 comportamentos distintos da razão $\mathrm{C} / \mathrm{N}$. Na palhada remanescente em 1999 (SQ 4) a diminuição da razão conforme o tamanho da fração é bastante evidenciada, partindo de aproximadamente 67 na fração > 4mm alcançando cerca de 25 na fração $<0,2 \mathrm{~mm}$, sendo que nesta última fração podemos observar a contaminação por partículas de solo presentes nas amostras. 
Para a palhada SQ5, foi encontrada a maior razão $\mathrm{C} / \mathrm{N}$ na fração $2-1 \mathrm{~mm}$ com valor aproximado de 55, sendo a razão mais elevada nessa palhada, inclusive, acima da encontrada na fração $>4 \mathrm{~mm}$ que foi de cerca de 54 . Entre as frações as diferenças foram menos acentuadas que a palhada SQ4. Os valores variaram entre 55 e 40.

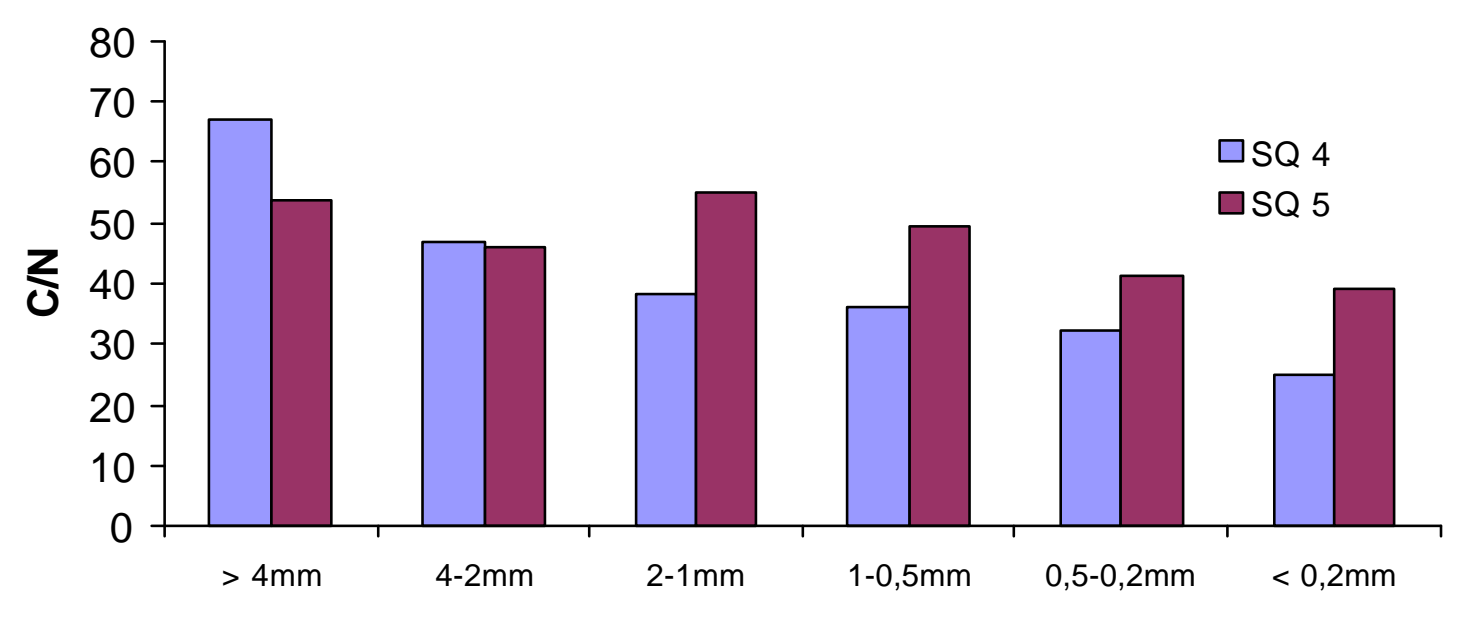

Tamanho das frações

Figura 10 - Razão C/N das frações na palhada remanescente nos anos de 1999 e 2000.

Quando são comparadas as razões $\mathrm{C} / \mathrm{N}$ entre cada fração nas duas palhadas, observa-se que, exceções feitas na fração > 4mm onde a relação da palhada SQ4 é maior e na fração $42 \mathrm{~mm}$ onde os valores são praticamente os mesmos, nas demais frações as razões foram sempre mais elevadas na palhada SQ5. 


\subsection{Conclusões}

- A produtividade de cana-de-açúcar foi $5 \%$ menor no sistema sem queima, com cerca de $95 \mathrm{Mg} \mathrm{ha}^{-1}$, enquanto que no sistema com queima foi da ordem de 101 $\mathrm{Mgha}^{-1}$;

- A deposição média de palhada foi equivalente a cerca de $15 \%$ da produtividade com um valor médio de 13,9 $\mathrm{Mg} \mathrm{MS} \mathrm{ha}^{-1} \mathrm{ano}^{-1}$;

- Após 3 anos ocorreu uma estabilização no estoque da palhada, do carbono e do nitrogênio, com valores entre 3,5 e 4,5 Mg MS. ha ${ }^{-1} 1350$ e $1600 \mathrm{~kg} \mathrm{Cha}^{-1}$ e 21 e $22 \mathrm{~kg} \mathrm{Nha}^{-1}$, respectivamente para as áreas sobre Latossolo Vermelho e Neossolo Quartzarênico;

- Quando analisado um mesmo tipo de solo, não foi encontrada influência da variedade da cana-de-açúcar e nem das diferentes quantidades de palhada depositada sobre o solo, em relação aos estoques de palhada e de carbono;

- Comparando variedades diferentes e tipos de solos diferentes, também não foram observadas diferenças no processo de acumulação de palhada e de carbono;

- A distribuição granulométrica da palhada não foi influenciada pelo fator quantidade de palhada depositada, pelo tempo de implantação do sistema e nem pela variedade da cana-de-açúcar cultivada;

- A razão $\mathrm{C} / \mathrm{N}$ foi influenciada pelo tempo de deposição/acumulação da palhada sobre o solo. 


\section{DECOMPOSIÇÃO ANUAL DA PALHADA DA CANA-DE-AÇÚCAR}

\section{Resumo}

O trabalho foi realizado em uma área experimental instalada pela COPERSUCAR sobre um Latossolo Vermelho onde se comparavam os sistemas de colheita, na usina São Martinho, localizada na região de Ribeirão Preto (SP). O objetivo do trabalho foi acompanhar e avaliar durante um ano, a decomposição da palhada deixada sobre o solo após a colheita da cana-de-açúcar, através do acompanhamento da variação do peso seco da palhada e dos estoques de carbono na mesma. Para tanto foram coletadas e analisadas amostras da palhada durante o ciclo iniciado em agosto de 1999 com o corte da cana-de-açúcar, até o corte seguinte ocorrida em agosto de 2000. O remanescente de palhada dos anos anteriores foi da ordem de 4,5 $\mathrm{Mg} \mathrm{MS} \mathrm{ha}^{-1}$, cerca de 1,6 $\mathrm{Mg} \mathrm{Cha}^{-1}$. O total de palhada em $\mathrm{T} 0$ foi da ordem de $14 \mathrm{Mg} \mathrm{MS} \mathrm{ha}^{-1}$ e de $6 \mathrm{MgCha}^{-1}$ e, após 12 meses foi de cerca de $6 \mathrm{MgMS} \mathrm{ha}^{-1}$ e $2,3 \mathrm{Mg} \mathrm{C}^{-1}$ com uma decomposição de $60 \%$ da palhada inicial mais o remanescente dos anos anteriores e de $61 \%$ no carbono, proporcionando um aumento de cerca de $1,5 \mathrm{Mg} \mathrm{MS} \mathrm{ha}^{-1}$ no estoque de palhada o que corresponde a um estoque de $0,7 \mathrm{Mg} \mathrm{Cha}^{-1}$. A distribuição da palhada nas frações foi diferente para as duas épocas, em T 0 encontramos cerca de $65 \%$ de MS e $69 \%$ do C da palhada na fração > 4mm, e menos que 5\% nas frações < 0,5mm. Em T 12 a distribuição da palhada foi um pouco diferente, com cerca de $53 \%$ de MS e $59 \%$ do C na fração > 4 mm. A razão $\mathrm{C} / \mathrm{N}$ entre as palhadas de $\mathrm{T} \quad 0$ e $\mathrm{T} 12$ não apresentou diferenças estatisticamente significativas quando analisamos cada uma das frações, sendo que sempre foi mais elevada na palhada $\mathrm{T} 12$, exceção feita às frações $<0,5 \mathrm{~mm}$ que foi inversa. Isso significa que durante o processo de decomposição intra-anual da palhada as perdas de nitrogênio são relativamente maiores que as de carbono. 


\section{Summary}

The work was accomplished in an experimental area installed by COPERSUCAR on a Hapludox where the crop systems were compared, in the plant São Martinho, located in the area of Ribeirão Preto (SP). The objective of the work was to accompany and to evaluate during one year, the decomposition of the trash left on the soil after the crop of the sugar-cane, through the accompaniment of the variation of the dry weight of the trash and of the stocks of carbon in the same. For so much they were collected and analyzed samples of the trash during the initiate cycle in August of 1999 with the cut of the sugar-cane, until the following cut happened in August of 2000. The remainder of trash of the previous years was of the order of 4,5 $\mathrm{Mg} \mathrm{MS} \mathrm{ha}^{-1}$, about 1,6 $\mathrm{MgC} \mathrm{ha}{ }^{-1}$. The trash total in $\mathrm{T} 0$ was of the order of $14 \mathrm{Mg} \mathrm{MS} \mathrm{ha}^{-1}$ and of $6 \mathrm{MgCh}^{-}$ 1 and, after 12 months it was about $6 \mathrm{Mg} \mathrm{MSha}^{-1}$ and 2,3 $\mathrm{MgCha}^{-1}$ with a decomposition of $60 \%$ of the initial trash more the remainder of the previous years and of $61 \%$ in the carbon, providing an increase of about $1,5 \mathrm{Mg} \mathrm{MS} \mathrm{ha}^{-1}$ in the trash stock that corresponds her/it a stock of $0,7 \mathrm{MgCha}^{-1}$. the distribution of the trash in the fractions was different for the two times, in T 0 we found about $65 \%$ of MS and $69 \%$ of $\mathrm{C}$ of the trash in the fraction $>4 \mathrm{~mm}$, and less than $5 \%$ in the fractions $<0,5 \mathrm{~mm}$. In T 12 the distribution of the trash was a little different, with about $53 \%$ of MS and $59 \%$ of $\mathrm{C}$ in the fraction $>4 \mathrm{~mm}$. the relationship $\mathrm{C} / \mathrm{N}$ between the trash of $\mathrm{T} 0$ and $\mathrm{T} 12 \mathrm{did}$ not present differences significant statistically when we analyzed each one of the fractions, and it was always higher in the trash $\mathrm{T} 12$, exception done to the fractions $<0,5 \mathrm{~mm}$ that was inverse. That means that during the process of intra-annual decomposition of the trash the losses of healthy nitrogen relatively larger than the one of carbon.

\subsection{Introdução}

A colheita da cana-de-açúcar manejada sem a queima, condiciona o uso de máquinas colheitadeiras, uma vez a grande quantidade de biomassa foliar diminuiria a eficiência da colheita manual e poderia aumentar a incidência de acidentes (Rípoli et al., 1995) e o custo da colheita manual subiria muito, tornando essa prática inviável (Sparovek et al., 1997). 
Com a colheita mecanizada e sem a queima do canavial a palhada, formada pela palha seca, ponteiros e folhas verdes (Oliveira et al., 1999) pode permanecer depositada sobre o solo. A quantidade de palhada depositada é dependente de algumas condições específicas tais como estágio da cultura e eficiência da máquina colhedora.

A deposição média anual é da ordem de $14 \mathrm{Mg}$ (megagrama ) de massa seca por hectare, que forma uma camada de cerca de 10-12 cm centímetros de espessura, que age de maneira positiva na proteção, conservação e recuperação dos solos.

Com a cobertura do solo, podem ser criadas condições favoráveis para o estabelecimento de um microclima nessas áreas, uma vez que não ocorrem mudanças bruscas na temperatura e na umidade do solo. Essa condição pode favorecer o estabelecimento de uma comunidade biológica que atuará na decomposição da palhada, permitindo o reaproveitamento dos nutrientes.

A cobertura do solo pela palhada, também controla as ervas daninhas, possibilitando, assim, a diminuição do uso de herbicidas, o que é importante pois esse produto representa um risco potencial ao ambiente, e a diminuição do uso desse produto acarretará um ganho econômico para o produtor.

A deposição e manutenção da palhada sobre a superfície do solo é apontada como uma técnica de manejo que contribui para a conservação do solo (Furlani Neto et al., 1994), pois possibilitará uma diminuição na erosão sofrida por esse solo, já que impede a ação direta dos ventos e o transporte de partículas (erosão eólica) e também, protegendo o solo da erosão causada pelas chuvas (de impacto e laminar), ajudando a conservar solos (Sallaway, 1979; Page et al, 1986).

A decomposição da palhada pode ocasionar aumento no teor de matéria orgânica no solo (MOS) (Luca, 2002), já que parte do material decomposto pode ser incorporado ao solo, possibilitando aumento da agregação, da capacidade de troca de cátions (CTC) e, aumento do poder tampão do solo, o que é importante para solos quimicamente adubados (Primavesi, 1987) e ainda, com o aumento do teor de MOS, pode ocorrer diminuição do uso de adubação química.

Contudo, em relação às práticas agronômicas ainda pode causar alguns problemas relacionados ao manejo da cultura. 
Dentre os principais problemas, destacam-se as dificuldades encontradas durante as operações de cultivo e adubação da soca (Aude et al., 1993; Barbosa, 1997), a baixa taxa líquida de mineralização do nitrogênio no período de um ano agrícola $(\mathrm{Ng}$ Kee Kwong \& Deville, 1987; Rípoli et al., 1991; Trivelin et al., 1995), a dificuldade de execução de controle seletivo de plantas daninhas e, o aumento das populações de pragas que se abrigam e multiplicam sob a palhada, além de diminuição do rendimento por problemas de brotação da nova planta após o corte.

A decomposição da palhada vai estar ligada diretamente às condições ambientais, tais como disponibilidade hídrica, e de oxigênio, além da composição química do substrato ( $\mathrm{C} / \mathrm{N}$, teores de celulose, hemicelulose, lignina e polifenóis), (Oliveira et al., 1999), influenciando, desta forma a taxa de decomposição e a dinâmica do carbono.

Os tecidos vegetais podem ser fracionados em celulose, hemicelulose lignina, proteína, materiais hidrossolúveis e materiais éter-solúveis (Abramo Filho 1995). A palhada contém principalmente matérias celulósicas (celulose + hemicelulose $=69,71 \%$ ) e lignina (19,71\%), a velocidade da decomposição da celulose e hemicelulose é bem maior do que a da lignina, sendo que esta última, juntamente com o $\mathrm{N}$ são apontados como agentes controladores da axa de decomposição de substratos vegetais (Melillo et al., 1982; Sanger et al., 1998).

A razão $\mathrm{C} / \mathrm{N}$, que é um parâmetro indicador do potencial húmico dos resíduos orgânicos no solo (Robin, 1997), no caso da palhada, é de aproximadamente 80:1, enfatizando que tanto o carbono como o nitrogênio são muito importantes na decomposição (Lynch, 1986). Quando a razão C/N atinge 17/1, ocorre uma igualdade entre a quantidade de nitrogênio imobilizado e a quantidade mineralizada.

Segundo Galvão et al. (1991) a quantidade inicial de nitrogênio está entre os fatores que mais influenciam a velocidade de decomposição do material orgânico, mas também que as diferenças nas composições da matéria orgânica de compostos como a lignina por exemplo, vão influenciar a velocidade da decomposição, quanto maior o teor de lignina, mais demorada será a decomposição. 
A incorporação da palhada poderia causar falta de nitrogênio durante a decomposição da mesma, contudo, a medida que a palhada é mantida sobre a superfície do solo, ou superficialmente incorporada (Stuble-mulch), não provoca a falta de $\mathrm{N}$ no solo para o crescimento da planta, neste caso, o efeito desfavorável da palhada ocorre somente pela ação das fitotoxinas liberadas no início da decomposição (Abramo Filho 1995).

Primavesi (1987), sugere então, que não se deve plantar quando a palhada for recém aplicada ou deixada sobre o solo, deve-se esperar pela chuva abundante para permitir que os produtos liberados no início da decomposição possam ser lixiviados, não comprometendo, assim, o desenvolvimento da planta.

É importante salientar que são poucos os estudos relacionados à decomposição da palhada da cana-de-açúcar, Abramo Filho (1995) realizou um estudo em área sobre Latossolo vermelho escuro (LE) na região de Piracicaba, onde se utilizava vinhaça sobre a palhada depositada no solo e, com o aumento de áreas onde o canavial é cortado sem a queima prévia, mais estudos se fazem necessários para medir todas as mudanças ambientas que poderão ocorrer com a adoção desta prática.

Diante disso, podemos considerar a seguinte questão: A adoção do sistema de colheita sem a queima prévia do canavial e deposição da palhada possibilitará a acumulação de palhada sobre o solo, permitindo que parte do carbono que seria liberado durante a queimada permaneça no sistema e seja incorporado a MOS?

Para responder a esta questão, o objetivo deste trabalho foi acompanhar a decomposição e acumulação da palhada ao longo de um ano.

Os estudos foram realizados em ensaios agronômicos, referentes aos sistemas de colheita com e sem a queima prévia do canavial, pré-instalados pela COPERSUCAR sobre Latossolo Vermelho (Usina São Martinho, Pradópolis-SP) que fica localizada na região nordeste do Estado de São Paulo. Os ensaios foram instalados em 1995, com o plantio da cana, e as coletas foram realizadas entre agosto de 1999 e agosto de 2000. 


\subsection{Material e métodos}

\subsubsection{Amostragem da palhada}

Para o estudo do comportamento intra-anual da palhada, a mesma foi coletada do interior das câmaras utilizados para a coleta dos gases, as quais eram circulares com um diâmetro de $29,7 \mathrm{~cm}$ e área total de $692,8 \mathrm{~cm}^{2}$, que foram instaladas nas linhas e também nas entre-linhas de plantio (figura 1). As amostras coletadas no campo foram processadas no laboratório de biogeoquímica ambiental do CENA/USP.

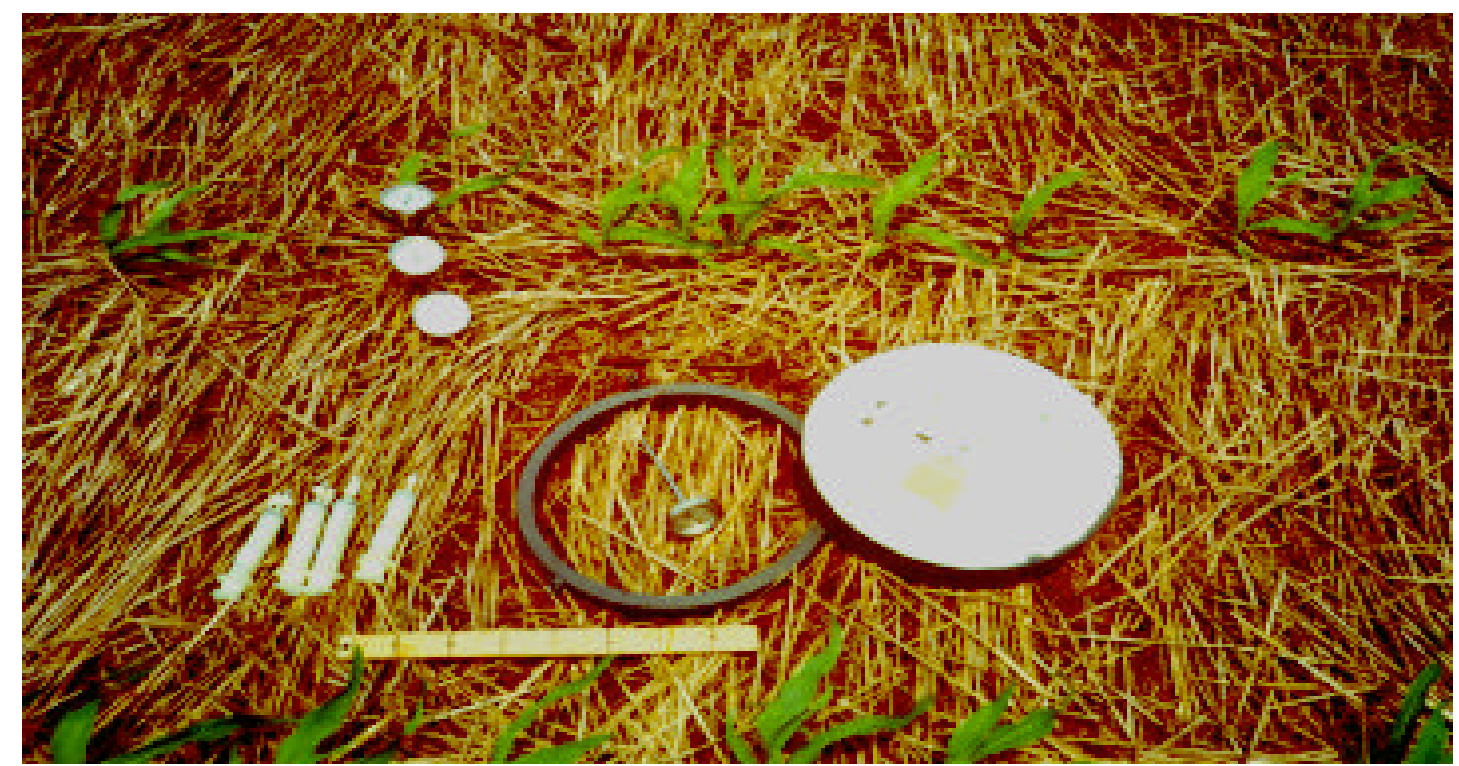

Figura 1 - Câmara utilizada para amostragem dos gases provenientes do solo, do interior da qual foi coletada a palhada. 


\subsubsection{Fracionamento físico da palhada remanescente e determinação das concentrações e estoque de carbono e nitrogênio nas frações}

As amostras foram secas em estufa a $60^{\circ} \mathrm{C}$ durante 3 dias. Depois desse período procedeu-se o fracionamento físico das amostras, através da utilização de peneiras de diferentes diâmetros, foram obtidas 6 frações da palhada: > 4 ; 4-2; 2-1;1-0,5;0,5-0,2 e $<0,2 \mathrm{~mm}$.

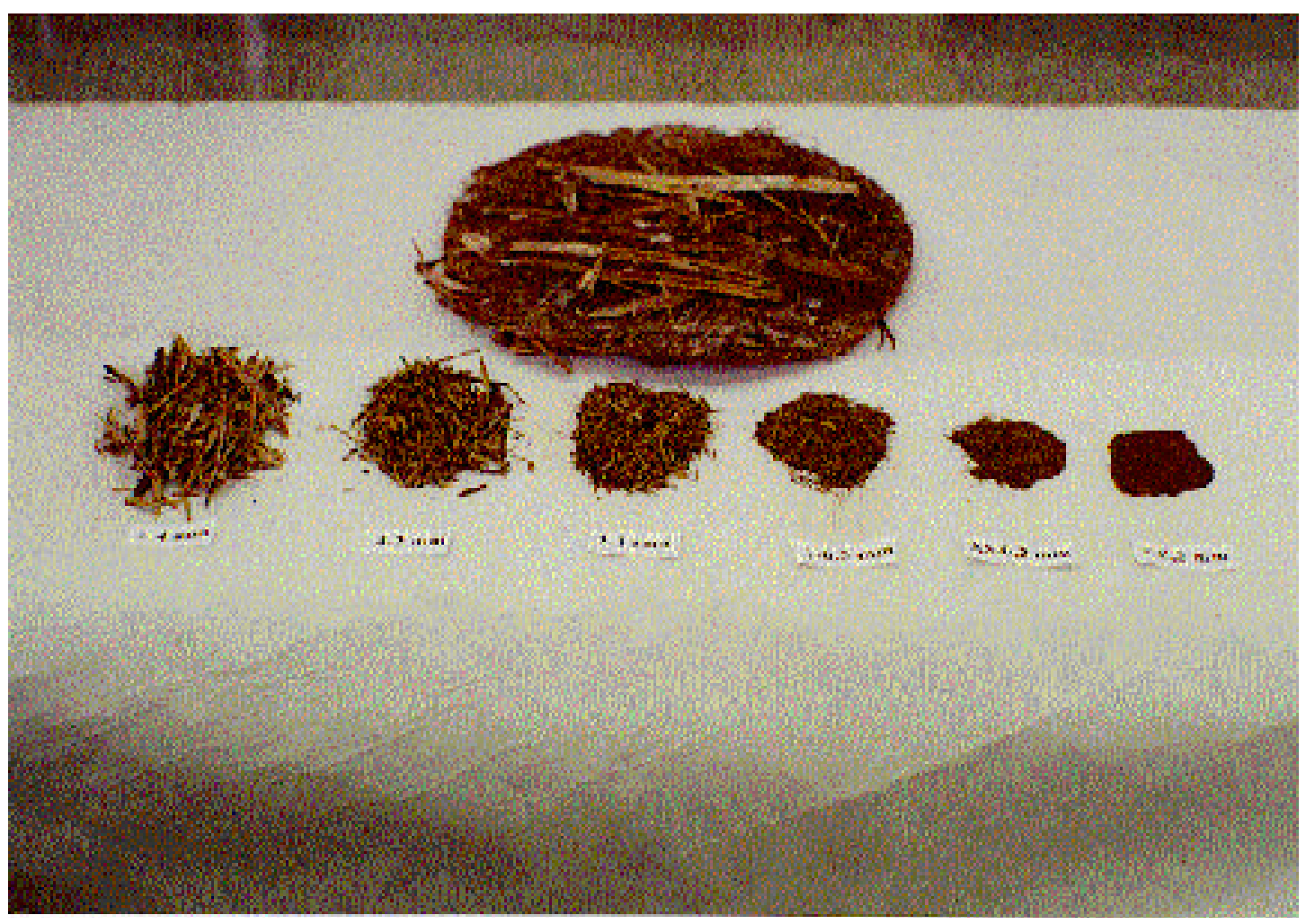

Figura 2 - Amostras da palhada provenientes do fracionamento físico.

Cada fração obtida foi pesada e calculada a porcentagem em relação ao peso total da amostra. Para a obtenção dos teores de C e N, cada fração foi moída e analisada no auto-analisador Leco CR 2000. Com os valores das concentrações procedeu-se o cálculo dos estoques, multiplicando a concentração do elemento pela massa de matéria seca correspondente a cada fração. 


\subsection{Resultados e discussão}

\subsubsection{Variação intra-anual do remanescente de matéria seca e carbono na palhada}

Nas figuras 3, 4 e 5 pode-se observar os remanescentes de MS e C da palhada em megagramas por hectare em agosto de 1999, que é chamada de T0 e em julho de 2000 chamada de T 12.

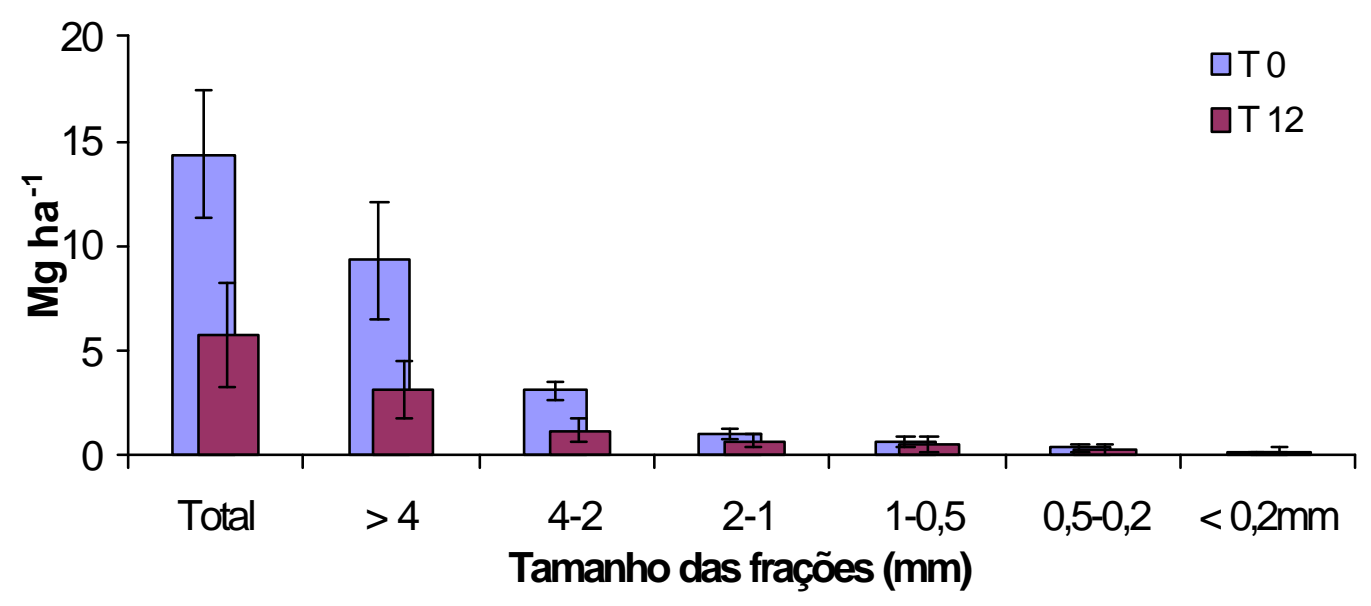

Figura 3 - Remanescente de palhada em T0 e T 12.

O total de palhada em $\mathrm{T} 0$ foi da ordem de $14 \mathrm{Mg} \mathrm{MS} \mathrm{ha}^{-1}$ e de $6 \mathrm{MgCha}^{-1} \mathrm{e}$ que após 12 meses foi de cerca de $6 \mathrm{Mg} \mathrm{MSha}^{-1}$ e 2,3 $\mathrm{MgCha}^{-1}$ com uma decomposição de $60 \%$ da palhada inicial mais o remanescente dos anos anteriores.

A distribuição da palhada nas frações foi diferente para as duas épocas, em $\mathrm{T} 0$ encontramos cerca de $65 \%$ de MS e $69 \%$ do C da palhada na fração > 4mm, e menos que $5 \%$ nas frações $<0,5 \mathrm{~mm}$.

Em T 12 a distribuição da palhada foi um pouco diferente, com cerca de 53\% de MS e $59 \%$ do C na fração $>4 \mathrm{~mm}$. A somatória das frações $<0,5 \mathrm{~mm}$ totalizou cerca de $8 \%$ do total. 


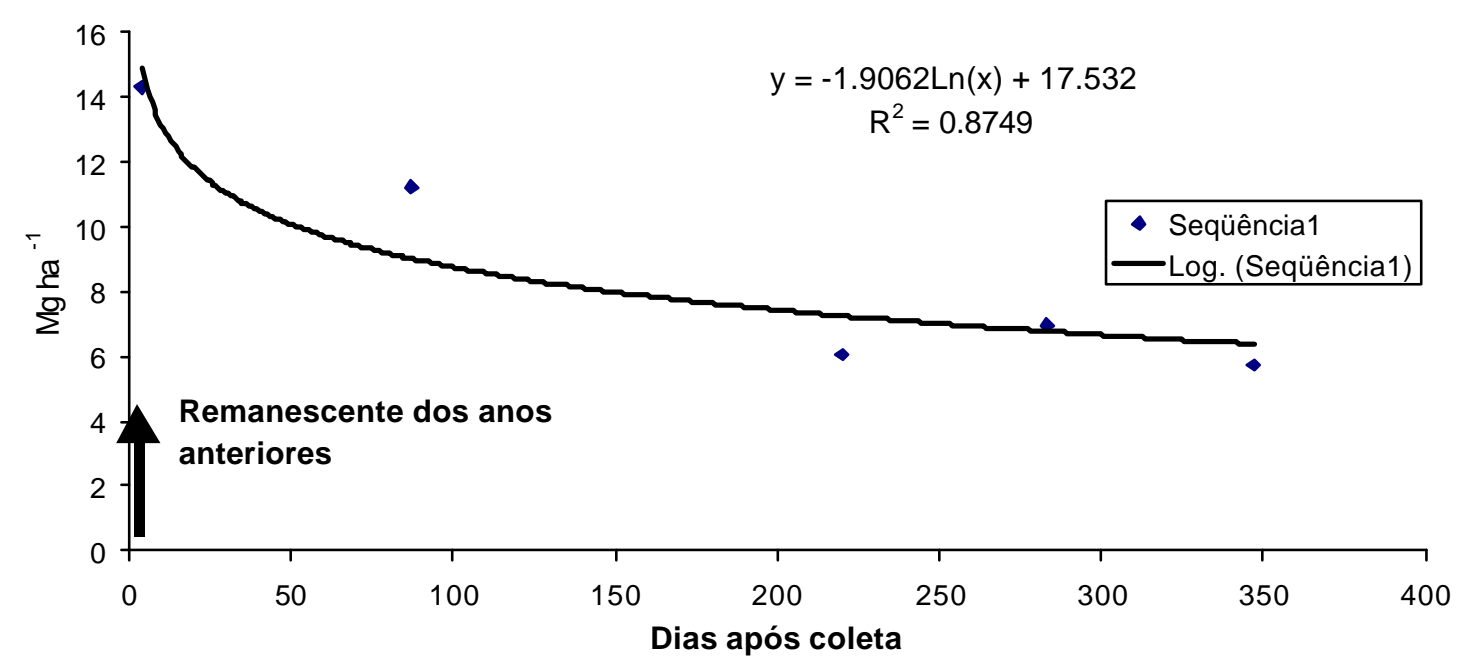

Figura 4 - Comportamento do remanescente de palhada durante um ano.

Na figura 4 pode-se acompanhar a decomposição da palhada durante o período de estudos e é possível notar uma boa correlação entre o tempo após a colheita e a diminuição do estoque da palhada, mostrando que no início a decomposição é mais rápida e com o tempo o processo fica mais lento, tendendo para uma estabilização no estoque. A equação logarítmica ajustada para os valores de decomposição da palhada foi:

$$
y=-1.9062 \operatorname{Ln}(x)+17.532 \operatorname{com} R^{2}=0.8749
$$

Na figura 5, onde são demonstrados os estoques de carbono em T0 e T12 podese observar o decréscimo da ordem de $61 \%$ no estoque total de carbono entre ago/99 (logo após o corte) e jul/00 (uma semana antes do corte).

O maior estoque ocorreu nas frações > $4 \mathrm{~mm}$ com cerca de 4000 e 1300 $\mathrm{kgC} \mathrm{ha}^{-1}$ (69 e 59\% do total) para ago/99 e jul/00 respectivamente. Uma observação interessante pode ser feita nas frações $42 \mathrm{~mm}$ onde os estoques de cerca de 1250 e 490 $\mathrm{kgC} \mathrm{ha}^{-1}$ para ago/99 e jul/00 respectivamente, representam $21 \%$ do total depositado, apesar de o estoque inicial ter sido quase três vezes maior. 


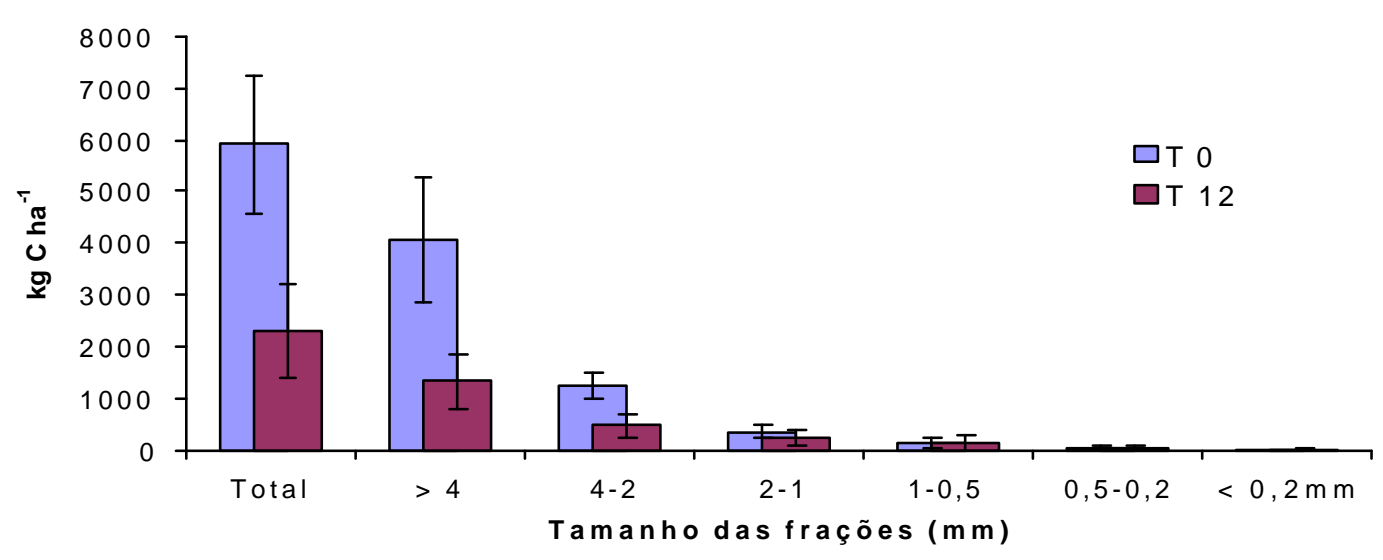

Figura 5 - Estoque de carbono nas frações físicas da palhada no T 0 e T 12.

A razão $\mathrm{C} / \mathrm{N}$ diminuiu das frações maiores para as frações menores em $\mathrm{T} 0$ e $\mathrm{T}$ 12 (figura 6). No caso da palhada de agosto de 1999, a relação variou entre 119 na fração $>4 \mathrm{~mm}$ até 28 na fração menor que $0,2 \mathrm{~mm}$. Na palhada de julho de 2000 a variação foi entre 81 e 19 para as mesmas frações.

As razões $\mathrm{C} / \mathrm{N}$ entre as frações são mais próximas na palhada $\mathrm{T} 12$ do que na palhada T0, sendo que nesta última as frações maiores que $2 \mathrm{~mm}$ apresentam razões $\mathrm{C} / \mathrm{N}$ bem superiores às frações menores, enquanto que na palhada T12, essas diferenças não são tão acentuadas.

Isso é explicado pelo fato de a palhada nova, que é predominante em T0, apresentar maior distribuição nas frações maiores que $2 \mathrm{~mm}$ e ter uma razão $\mathrm{C} / \mathrm{N}$ mais elevada. Após 12 meses, as diferenças das relações entre as frações diminui.

Quando comparadas as relações nas frações menores que $2 \mathrm{~mm}$ entre T0 e T12, observa-se que as diferenças entre elas são menores, indicando que durante o processo de decomposição intra-anual da palhada as perdas de nitrogênio são relativamente menores que as de carbono. 


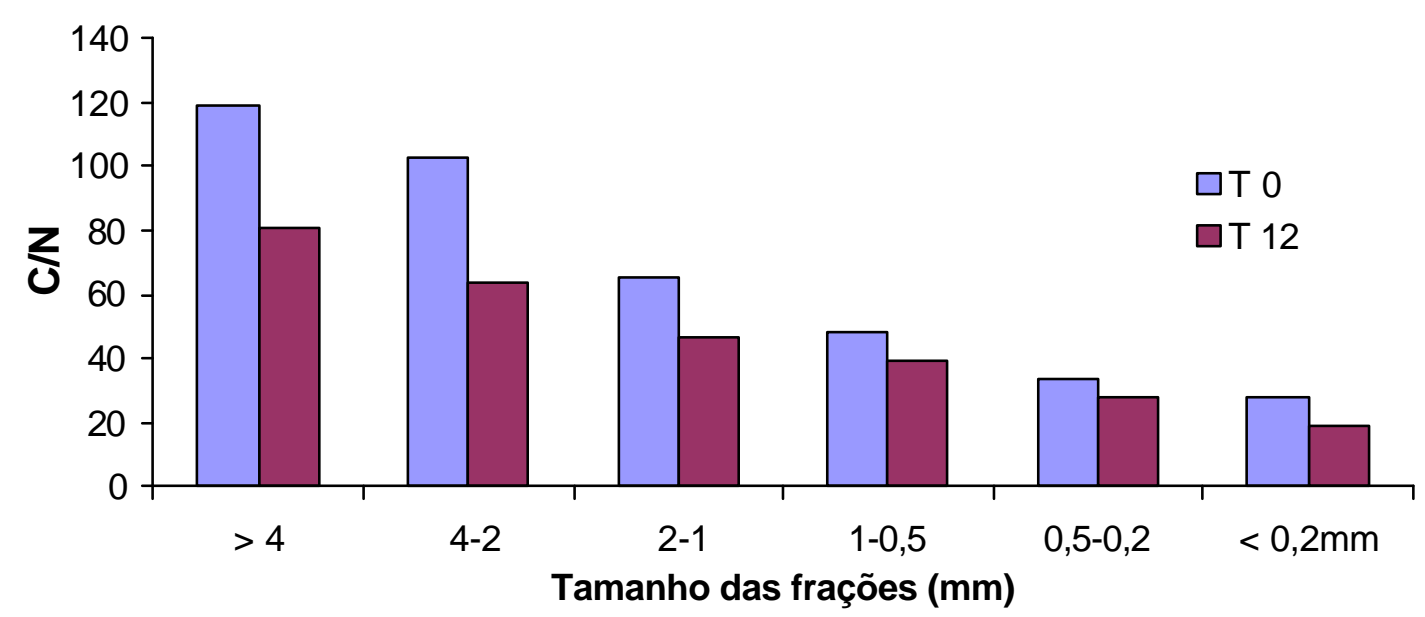

Figura 6 - Razão C/N nas frações da palhada no T 0 e T 12.

Abramo Filho (1995) encontrou resultados próximos aos encontrados neste estudo, com teores de carbono da palhada declinando de 375,50 para $283,50 \mathrm{gC} \mathrm{Kg}^{-1} \mathrm{MS}$ (do início ao final do processo) enquanto os teores de nitrogênio se elevaram no mesmo período (4,9 a 8,5 $\mathrm{g} \mathrm{kg}^{-1} \mathrm{MS}$ ). A razão $\mathrm{C} / \mathrm{N}$ variou de 69 a 33 durante o período estudado. Já Spain \& Hodgen (1994) trabalhando na região nordeste da Austrália e estudando a decomposição da palhada, encontraram razões C/N amplas e variáveis (170, 240 e 70) ao longo do processo considerado.

\subsection{Conclus ões}

- O remanescente de palhada dos anos anteriores foi de 4,5 $\mathrm{Mg} \mathrm{MS} \mathrm{ha}^{-1}$, cerca de 1,6 $\mathrm{MgC} \mathrm{ha}^{-1}$. O total de palhada depositada em $\mathrm{T} 0$ foi da ordem de 14 $\mathrm{Mg} \mathrm{MS} \mathrm{ha}{ }^{-1}$ e de $6 \mathrm{Mg} \mathrm{C}^{-1}$;

- Após 12 meses foi de cerca de $6 \mathrm{Mg} \mathrm{MSha}^{-1} \mathrm{e} 2,3 \mathrm{MgCha}^{-1}$ com uma decomposição de $60 \%$ da palhada inicial mais o remanescente dos anos anteriores e de $61 \%$ no carbono, proporcionando um aumento de cerca de $1,5 \mathrm{Mg} \mathrm{MS} \mathrm{ha}^{-1}$ no estoque de palhada, o que corresponde a um estoque de $0,7 \mathrm{Mg} \mathrm{Cha}^{-1}$;

- A distribuição da palhada nas frações foi diferente para as duas épocas. Em T0 foram encontrados cerca de $65 \%$ de MS e $69 \%$ do C da palhada na fração $>4 \mathrm{~mm}$, e 
menos de $5 \%$ nas frações $<0,5 \mathrm{~mm}$. Em T 12 a distribuição da palhada foi um pouco diferente, com $53 \%$ de MS e 59\% do C na fração >4mm;

- A razão C/N entre as palhadas de T 0 e T 12 apresentou comportamento similar quanto a distribuição nas frações, sendo mais elevada em T0 pela predominância de palhada. Após 12 meses, ocorre diminuição das diferenças das razões entre as frações, indicando que durante o processo de decomposição intra-anual da palhada as perdas de nitrogênio são relativamente menores que as de carbono. 


\section{CARACTERIZAÇÃO MORFOLÓGICA, QUÍMICA E BIOQUÍMICA DE DIFERENTES CAMADAS DA PALHADA REMANESCENTE DA CANADE AÇÚCAR}

\section{Resumo}

No manejo sem queima, onde a colheita é realizada geralmente por máquinas, a parte foliar (cerca de $14 \mathrm{Mg} \mathrm{ha}^{-1}$ ano $^{-1}$ em matéria seca ou 6,5 $\mathrm{Mg} \mathrm{C} \mathrm{ha}^{-1}$ ano $^{-1}$ ) pode ser depositada anualmente sobre o solo e se decompor naturalmente. Estudou-se o manejo sem queima da cana-de-açúcar em área experimental sobre Latossolo vermelho. Após quatro anos observou-se a formação de um novo horizonte de húmus, constituído de uma palhada com diferentes níveis de decomposição. Neste horizonte distinguimos, visualmente, três camadas: uma camada nova, mais recente; uma camada velha, entre um ano e dois anos após a deposição e uma camada muito velha, com pelo menos três anos. O objetivo deste trabalho foi quantificar e caracterizar essas diferentes camadas. O estudo proposto baseou-se na determinação de três parâmetros qualitativos: micro-morfológico (observações microscópicas da superfície topográfica da palhada), bioquímico (teores de fibras), químico (teores de carbono e de nitrogênio totais) e a análise espectroscópica em Ressonância Paramagnética Eletrônica (EPR). Após 4 anos o total de palhada remanescente foi da ordem de 4,5 $\mathrm{Mg} \cdot \mathrm{ha}^{-1}$, equivalentes a $11 \%$ do total depositado. $\mathrm{O}$ estoque de carbono na palhada foi de $1,6 \mathrm{Mg} \mathrm{C} \mathrm{ha}^{-1}\left(0,5 \mathrm{Mg} \mathrm{C} \mathrm{ha}^{-1}\right.$.ano $\left.{ }^{-1}\right)$, e o de nitrogênio foi de $0,03 \mathrm{Mg} \mathrm{N}^{-1}\left(0,01 \mathrm{Mg} \mathrm{N}^{-1}\right.$ ano $\left.^{-1}\right)$. Na camada nova a maior parte da palhada e do carbono (92\%) está na fração > 4mm, enquanto que na palhada velha encontramos cerca de 55\% nessa fração e na camada muito velha encontramos $59 \%$. As observações por microscopia eletrônica de varredura e análise bioquímica, demonstraram que os tecidos vegetais das camadas velha e muito velha, foram alterados particularmente 
pelos fungos, com diminuição da celulose, aumento da lignina e de outras substâncias húmicas e diminuição da razão $\mathrm{C} / \mathrm{N}$. A análise espectroscópica em Resonância Paramagnética Eletrônica (EPR) mostrou maior concentração de grupo semiquinona na camada velha $\left(1,66 \times 10^{17}\right.$ spins $\left.\mathrm{g}^{-1}\right)$ em relação à camada nova $\left(1,03 \times 10^{17}\right.$ sping $\left.^{-1}\right), \mathrm{o}$ que é característico de material com maior nível de humificação.

\section{Summary}

In the management without burning, where the crop is usually accomplished by machines, the part to foliate (about $14 \mathrm{Mg}$ have- 1 year- 1 in matter it evaporates or 6,5 $\mathrm{Mg} \mathrm{C}$ have $^{-1}$ year $^{-1}$ ) it can be deposited annually on the soil and to decompose naturally. The management was studied without it burns of the sugar-cane in experimental area on Haplodux. After four years the formation of a new humus horizon was observed, constituted of a trash with different decomposition levels. In this horizon we distinguished, visually, three layers: a layer new, more recent; an old layer, between one year and two years after the deposition and a very old layer, with at least three years. The objective of this work was to quantify and to characterize those different layers. The proposed study based on the determination of three qualitative parameters: personal computer-morphologic (observations submicroscopic of the topographical surface of the trash), biochemical (teors of fibres), chemical (tenors of carbon and of nitrogen total) and analysis espectroscopic Eletronic Paramagnetic Ressonance (EPR). After 4 years the total of remaining trash was of the order of $4,5 \mathrm{Mgha}^{-1}$, equivalent to $11 \%$ of the deposited total. The stock of carbon in the trash was of $1,6 \mathrm{MgC} \mathrm{ha}^{-1}\left(0,5 \mathrm{MgC} \mathrm{ha}^{-1} \mathrm{ano}^{-1}\right)$, and the one of nitrogen was of $0,03 \mathrm{Mg} \mathrm{N} \mathrm{ha}^{-1}\left(0,01 \mathrm{Mg} \mathrm{N} \mathrm{ha}^{-1} \mathrm{ano}^{-1}\right)$. In the new layer the larger largest part of the trash and of the carbon $(92 \%)$ it is in the fraction> $4 \mathrm{~mm}$, while in the old trash we found about $55 \%$ in that fraction and in the very old layer we found $59 \%$. The observations for electronic microscopic of sweeping and biochemical analysis, demonstrated that the vegetable fabrics of the old and very old layers, they were altered particularly by the mushrooms, with decrease of the cellulose, increase of the lignin and decrease of the relationship $\mathrm{C} / \mathrm{N}$. However, that increase verified in the lignin tenors, it is not properly of lignina but substances humics produced during the decomposition that, 
for the method used for the determinations, they end up being identified as being lignin. The analysis espectroscopic Eletronic Paramagnetic Ressonance (EPR) it showed

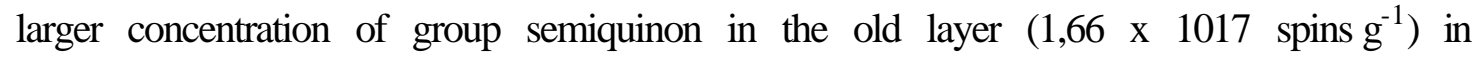

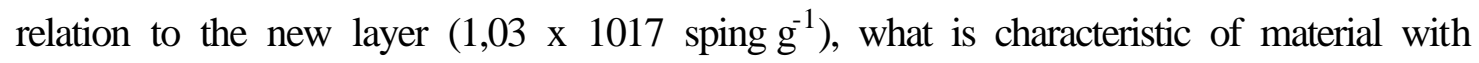
larger humification level.

\subsection{Introdução}

A dinâmica da palhada que fica depositada sobre o solo após a colheita mecanizada e sem a queima do canavial, vai estar ligada diretamente às condições ambientais, tais como disponibilidade hídrica, e de oxigênio, além de estar ligada também a composição química do substrato $(\mathrm{C} / \mathrm{N}$, teores de celulose, hemicelulose, lignina e polifenóis), (Oliveira et al., 1999), influenciando, desta forma a taxa de decomposição e a dinâmica do carbono.

Os tecidos vegetais podem ser fracionados em celulose, hemicelulose lignina, proteína, materiais hidrossolúveis e materiais éter-solúveis (Abramo Filho 1995). A palhada contém principalmente matérias celulósicas (celulose + hemicelulose $=69,71 \%$ ) e lignina (19,71\%), a velocidade da decomposição da celulose e hemicelulose é bem maior do que a da lignina, sendo que esta última, juntamente com o $\mathrm{N}$ são apontados como agentes controladores da taxa de decomposição de substratos vegetais (Melillo et al., 1982; Sanger et al., 1998).

A razão $\mathrm{C} / \mathrm{N}$, que é um parâmetro indicador do potencial húmico dos resíduos orgânicos no solo (Robin, 1997), no caso da palhada, é de aproximadamente 80:1, enfatizando que tanto o carbono como o nitrogênio são muito importantes na decomposição (Lynch, 1986). Quando a razão C/N atinge 17/1, ocorre uma igualdade entre a quantidade de nitrogênio imobilizado e a quantidade mineralizada.

Segundo Galvão et al. (1991) a quantidade inicial de nitrogênio está entre os fatores que mais influenciam a velocidade de decomposição do material orgânico, mas também que as diferenças nas composições da matéria orgânica de compostos como a lignina por exemplo, vão influenciar a velocidade da decomposição, quanto maior o teor dessa substância, mais demorado o processo. 
A incorporação da palhada poderia causar a falta de nitrogênio durante a decomposição da mesma, contudo, a medida que a palhada é mantida sobre a superfície do solo, ou superficialmente incorporada (Stuble-mulch), não provoca a falta de $\mathrm{N}$ no solo para o crescimento da planta, neste caso, o efeito desfavorável da palhada ocorre somente pela ação das fitotoxinas liberadas no início da decomposição (Abramo Filho 1995).

Primavesi (1987), sugere que não se deve plantar quando a palhada for recém aplicada ou deixada sobre o solo, deve-se esperar pela chuva abundante para permitir que os produtos liberados no início da decomposição possam ser lixiviados, não comprometendo, assim, o desenvolvimento da planta.

Com a formação de uma camada de palhada sobre o solo, torna-se necessário estudar o que acontece com esse material, durante o período que permanece no ambiente. A cada ano uma nova camada de palhada é depositada após cada colheita, interferindo na dinâmica da matéria orgânica no sistema.

São raras as pesquisas relacionadas à decomposição da palhada da cana-deaçúcar por isso, mais estudos são necessários para medir as principais mudanças ambientas que poderão ocorrer com a adoção da prática de colheita sem a queima prévia do canavial.

Diante disso, podemos considerar a seguinte questão: Como ocorrerá a acumulação do carbono na palhada remanescente sobre o solo?

Para responder a esta questão, procedeu-se a caracterização microscópica, química e bioquímica das camadas de palhada com diferentes níveis de decomposição.

Essa pesquisa foi realizada a partir de ensaios agronômicos, referentes aos sistemas de colheita com e sem a queima prévia do canavial, pré-instalados pela COPERSUCAR sobre Latossolo Vermelho (Usina São Martinho, Pradópolis-SP), que ficam localizadas na região nordeste do Estado de São Paulo. Os ensaios foram instalados em 1995, com o plantio da cana, e as coletas foram realizadas em 1999. 


\subsection{Material e métodos}

\subsubsection{Caracterização da palhada}

Em áreas com cana-de-açúcar da variedade SP 80-185 colhida sem queima, foram amostrados os seguintes substratos vegetais:

a) Folhas do ponteiro e folhas do colmo remanescentes na superfície do solo uma semana após o corte da cultura.

b) Raízes extraídas da planta recém colhida.

C) Cobertura morta ("mulch") constituída por três camadas distintas:

C 1) palhada nova coletada uma semana após o corte (PN);

C 2) palhada velha coletada um ano após o corte (PV);

C 3)palhada muito velha coletada entre um e três anos após o corte (MV).

Em áreas sujeitas a despalha à fogo (cultivo convencional), as amostras foram coletadas uma semana após a colheita da cultura, sendo as mesmas constituídas por restos de ponteiros em diferentes estágios de carbonização na superfície do solo.

As amostras foram coletados em agosto de 1999.

\subsubsection{Preparo e análise de amostras}

\section{Micro-morfologia}

Observações microscópicas foram conduzidas em excisões de tecidos $\left(0,5 \mathrm{~cm}^{2}\right)$ indeformados de palhada (nova, velha e muito velha), montadas em suportes de $12 \mathrm{~mm}$ de diâmetro, previamente revestidos com fita adesiva de crbono, metalizados com ouro e examinados ao microscópio eletrônico de varredura (JEOL, Modelo JSM-5600 LV) do Núcleo de Pesquisas em Geoquímica e Geofísica da Litosfera-NUPEGEL/USP.

\section{Bioquímico}

A determinação dos teores de fibras foi feito no laboratório de Biogeiquímica Ambiental - CENA onde foi empregado o Método de Van Soest modificado (Van Soest, 1963). De acordo com este método gravimétrico, a amostra vegetal foi submetida a três tratamentos químicos sequenciais destinadas as extrações dos seguintes componentes: 


\section{Fibra em Detergente Neutro - FDN}

O preparo de amostras visando a obtenção deste componente envolveu inicialmente a pesagem de $1 \mathrm{~g}$ de material vegetal seco (MS inicial) a $60^{\circ} \mathrm{C}$ por 72 horas e moído a uma granulometria de aproximadamente $1 \mathrm{~mm}$ de diâmetro.

Em seguida foram adicionados $100 \mathrm{~mL}$ de solução tampão $(\mathrm{pH}$ 6,9-7,1) de sódio lauril sulfato e EDTA, denominada de Solução Detergente Neutro-SDN, mantendo-se esta mistura sob ebulição e agitação constantes por 1 hora, de modo a possibilitar a remoção do conteúdo celular (CC), ou seja, de componentes solúveis (açúcares simples, taninos, pectinas, proteínas amidos e minerais).

Após este período, a amostra foi filtrada em cadinho com porosidade entre 40 e $90 \mu \mathrm{m}$, e, lavada com água fervida (1L) até a remoção total da solução detergente (ausência de espuma). A filtragem da amostra foi concluída com o emprego de acetona $(2 \times 30 \mathrm{~mL})$ mediante a constatação da transparência do filtrado.

O resíduo FDN obtido deste tratamento químico foi seco a diferentes temperaturas $\left(50^{\circ}, 105^{\circ} \mathrm{C}\right.$ e $\left.500^{\circ} \mathrm{C}\right)$ a cada 12 horas, e, em seguida, resfriado em dessecador e pesado $\left(50^{\circ} \mathrm{C}=\mathrm{P}_{1} ; 105^{\circ} \mathrm{C}=\mathrm{P}_{2} ; 500^{\circ} \mathrm{C}=\mathrm{P}_{3}\right)$. Os resultados obtidos permitiram determinar os teores de FDN apresentados a seguir:

$$
\begin{aligned}
& \mathrm{FDN}_{50^{\circ} \mathrm{C}}=\left(\mathrm{P}_{1}-\mathrm{P}_{3}\right) * 100 / \mathrm{m} \\
& \mathrm{FDN}_{105^{\circ} \mathrm{C}}=\left(\mathrm{P}_{2}-\mathrm{P}_{3}\right) * 100 / \mathrm{m}
\end{aligned}
$$

onde: $\mathrm{m}=$ massa da amostra seca $\mathrm{a} 105^{\circ} \mathrm{C}$

\section{Fibra em Detergente Ácido - FDA}

A extração deste componente foi realizada seqüencialmente sobre a fração FDN anterior, a partir da retomada do filtro + amostra em $100 \mathrm{~mL}$ de Solução Detergente Ácido-SDA, por 1 hora, a mesma sendo preparada a partir de $\mathrm{H}_{\mathbf{L}} \mathrm{SO}_{4} \mathrm{~N}$ em brometo de trimetil-cetil-amonio, $\mathrm{p} / \mathrm{v}$.

As etapas subseqüentes envolvendo a filtração, secagem $\left(50^{\circ} \mathrm{C}=\mathrm{P}_{4} ; 105^{\circ} \mathrm{C}=\mathrm{P}_{5}\right)$, mineralização $\left(500^{\circ} \mathrm{C}=\mathrm{P}_{6}\right)$ e pesagem da amostra contendo o resíduo FDA seguem os 
mesmos procedimentos anteriormente descritos para o resíduo FDN. O filtrado resultante deste processo de extração foi neutralizado antes do descarte do mesmo.

$$
\begin{aligned}
& \mathrm{FDA}_{50^{\circ} \mathrm{C}}=\left(\mathrm{P}_{4}-\mathrm{P}_{6}\right) * 100 / \mathrm{m} \\
& \mathrm{FDA}_{105^{\circ} \mathrm{C}}=\left(\mathrm{P}_{5}-\mathrm{P}_{6}\right) * 100 / \mathrm{m}
\end{aligned}
$$

onde: $\mathrm{m}=$ massa da amostra seca $\mathrm{a} 105^{\circ} \mathrm{C}$

\section{Lignina em Detergente Ácido - LDA}

Neste tratamento o resíduo FDA foi retomado e atacado durante 3 horas por uma solução de $\mathrm{H}_{2} \mathrm{SO}_{4} 72 \%$ (p/v), resultando na extração do resíduo LDA ou lignina sulfúrica. Durante o período de extração desta fibra tomou-se o cuidado de completar a cada hora, o volume de ácido no interior do filtro, homogeneizando regularmente a solução com um bastão de vidro, de modo que todo o resíduo permanecesse em contato com o ácido.

A filtração da amostra com água fervida se estendeu até a neutralidade do filtrado. Em seguida, o resíduo LDA foi mantido sob secagem em estufa e posteriormente pesado $\left(50^{\circ} \mathrm{C}=\mathrm{P}_{7} ; 105^{\circ} \mathrm{C}=\mathrm{P}_{8}\right)$. Após a mineralização da amostra à $500^{\circ} \mathrm{C}$ por 12 horas, a mesma foi novamente pesada $\left(\mathrm{P}_{9}\right)$. O volume de ácido residual resultante do processo de extração da LDA foi também neutralizado antes do descarte.

$$
\begin{aligned}
& \mathrm{LDA}_{50^{\circ} \mathrm{C}}=\left(\mathrm{P}_{7}-\mathrm{P}_{9}\right) * 100 / \mathrm{m} \\
& \mathrm{LDA}_{105^{\circ} \mathrm{C}}=\left(\mathrm{P}_{8}-\mathrm{P}_{9}\right) * 100 / \mathrm{m}
\end{aligned}
$$

A partir destes parâmetros, foram também estimados os teores de hemicelulose $=\mathrm{H}(\mathrm{FDN}-\mathrm{FDA})$, celulose $=\mathrm{C}(\mathrm{FDA}-\mathrm{LDA})$ e conteúdo celular $=\mathrm{CC}(\mathrm{MS}-\mathrm{FDN}-$ $\mathrm{MM}$ ), além das relações $\mathrm{FDN} / \mathrm{CC}$ e $\mathrm{H}+\mathrm{C}+\mathrm{L} / \mathrm{L}$, onde $\mathrm{MS}=$ Material vegetal seco inicial e L= Lignina.

As principais etapas metodológicas envolvendo a extração das fibras FDN, FDA e LDA segundo Van Soest (1963) são apresentadas na Figura 1, a seguir. 


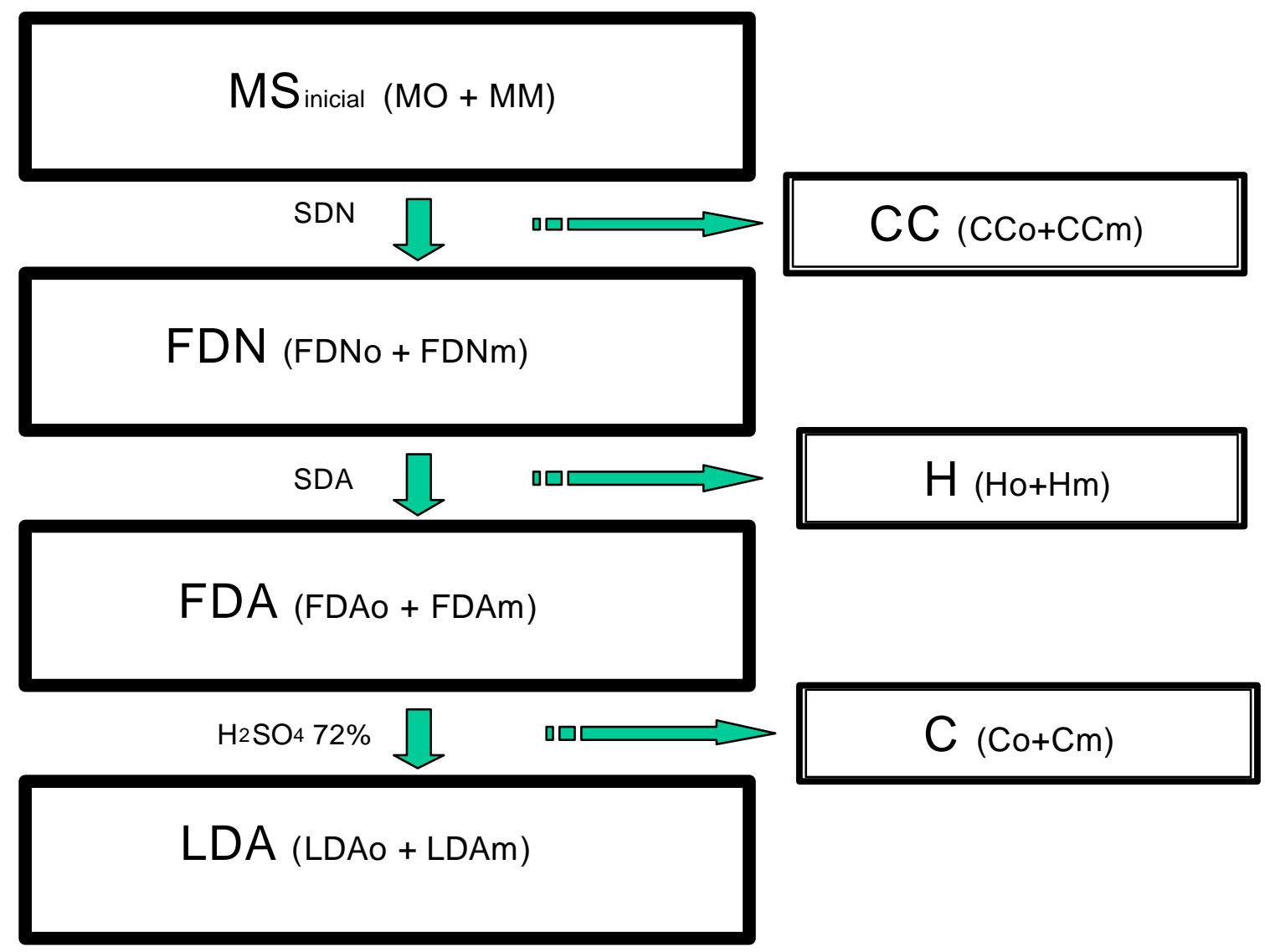

Figura 1 - Extração sequiencial do conteúdo de fibras em restos culturais de cana-deaçúcar.

Fonte: Adaptado de Van Soest (1963)

MS inicial $=$ Material Vegetal Seco $(\mathrm{MO}=$ Matéria Orgânica; $\mathrm{MM}=$ Material Mineral $)$

$\mathrm{SDN}=$ Solução Detergente Neutro;

$\mathrm{CC}=$ Conteúdo Celular (CCo = CC orgânico; $\mathrm{CCM}=\mathrm{CC}$ mineral)

FDN $=$ Fibra em Detergente Neutro $($ FDNo $=$ FDN orgânico; FDNm $=$ FDN mineral $)$

SDA = Solução Detergente Ácido

$\mathrm{H}=$ Hemicelulose ( $\mathrm{Ho}=\mathrm{H}$ orgânica; $\mathrm{Hm}=\mathrm{H}$ mineral)

FDA = Fibra em Detergente Acido (FDAo = FDA orgânico; FDAm = mineral)

$\mathrm{C}=$ Celulose ( $\mathrm{Co}=\mathrm{C}$ orgânica; $\mathrm{Cm}=\mathrm{C}$ mineral)

LDA = Lignina em Detergente Ácido (LDAo = LDA orgânico; LDAm= LDA mineral) 


\section{Químico}

Os teores de carbono e nitrogênio totais foram determinados por combustão à seco, utilizando-se um autoanalisador LECO CN-2000 a partir de 100 a 300 mg de amostras secas, moídas e peneiradas a 100 "meshes".

\section{EPR}

O fenômeno de Ressonância Paramagnética Eletrônica (EPR) somente pode ser observado quando a amostra investigada contiver átomos ou moléculas com pelo menos um elétron desemparelhado. Neste tipo de experimento a amostra é submetida a um campo magnético estático para que os elétrons dos átomos ou moléculas percam a degenerescência de spin e os níveis Zeeman eletrônicos sejam estabelecidos (Knowles et al., 1976; Poole \& Farach, 1972).

Quando uma amostra para análise paramagnética está sujeita a um campo magnético uniforme $H_{0}$, a degenerescência do spin total de seus átomos ou moléculas desaparece. Este fenômeno é atribuído ao desdobramento Zeeman eletrônico, que consiste na quantificação espacial dos momentos magnéticos $\vec{\mu}_{e}$ dos elétrons. Inicialmente quando $H_{0}=0$, os momentos magnéticos $\vec{\mu}_{i}$ de cada elétron estão orientados ao acaso, sujeitos apenas aos campos magnéticos locais de seus próprios vizinhos.

Para quantificar dos radicais livres tipo semiquinona foi utilizado o método do padrão secundário (Singer, 1959), com um cristal de rubi $\left(\mathrm{Ab}_{2} \mathrm{O}_{3}\right)$ contendo $0,5 \%$ de $\mathrm{Cr}^{+3}$ por peso. Seu fator $g$ é de 1,263 e, portanto, não interfere com o sinal do radical livre semiquinona, cujo valor de $g$ está em torno de 2,003 (Martin-Neto et al., 1998).

Para esta determinação, as amostras fracionadas de palhadas com diferentes idades, foram moídas e levadas ao laboratório da EMBRAPA/CNPDIA, onde foi utilizado um espectrômetro BRUKER EMX banda X ( 9 GHz). 


\subsection{Resultados e discussão}

\subsubsection{Micromorfologia}

As características anatômicas microscópicas da superfície da palhada de canade-açúcar em decomposição no solo são apresentadas na figura 2.

Observou-se que a palhada nova colhida 1 semana após o corte da cultura (Figura 2a), mantêm preservado o padrão foliar, permitindo o reconhecimento de micro-estruturas (por exemplo, pelos e estômatos), típicas da epiderme. Tais evidências revelam que este material vegetal não se encontra decomposto no solo durante o período considerado.

Em substratos mais envelhecidos com pelo menos um ano (Figura 2b) e com mais de um ano (Figura 2c), se evidencia o estabelecimento de uma comunidade biótica (principalmente fungos saprófitos) sobre a superfície topográfica destes materiais, sendo esta ação mais acentuada na palhada muito velha (Figura 2c). Nesta, os microorganismos contribuíram mais intensamente para a descaracterização do padrão foliar e de micro-estruturas histológicas. Neste estágio avançado do processo de decomposição se observa a degeneração do tecido foliar. 

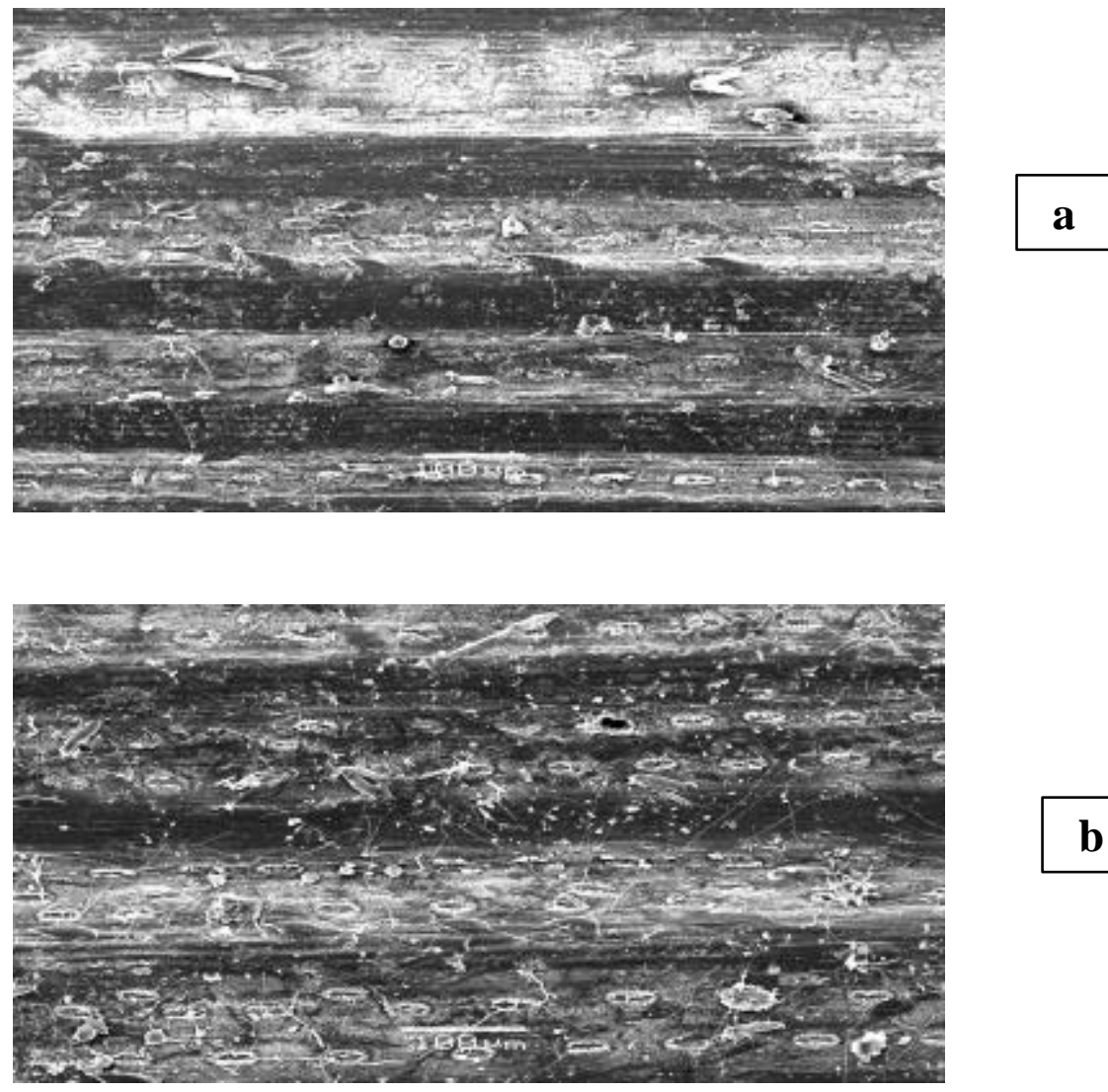

\section{b}
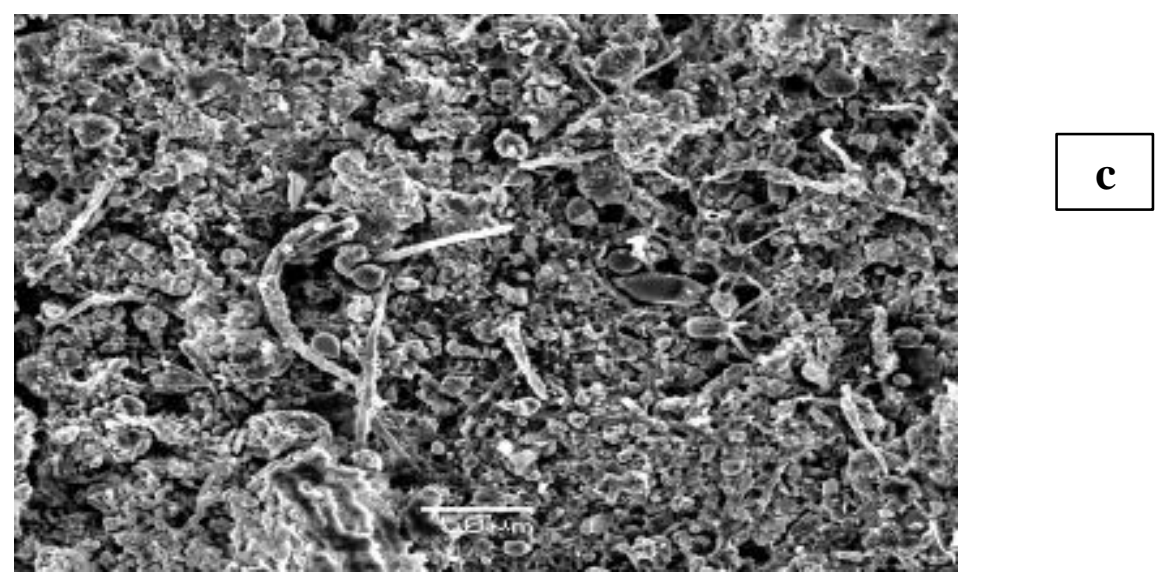

Figura 2 - Microscopia eletrônica de varredura da palhada de cana-de-açúcar da Usina São Martinho, em diferentes estágios de decomposição. a): palhada nova - 1 semana após o corte; b): palhada velha - 1 ano; c) palhada muito velha mais que 1 ano. 


\subsubsection{Bioquímicos}

Os resultados referentes aos teores de fibras são apresentados na tabela 1 . Observa-se que em áreas experimentais sem queima os teores de fibras insolúveis totais (FDN) e do complexo lignocelulósico (FDA) determinados em condições experimentais a $50^{\circ} \mathrm{C}$ variaram respectivamente entre 751,3 (palhada muito velha) e $923,4 \mathrm{~g} \cdot \mathrm{Kg}^{-1} \mathrm{MS}$ (folha do colmo), e, entre 451,9 (palhada muito velha) e 598,4 g. $\mathrm{Kg}^{-1} \mathrm{MS}$ (raiz). Quanto aos teores de lignina (LDA), apresentaram variações entre 53,9 (folha do ponteiro) e 134,8 g. $\mathrm{Kg}^{-1} \mathrm{MS}$ (raiz e palhada muito velha).

Estimativas envolvendo os teores de hemicelulose (304,8: palhada muito velha a 457,7 g. $\mathrm{Kg}^{-1}$ MS: folha do colmo), celulose (299,0: palhada muito velha a 477,97 g. $\mathrm{Kg}^{-}$ 1 MS: folha do colmo) e conteúdo celular (32,0: folha do colmo 248,2 g. $\mathrm{Kg}^{-1} \mathrm{MS}$ : palhada muito velha) revelaram variações entre os diferentes substratos analisados.

Em áreas com queima os resíduos amostrados (ponteiros queimados) apresentam características distintas daquelas observadas no sistema de manejo sem queima $\left(\mathrm{FDN}=713,8\right.$ g. $\mathrm{Kg}^{-1} \mathrm{MS}, \mathrm{FDA}=479,7 \mathrm{~g} \cdot \mathrm{Kg}^{-1} \mathrm{MS} ; \mathrm{LDA}=238,8 \mathrm{~g} \cdot \mathrm{Kg}^{-1} \mathrm{MS}$; hemicelulose $=234,10 \mathrm{~g} \cdot \mathrm{Kg}^{-1} \mathrm{MS}$ e celulose $=234,10 \mathrm{~g} \cdot \mathrm{Kg}^{-1} \mathrm{MS}$, conteúdo celular = 285,5 g. $\left.\mathrm{Kg}^{-1} \mathrm{MS}\right)$.

Os dados submetidos a análise de variância (teste F) e teste de Tukey (SAS,Institute, 1987), tabela 2, apresentam estatisticamente as seguintes relações quanto à natureza das fibras e conteúdo celular :

Fibra em Detergente Neutro

Fibra em Detergente Ácido

Lignina em Detergente Ácido

Hemicelulose

Celulose

Conteúdo celular

$$
\begin{aligned}
& \mathrm{FP}=\mathrm{FC}=\mathrm{R}=\mathrm{PNO}=\mathrm{PVE}>\mathrm{PMV}=\mathrm{PQ} \\
& \mathrm{R}=\mathrm{PNO}<\mathrm{FP}=\mathrm{FC}=\mathrm{PVE}=\mathrm{PQ}=\mathrm{PMV} \\
& \mathrm{PQ}<\mathrm{R}=\mathrm{PMV}=\mathrm{FC}=\mathrm{PNO}=\mathrm{PVE}=\mathrm{FP} \\
& \mathrm{FP}=\mathrm{FC}=\mathrm{PNO}=\mathrm{PVE}=\mathrm{R}=\mathrm{PMV}=\mathrm{PQ} \\
& \mathrm{FC}=\mathrm{R}=\mathrm{PNO}=\mathrm{FP}=\mathrm{PVE}=\mathrm{PMV}=\mathrm{PQ} \\
& \mathrm{PQ}=\mathrm{PMV}>\mathrm{PVE}=\mathrm{PNO}=\mathrm{FP}=\mathrm{R}<\mathrm{FC}
\end{aligned}
$$


Tabela 1. Teores de fibras em restos culturais de cana-de-açúcar da Usina São Martinho a $50^{\circ} \mathrm{C}$.

\begin{tabular}{|c|c|c|c|c|c|c|c|c|c|c|c|c|}
\hline \multirow{3}{*}{ Material vegetal } & \multirow{2}{*}{\multicolumn{2}{|c|}{$\begin{array}{c}\text { Fibra em Detergente } \\
\text { Neutro (FDN) } \\
\end{array}$}} & \multirow{2}{*}{\multicolumn{2}{|c|}{ Conteúdo celular(CC) }} & \multicolumn{2}{|c|}{$\begin{array}{l}\text { Fibra em Detergente } \\
\text { Ácido (FDA) }\end{array}$} & \multicolumn{2}{|c|}{$\begin{array}{l}\text { Lignina em Detergente } \\
\text { Ácido (LDA) }\end{array}$} & \multicolumn{2}{|c|}{ Hemicelulose } & \multicolumn{2}{|c|}{ Celulose } \\
\hline & $\mathrm{n}=6$ & & & & \multicolumn{2}{|c|}{$\mathrm{n}=4$} & \multicolumn{2}{|c|}{$n=2$} & \multicolumn{2}{|c|}{$n=4$} & \multicolumn{2}{|c|}{$n=2$} \\
\hline & média & $\mathrm{CV}(\%)$ & média & $\mathrm{CV}(\%)$ & média & $\mathrm{CV}(\%)$ & média & $\mathrm{CV}(\%)$ & média & $\mathrm{CV}(\%)$ & média & $\mathrm{CV}(\%)$ \\
\hline \multicolumn{13}{|c|}{ g.kg ${ }^{-1} \mathrm{MS}$} \\
\hline \multicolumn{13}{|c|}{ SEM QUEIMA } \\
\hline $\begin{array}{l}\text { Folha do } \\
\text { ponteiro }\end{array}$ & 895,1 & 0,2 & 104,6 & 2,4 & 460,2 & 2,6 & 53,9 & 5,8 & 435,7 & 3,2 & 425,2 & 4,8 \\
\hline $\begin{array}{l}\text { Ponteiro do } \\
\text { colmo }\end{array}$ & 923,4 & 10,8 & 32,0 & 31,8 & 507,1 & 13,2 & 65,3 & 15,0 & 457,7 & 16,5 & 477,9 & 2,1 \\
\hline Raiz & 906,6 & 0,7 & 93,4 & 6,6 & 598,4 & 3,1 & 134,8 & 20,6 & 310,6 & 6,2 & 475,9 & 4,9 \\
\hline Palhada nova & 893,4 & 0,9 & 106,3 & 7,1 & 540,4 & 3,3 & 73,2 & 1,1 & 351,0 & 5,6 & 473,8 & 4,7 \\
\hline Palhada velha & 864,7 & 0,7 & 135,1 & 4,4 & 509,9 & 1,7 & $73,2 *$ & 0,0 & 354,3 & 2,8 & 434,4 & 0,0 \\
\hline Palhada muito & 751,3 & 5,7 & 248,2 & 17,5 & 451,9 & 7,4 & 134,8 & 0,2 & 304,8 & 23,8 & 299,0 & 13,4 \\
\hline \multicolumn{13}{|c|}{ COM QUEIMA } \\
\hline $\begin{array}{l}\text { Ponteiro } \\
\text { queimado }\end{array}$ & 713,8 & 2,3 & 285,5 & 9,6 & 479,7 & 1,6 & 238,8 & 0,8 & 234,1 & 0,3 & 234,1 & 0,3 \\
\hline
\end{tabular}

$\mathrm{N}=$ número de repetições analisadas. 
Tabela 2. Caracterização bioquímica de restos culturais de cana-de-açúcar da Usina São Martinho a $105^{\circ} \mathrm{C}$.

\begin{tabular}{|c|c|c|c|c|c|c|c|c|c|}
\hline Material vegetal & Minerais & $\begin{array}{c}\text { Matéria } \\
\text { Orgânica Total }\end{array}$ & FDN & FDA LDA & \multicolumn{2}{|c|}{$\begin{array}{c}\text { Hemicelulos } \\
\text { e }\end{array}$} & Celulose & FDN/CC & $(\mathrm{Cel}+\mathrm{Hem}) / \mathrm{LDA}$ \\
\hline & & & & SEM QUEIMA & & & & & \\
\hline Folha do ponteiro & 49,0 & 951,0 & 844,0 a $150,0 \mathrm{~b}$ & bc 439,0 bc $39,0 \quad$ c & 405,0 & $\mathrm{a}$ & $400,0 \mathrm{ab}$ & 5.6 & 20.6 \\
\hline Folha do colmo & 55,0 & 945,0 & 842,0 a 153,8 & d 515,0 bc 67,0 bc & 327,0 & $\mathrm{a}$ & 448,0 & 5.5 & 11.6 \\
\hline Raiz & 24,0 & 976,0 & 864,0 a 126,4 & c 560,0 a 101,0 b & 304,0 & $\mathrm{bc}$ & 459,0 & 6.8 & 7.5 \\
\hline Palhada nova & 32,0 & 968,0 & 847,0 a 150,31 & bc 496,0 ab 65,0 bc & 352,0 & $a b$ & $431,0 \mathrm{a}$ & 5.6 & 12.1 \\
\hline Palhada velha & 40,0 & 960,0 & 716,0 a 275,4 & b 455,0 bc 65,0 bc & 261,0 & $\mathrm{ab}$ & $390,0 \mathrm{ab}$ & 2.6 & 10.0 \\
\hline Palhada muito velha & 143,0 & 857,0 & 640,0 b 318,3 & $\begin{array}{l}\text { a } 335,0 \text { c } 120,0 \text { b } \\
\text { COM QUEIMA }\end{array}$ & 306,0 & $\mathrm{bc}$ & 215,0 bc & 2.0 & 4.3 \\
\hline Ponteiro queimado & 156,0 & 844,4 & 638,0 b 286,1 & a 430,0 bc 227,0 a & 208,0 & $\mathrm{c}$ & 204,0 & 2.2 & 1.8 \\
\hline
\end{tabular}

* Letras iguais dentro das colunas significa que não houve diferença estatisticamente significativa. 


\section{Químicos}

Os teores de carbono $(\mathrm{C})$ e de nitrogênio $(\mathrm{N})$ dos substratos vegetais amostrados são apresentados na tabela 3. Observa-se que os materiais sem queima apresentam teores elevados de carbono (entre 396,1 g. $\mathrm{Kg}^{-1} \mathrm{MS}$ : folha do colmo e 430,0 g. $\mathrm{Kg}^{-1} \mathrm{MS}$ : raiz e palhada nova), e teores relativamente baixos de nitrogênio $\left(3,1 \mathrm{gKg}^{-1} \mathrm{MS}\right.$ : palhada nova e 8,3 g. $\mathrm{Kg}^{-1} \mathrm{MS}$ : folha do ponteiro), resultando em razões $\mathrm{C} / \mathrm{N}$ amplas (51 a 139).

Tabela 3. Teores de carbono e de nitrogênio totais em restos culturais de cana-de-açúcar da Usina São Martinho sem fracionamento bioquímico (material inicial).

\begin{tabular}{|c|c|c|c|c|c|}
\hline \multirow[b]{2}{*}{ Material vegetal inicial } & \multicolumn{2}{|c|}{ Carbono } & \multicolumn{2}{|c|}{ Nitrogênio } & \multirow[t]{2}{*}{$\mathrm{C} / \mathrm{N}$} \\
\hline & Média & $\mathrm{CV}(\%)$ & Média & $\mathrm{CV}(\%)$ & \\
\hline \multicolumn{6}{|c|}{$\mathrm{g}, \mathrm{Kg}^{-1} \mathrm{MS}$} \\
\hline \multicolumn{6}{|c|}{ SEM QUEIMA } \\
\hline Folha do ponteiro & $423,0 \pm 14,5$ & 3,4 & $8,3 \pm 1,5$ & 17,7 & 51 \\
\hline Folha do colmo & $396,1 \pm 8,2$ & 2,1 & $4,6 \pm 1,5$ & 32,2 & 86 \\
\hline Raiz & $430,0 \pm 10,4$ & 2,4 & $6,3 \pm 2,7$ & 42,5 & 68 \\
\hline Palhada nova & $430,0 \pm 0,2$ & 0,1 & $3,1 \pm 0,1$ & 2,9 & 139 \\
\hline Palhada velha & $421,6 \pm 9,5$ & 2,3 & $3,7 \pm 0,3$ & 7,0 & 114 \\
\hline Palhada muito velha & $411,5 \pm 8,2$ & 2,0 & $6,1 \pm 0,2$ & 2,5 & 67 \\
\hline \multicolumn{6}{|c|}{ COM QUEIMA } \\
\hline Ponteiro queimado & $417,7 \pm 20,0$ & 4,8 & $10,4 \pm 1,3$ & 12,7 & 40 \\
\hline
\end{tabular}

Em áreas com queima, o ponteiro apresenta teor de carbono também elevado (417,7 $\left.\mathrm{g} \mathrm{kg}^{-1} \mathrm{MS}\right)$, assemelhando-se ao da palhada muito velha (411,7 $\left.\mathrm{g} \mathrm{kg}^{-1} \mathrm{MS}\right)$. Em relação ao nitrogênio, os teores deste elemento foram mais expressivos $\left(10,4 \mathrm{gkg}^{-1} \mathrm{MS}\right.$ do que àqueles observados nos substratos vegetais oriundos do sistema de colheita sem queima (3,1 a 8,3 $\left.\mathrm{g} \mathrm{kg}^{-1} \mathrm{MS}\right)$, resultando em razão $\mathrm{C} / \mathrm{N}=113$.

Spain \& Hodgen (1994) estudando a decomposição dos resíduos culturais de cana-de-açúcar sem queima no nordeste da Austrália, obteve teores de carbono (437,4 g. $\left.\mathrm{Kg}^{-1} \mathrm{MS}\right)$ e de nitrogênio (4,4 g. $\left.\mathrm{Kg}^{-1} \mathrm{MS}\right)$ semelhantes a este estudo. 


\subsubsection{Efeito da decomposição sobre a qualidade da palhada no solo}

\subsubsection{Bioquímicos}

Analisando o efeito da decomposição sobre a qualidade da palhada (tabela 3, figura3) observa-se que as três camadas analisadas (nova, velha e muito velha) apresentaram diferentes teores de fibras.

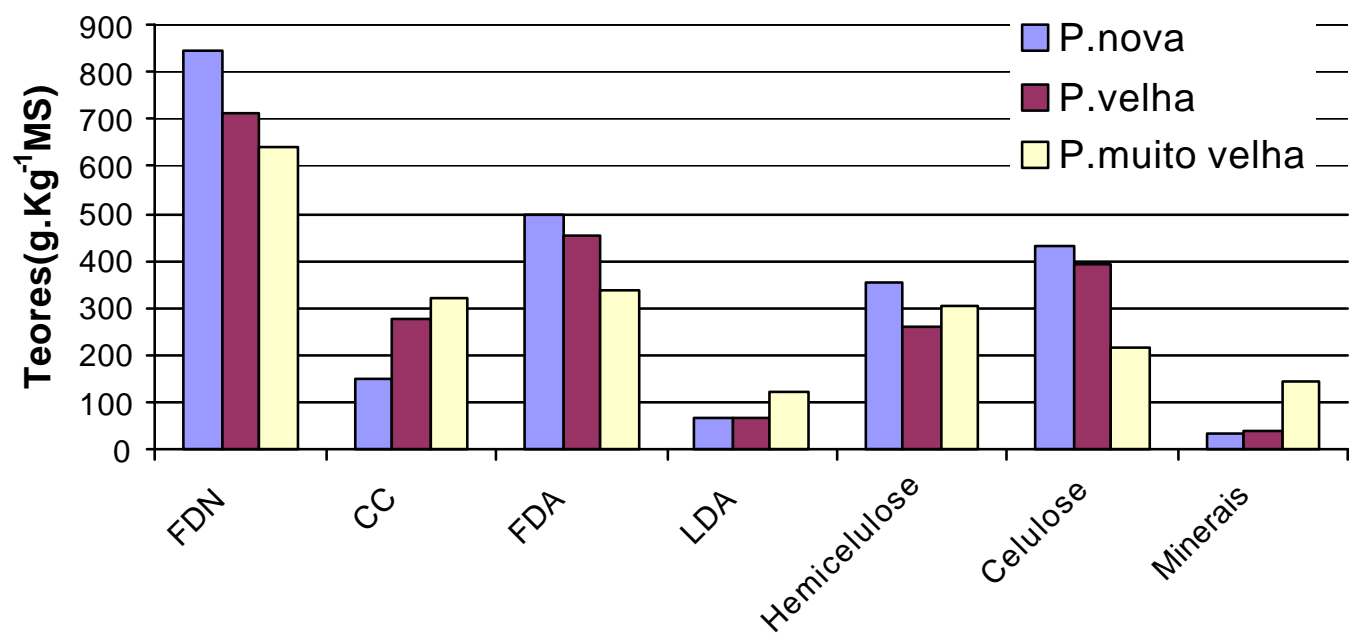

Figura 3 - Características bioquímicas da palhada de cana-de-açúcar em decomposição (g. $\left.\mathrm{Kg}^{-1} \mathrm{MS}\right)$ a $105^{\circ} \mathrm{C}$.

A palhada nova mantida há 1 semana na superfície do solo apresenta um teor de FDN mais expressivo (847,00 $\left.\mathrm{g} \mathrm{Kg}^{-1} \mathrm{MS}\right)$ do que as palhadas oriundas de restituições mais antigas: 1 ano $\left(716,0 \mathrm{~g} \mathrm{Kg}^{-1} \mathrm{MS}\right.$, palhada velha) e > 1 ano $(640,00$ $\mathrm{g} \mathrm{Kg}^{-1} \mathrm{MS}$ palhada muito velha). $\mathrm{O}$ mesmo se verifica em relação aos teores de FDA presentes nas três camadas analisadas (496,0 $\mathrm{g} \mathrm{Kg}^{-1} \mathrm{MS}$ : palhada nova; 455,0: $\mathrm{g} \mathrm{Kg}^{-}$ ${ }^{1} \mathrm{MS}$; palhada velha e $335,0 \mathrm{~g} \mathrm{Kg}^{-1} \mathrm{MS}$ : palhada muito velha).

As variações observadas nos teores de fibras (FDN e FDA) da camada de palhada nova em relação às demais, provavelmente estejam relacionadas à integridade do 
material vegetal, posto que nesta etapa do processo de decomposição (1 semana), a atividade biológica (fungos celulolíticos saprófitos) é baixa (Abramo Filho, 1995). Acredita-se que as diferenciações micro-morfológicas evidenciadas ao longo do tempo de decomposição da palhada no solo, sejam fortes indicativos para explicar as variações ocorridas nos teores de fibras estruturais analisadas (figura 2a-c).

A partir de FDN ocorre uma diminuição de FDA devido a remoção do conteúdo celular ocasionada pela ação da Solução Detergente Neutro (SDN).

Verifica-se também que o conteúdo celular é mais elevado nos materiais vegetais mais envelhecidos (palhada velha: 275,4 $\mathrm{g} \mathrm{Kg}^{-1} \mathrm{MS}$ e palhada muito velha: 318,3 $\left.\mathrm{g} \mathrm{Kg}^{-1} \mathrm{MS}\right)$. O aumento observado provavelmente decorre da extração simultânea do conteúdo celular da palhada e de organismos fúngicos amplamente disseminados sobre as amostras mais decompostas (figuras $2 \mathrm{~b}$ e c).

Com o aumento do tempo de decomposição, os teores de LDA se tornam mais expressivos (65,0 a $\left.120 \mathrm{~g} \mathrm{Kg}^{-1} \mathrm{MS}\right)$.Teores semelhantes deste componente $\left(119,0 \mathrm{gK}^{-}\right.$ ${ }^{1}$ MS) foram também observados por Beunard (1999) em palhada de cereais (tabela 4). Spain \& Hodgen (1994) analisando os restos culturais de cana-de-açúcar no nordeste da Austrália constatam a mesma tendência nos teores de lignina em relação às demais fibras analisadas.

Características indicativas de lignificação de alguns órgãos de cana-de-açúcar (ponteiros e bagaço) foi também evidenciadas por Deepchand (1987) em estudos envolvendo a pirólise destes componentes vegetais, consequiência direta da baixa concentração de compostos voláteis e teores elevados de cinzas e de carvão observados durante a realização do experimento.

Quanto aos teores de hemicelulose (261,0 a $\left.352,0 \mathrm{gKg}^{-1} \mathrm{MS}\right)$, estes são mais expressivos na palhada nova do que nos demais substratos analisados, provavelmente devido à preservação do tecido vegetal considerado. $\mathrm{O}$ mesmo se verifica em relação à celulose (215,0 a 431,0 $\left.\mathrm{g} \mathrm{Kg}^{-1} \mathrm{MS}\right)$. 
Tabela 4. Composição bioquímica de restos culturais $\left(\mathrm{gkg}^{-1} \mathrm{MS}\right)$.

\begin{tabular}{cccccc}
\hline \multirow{2}{*}{ Material Vegetal } & \multicolumn{5}{c}{ Resíduos Bioquímicos } \\
\cline { 2 - 6 } & FDN & FDA & LDA & Hemicelulose & Celulose \\
\cline { 2 - 6 } & 847 & 496 & 65 & 352 & 431 \\
\hline Palhada cana-de-açúcar & 799 & 287 & 119 & 512 & 168 \\
Palhada de cereais & 723 & 643 & 273 & 55 & 369 \\
Torta de café & 692 & 541 & 299 & 136 & 243 \\
Polpa de oliva & 428 & 288 & 185 & 120 & 103 \\
Torta de cacau & & & &
\end{tabular}

Fonte: Adaptado de Beunard (1999)

Comparando-se os dados obtidos com alguns produtos agro-alimentares e agrícolas apontados por Beunard (1999), tabela 4, observa-se que os teores mais expressivos de hemicelulose e celulose referem-se respectivamente à palha de cereais (512,0 $\left.\mathrm{g} \mathrm{kg}^{-1} \mathrm{MS}\right)$ e àtorta de café $\left(368,0 \mathrm{~g} \mathrm{~kg}^{-1} \mathrm{MS}\right)$

Considerando os teores destes componentes na palhada de cana-de-açúcar, observa-se que a hemicelulose tende a decrescer com o tempo de decomposição, enquanto que o teor de celulose aumenta neste material vegetal. Estas informações estão coerentes com àquelas observadas por Oliveira et al. (1999) em estudos envolvendo a degradação da palhada de cana-de-açúcar no solo.

As diferenças observadas provavelmente estejam relacionadas a dois fatores. $\mathrm{O}$ primeiro deles intrínseco ao efeito da decomposição que pode ter atuado no enfraquecimento de pontes de hidrogênio, e com isto, facilita a remoção de moléculas de hemicelulose ligadas à microfilbrilas de celulose. A celulose, por se constituir em um arranjo de cadeias alongadas de moléculas, se apresenta com uma estrutura mais rígida e mais resistente que a hemicelulose, sendo dificilmente hidrolisada por sistemas enzimáticos pouco específicos (Raven et al., 1996).

Um outro fator que pode ter contribuído para as diferenças ocorridas entre os teores de hemicelulose e celulose, se relaciona ao emprego de solução detergente, 
reconhecida pela sua influência na solubilidade de hemicelulose assim como de proteínas (Van Soest 1963).

Comparando-se os resultados deste estudo com os da Tabela 4 (Beunard, 1999), observa-se que foi encontrado o maior teor de FDN na palhada da cana-de-açúcar em relação aos resíduos das demais culturas estudadas. Em relação a FDA, os resíduos de torta de café e de polpa de oliva, apresentaram teores mais elevados. Em relação a LDA, a palhada da cana-de-açúcar foi a que apresentou o menor teor. Tanto para a hemicelulose como para a celulose, a palhada de cana-de-açúcar apresentou teores mais elevados que os demais resíduos,

Quanto à natureza bioquímica dos resíduos semi-carbonizados (ponteiro queimado), observa-se que o mesmo apresenta teores de FDN (638,0 $\left.\mathrm{g} \mathrm{kg}^{-1} \mathrm{MS}\right)$ e FDA (430,0 $\mathrm{g} \mathrm{kg}^{-1} \mathrm{MS}$ ) semelhantes ao da palhada muito velha (FDN: 640,0 $\mathrm{g} \mathrm{kg}^{-1} \mathrm{MS}$; FDA: $335,0 \mathrm{~g} \mathrm{~kg}^{-1} \mathrm{MS}$ ).

Considerando as observações de Deepchand (1987), o teor elevado de LDA (227,0 $\mathrm{gkg}^{-1} \mathrm{MS}$ ) é inerente ao ponteiro da planta, muito embora seja reconhecido que o grau de deterioração da planta pela ação do fogo interfere na qualidade da mesma a partir do segundo dia após a queima da cultura (Sang et al., 1987).

O conteúdo celular elevado (286,12 $\left.\mathrm{g} \mathrm{kg}^{-1} \mathrm{MS}\right)$ observado na análise deste substrato provavelmente decorre da contribuição de exsudatos provocados por rachaduras nos colmos devido à queima da cultura (Stupiello, 1989), e, possivelmente devido a geração de dextrana formada durante o processo de deterioração da planta no solo (Sang et al., 1987).

\subsubsection{Químicos}

O efeito da decomposição sobre os teores de carbono e de nitrogênio da palhada (material vegetal inicial) pode ser avaliado através da Tabela 5.

Observa-se que a palhada nova apresenta teor de carbono mais elevado (430,0 $\mathrm{g} \mathrm{kg}^{-1} \mathrm{MS}$ ) do que os substratos vegetais mais envelhecidos (421,6 e 411,5 $\mathrm{gkg}^{-1} \mathrm{MS}$ para a palhada velha e muito velha respectivamente), ao contrário do que ocorreu com o nitrogênio (6,1 $\mathrm{g} \mathrm{kg}^{-1} \mathrm{MS}$ na palhada muito velha). Em decorrência dos valores 
apresentados, a razão $\mathrm{C} / \mathrm{N}$ sofreu um declínio (de 139 para 67) ao longo do período considerado (Figura 4).

Tabela 5. Comparação entre os teores de carbono e nitrogênio da palhada de cana-deaçúcar e das soluções extratoras.

\begin{tabular}{|c|c|c|c|c|c|}
\hline \multirow{3}{*}{ Tipo de Material vegetal } & \multicolumn{2}{|c|}{ Carbono } & \multicolumn{2}{|c|}{ Nitrogênio } & \multirow[t]{3}{*}{$\mathrm{C} / \mathrm{I}$} \\
\hline & Média & $\mathrm{CV}(\%)$ & Média & $\mathrm{CV}(\%)$ & \\
\hline & \multicolumn{4}{|c|}{ (g.Kg ${ }^{-1} \mathrm{MS}$} & \\
\hline & \multicolumn{4}{|c|}{ Palhada nova } & \\
\hline Inicial & $430,0 \pm 0,2$ & 0,1 & $3,1 \pm 0,1$ & 2,9 & 139 \\
\hline \multicolumn{6}{|l|}{ Resíduos bioquímicos: } \\
\hline FDN & $474,1 \pm 3,3$ & 0,7 & $1,8 \pm 0,1$ & 6,4 & 263 \\
\hline FDA & $483,6 \pm 4,2$ & 2,9 & $3,4 \pm 1,1$ & 32,6 & 142 \\
\hline \multirow[t]{2}{*}{ LDA } & 589,2 & nd & 6,4 & nd & 92 \\
\hline & \multicolumn{5}{|c|}{ Palhada velha } \\
\hline Inicial & $421,6 \pm 9,5$ & 2,3 & $3,7 \pm 0,3$ & 7,0 & 114 \\
\hline \multicolumn{6}{|l|}{ Resíduos bioquímicos: } \\
\hline FDN & $466,6 \pm 6,4$ & 1,4 & $2,7 \pm 0,5$ & 17,1 & 173 \\
\hline FDA & $462,1 \pm 5,2$ & 1,1 & $6,5 \pm 4,4$ & 67,7 & 71 \\
\hline LDA & 405,5 & nd & 10,2 & nd & 40 \\
\hline & \multicolumn{5}{|c|}{ Palhada muito velha } \\
\hline Inicial & $411,5 \pm 8,2$ & 2,0 & $6,1 \pm 0,2$ & 2,5 & 67 \\
\hline \multicolumn{6}{|l|}{ Resíduos bioquímicos: } \\
\hline FDN & $486,9 \pm 8,0$ & 1,6 & $5,4 \pm 1,3$ & 24,7 & 90 \\
\hline FDA & $497,4 \pm 45,4$ & 9,1 & $6,1 \pm 2,5$ & 41,4 & 82 \\
\hline LDA & 464,6 & nd & 4,1 & nd & 113 \\
\hline & \multicolumn{5}{|c|}{ Soluções extratoras } \\
\hline SDN & 253,2 & - & 14,0 & - & 18 \\
\hline SDA & 114 & & 7 & & 16 \\
\hline $\mathrm{H}_{2} \mathrm{SO}_{4}$ & 0 & & 0 & & 0 \\
\hline
\end{tabular}


FDN = fibra em detergente neutro; FDA = fibra em detergente ácido; LDA = lignina em detergente ácido; SDN = solução detergente neutro; SDA = solução detergente ácido

Os resultados obtidos no presente estudo estão coerentes com os estudos desenvolvidos por Abramo Filho (1995) em áreas canavieiras da região de Piracicaba.

Nesta localidade, o teor de carbono da palhada declinou de 375,50 para 283,50 $\mathrm{g} \mathrm{k}^{-1} \mathrm{MS}$ (do início ao final do processo) enquanto os teores de nitrogênio se elevaram no mesmo período (4,9 a $\left.8,5 \mathrm{gkg}^{-1} \mathrm{MS}\right)$. A razão $\mathrm{C} / \mathrm{N}$ variou de 69 a 33 ao longo do período considerado.

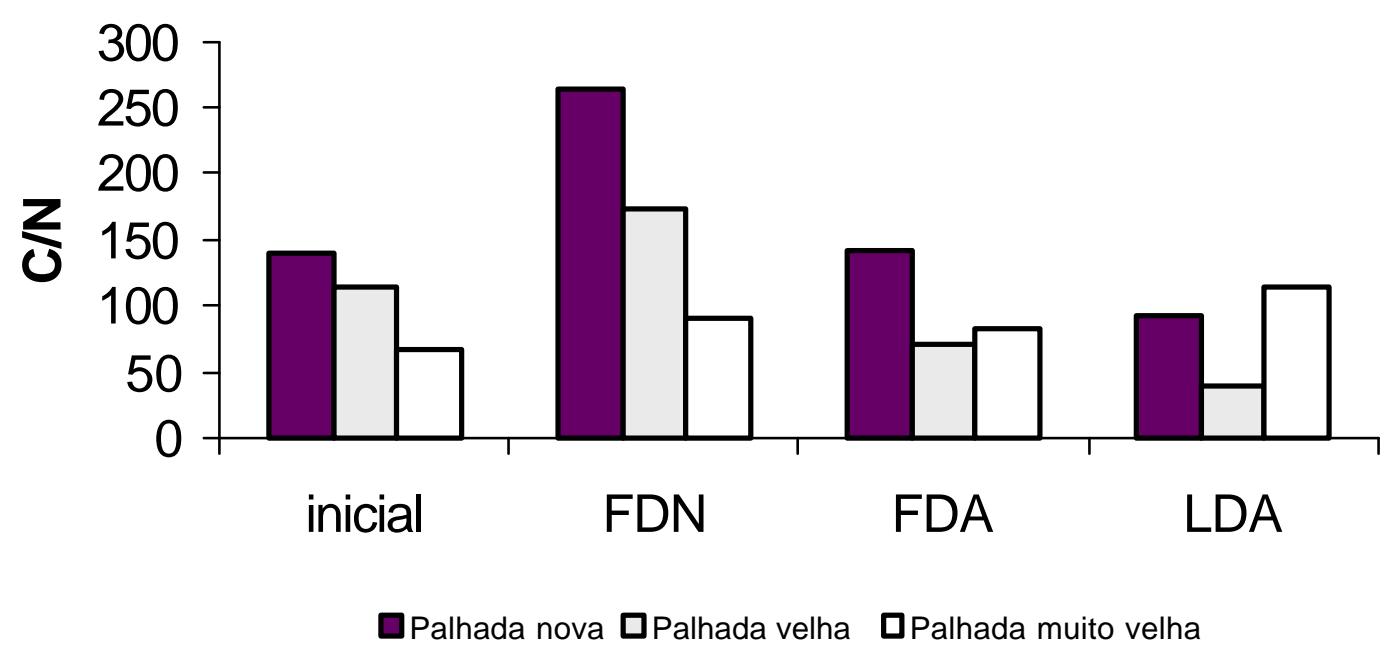

Figura 4 - Razão C/N da palhada de cana-de-açúcar: material inicial (sem fracionamento bioquímico) e resíduos bioquímicos: FDN, FDA e LDA (com fracionamento biquímico).

Spain \& Hodgen (1994) estudando a decomposição dos resíduos canavieiros sobre a superfície do solo no nordeste da Austrália, encontraram razões C/N também amplas e variáveis (170, 240 e 70) ao longo do processo considerado. 
Comparando-se os resultados da tabela 5 e figura 4, observa-se que na maioria dos casos as razões $\mathrm{C} / \mathrm{N}$ dos resíduos bioquímicos de palhada (FDN e FDA) apresentam grandes variações em relação aos seus respectivos materiais iniciais: maiores para FDN igual ou menores para FDA, exceto em relação àLDA.

\subsubsection{EPR}

A análise de EPR foi feita a título de investigação do material em diferentes estágios de decomposição. Foram analisadas palhada nova, palhada velha (1 ano de decomposição) e muito velha (com 2 anos de decomposição e com mais de 2 anos de decomposição). Não foi possível obter resultados para todas as amostras analisadas, uma vez que para essa análise, é necessário que se faça uma amostragem mais cuidadosa, principalmente no que se refere à contaminação da palhada com solo, que interferiu na análise.

Foram comparados os resultados obtidos nas diferentes frações de cada amostra, e também foram comparadas as diferentes idades de decomposição da palhada.

Para que se pudesse comparar as diferentes amostras, foi necessário a utilização de que se utilizasse um padrão, para se determinar a intensidade do radical orgânico, como demonstrado na figuras 5, para identificar os sinais destes radicais nas frações estudadas

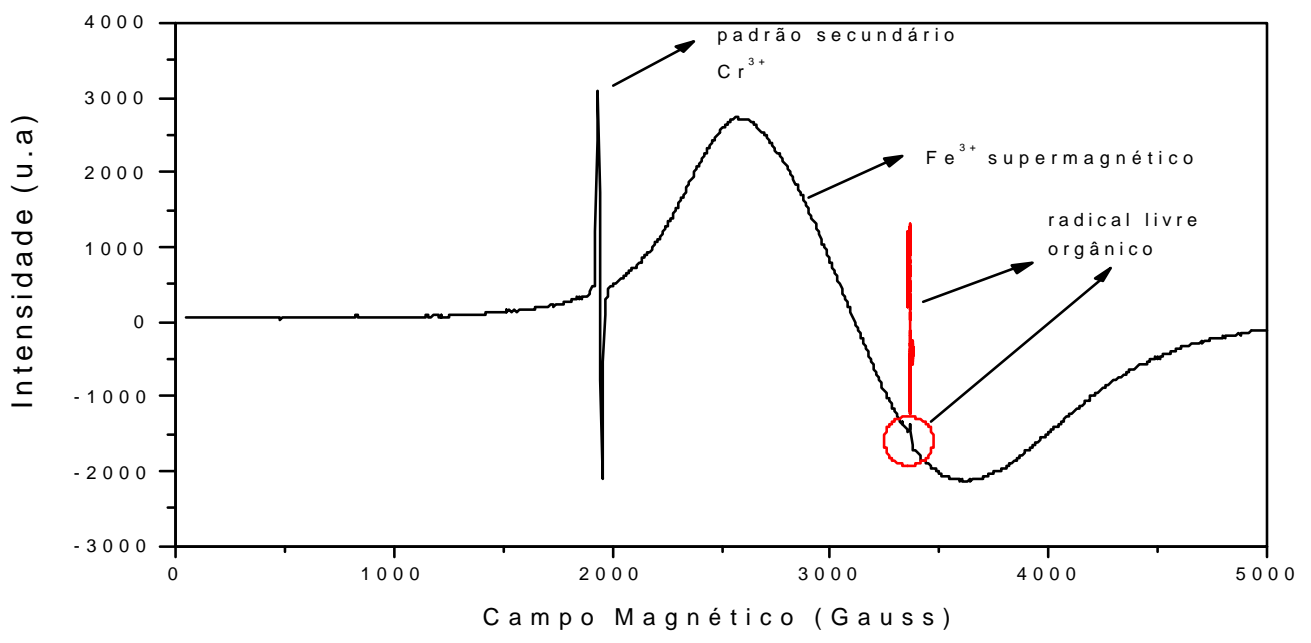


Figura 5 - Padrão de leitura de EPR.

Após a identificação do radical orgânico, foi determinada a intensidade de leitura deste radical, para identificação nas amostras das frações, como demonstrado na figura 6

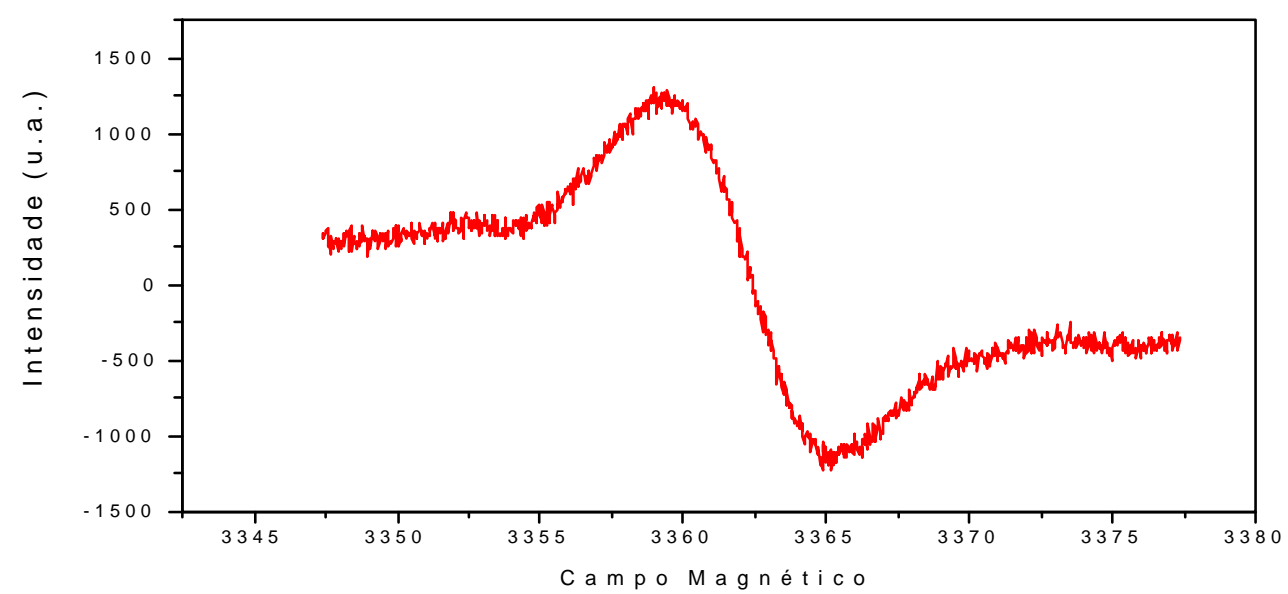

Figura 6 - Intensidade do radical orgânico.

$\mathrm{Na}$ figura 7, observa-se a intensidade de leitura de cada uma das frações analisadas, e a medida que diminui o diâmetro das frações, essa amplitude vai aumentando. Isso é característico, pelo menor tamanho das frações e também pelo grau de decomposição do material, que é maior nestas frações.

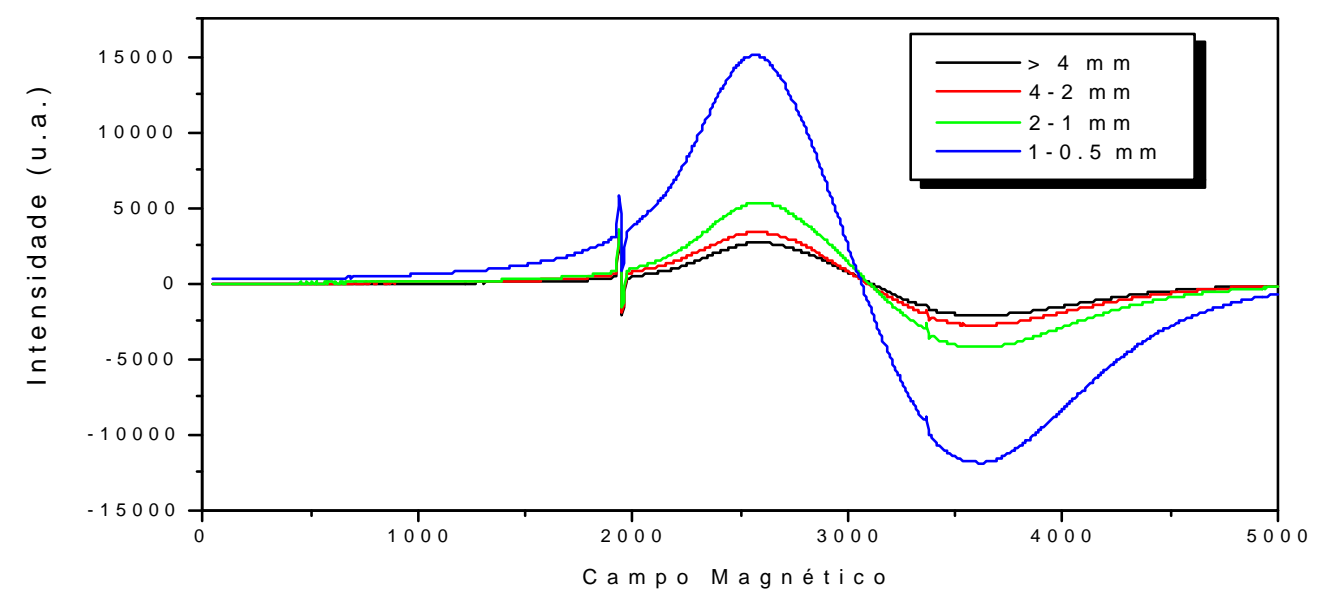


Figura 7 - Intensidade de leituras nas diferentes frações estudadas.

Após a leitura por espectroscopia, procedeu-se o cálculo do número de Spin por grama de Carbono, esse número é o parâmetro usado para determinar o grau de decomposição da amostra, visto que aumenta a concentração de semiquinona. $\mathrm{O}$ cálculo foi realizado utilizando-se o programa estatístico Origin.

$\mathrm{Na}$ figura 8, estão apresentadas as porcentagens de carbono em cada fração analisada nas palhadas em diferentes estágios de decomposição. Pode-se observar que na palhada nova, devido a mais de $92 \%$ do carbono se encontra na fração $>4 \mathrm{~mm}$, enquanto que na fração $42 \mathrm{~mm}$ encontra-se apenas $7 \%$ do carbono, o $1 \%$ restante nas demais frações.

Para as palhadas com mais de um ano de decomposição, as concentrações de carbono estão mais dvididas, e são bastante próximas. Na palhada velha, encontra-se 55 $\%$ do carbono na fração $>4 \mathrm{~mm}$ e na palhada muito velha, a porcentagem é de $59 \%$. Na fração 42 mm, as concentrações são bastante próximas, $24 \%$ para a velha e $22 \%$ para a muito velha. Nas frações $2-1 \mathrm{~mm}$ e $1-0,5 \mathrm{~mm}$ as concentrações foram de $8 \%$ para a velha e $7 \%$ par a muito velha e, na fração $<0,5 \%$ foram encontrados $5 \%$ para as duas palhadas.

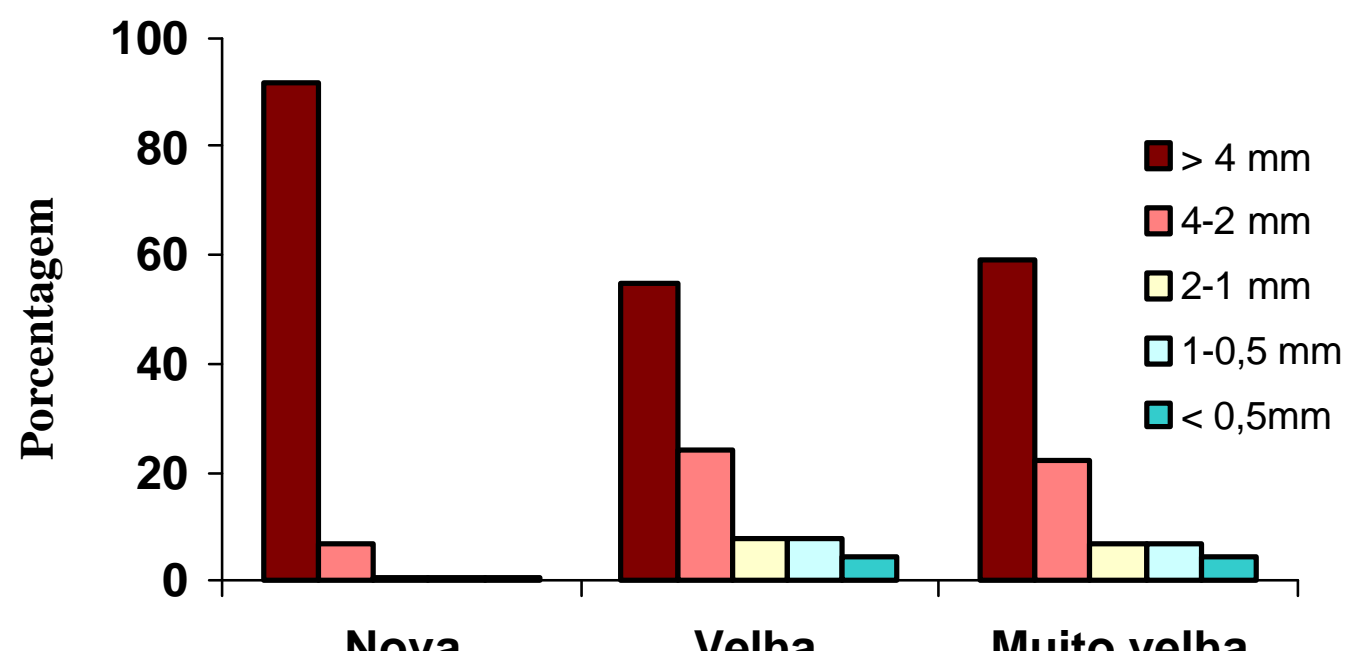


Figura 8 - Porcentagem de carbono em cada fração, nos diferentes estágios de decomposição da palhada.

Após o cálculo para se obter o número de spins por grama de carbono, foram montados gráficos onde se comparou o comportamento das frações nos diferentes estágio de decomposição da palhada. Inicialmente serão apresentados os resultados comparativos entre as frações nas diferentes fases de decomposição, para se comparar o efeito do tempo.

Na figura 9 estão apresentados os resultados referentes às frações $>4 \mathrm{~mm}$, nas diferentes idades de decomposição. Nas amostras de palhada nova, foram encontrados $0,5.10^{-17}$ spins g C, enquanto que na palhada de 1 ano, encontrou-se $2.10^{17}$ spins g C, uma alteração da ordem de quatro vezes, caracterizando, assim a diferença no estágio de decomposição das palhadas, após um ano.

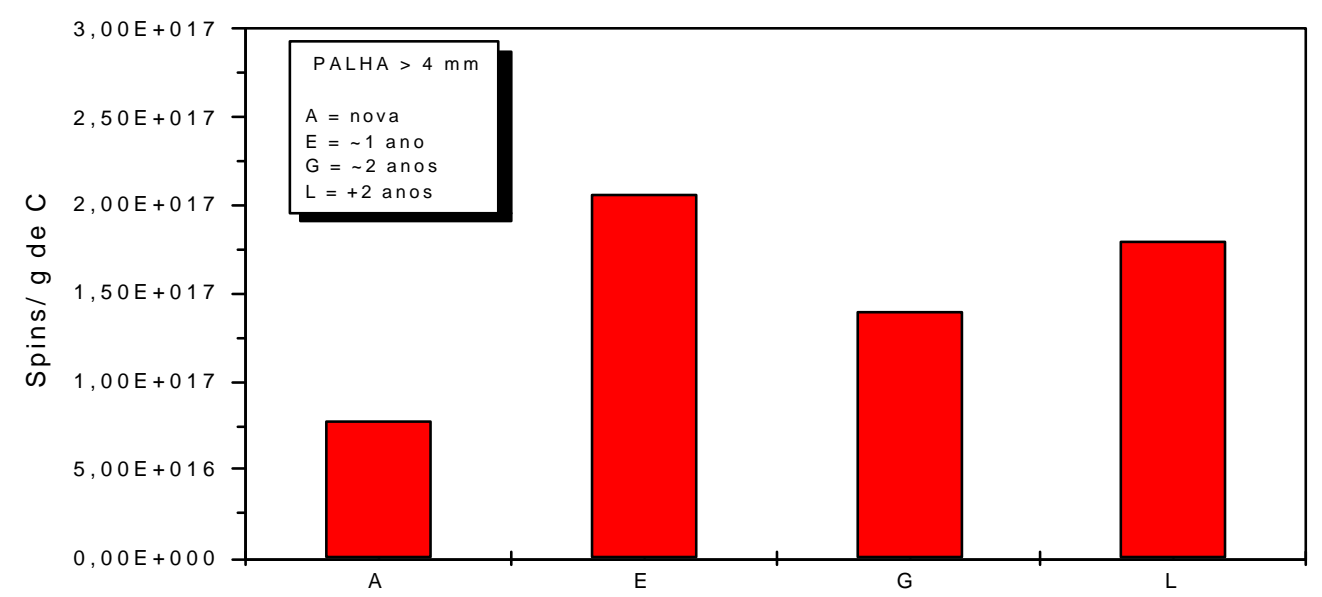

Figura 9 - Número de spins na fração > 4 mm nas diferentes fases de decomposição.

Na palhada muito velha ( 2 anos e mais de 2 anos) se manteve na faixa de $1,5.10^{17}$ spins g C, e o esperado era que se obtivesse valores entre $3,0-3,5.10^{17}$ spins $\mathrm{g}$ C, já que essas palhadas estão mais decompostas que as mais novas, entretanto, pode ter ocorrido a influência da contaminação do material por solo, uma vez que essa palhada 
está bastante decomposta formando uma camada compacta, dificultando, assim, a separação total do solo, para a obtenção apenas de material vegetal para a análise.

Pode-se observar que a principal diferença aparece após um ano de decomposição, enquanto que na palhada mais velha, o efeito do tempo pode ter sido mascarado pela contaminação das amostras com solo.

Na fração 4-2 mm não foi possível obter resultados nas amostras da palhada com mais de 2 anos de decomposição. Na figura 10 estão apresentados os resultados obtidos e observa-se uma variação de em função do tempo de decomposição entre a palhada nova, que apresentou 2,0.10 ${ }^{17}$ spins g C e a palhada de 1 ano com 2,8.10 ${ }^{17}$ spins g C. Na palhada de 2 anos, o número de spins foi praticamente o mesmo da palhada nova, mas, como já comentado anteriormente, provavelmente ocorreu ação do solo sobre as amostra.

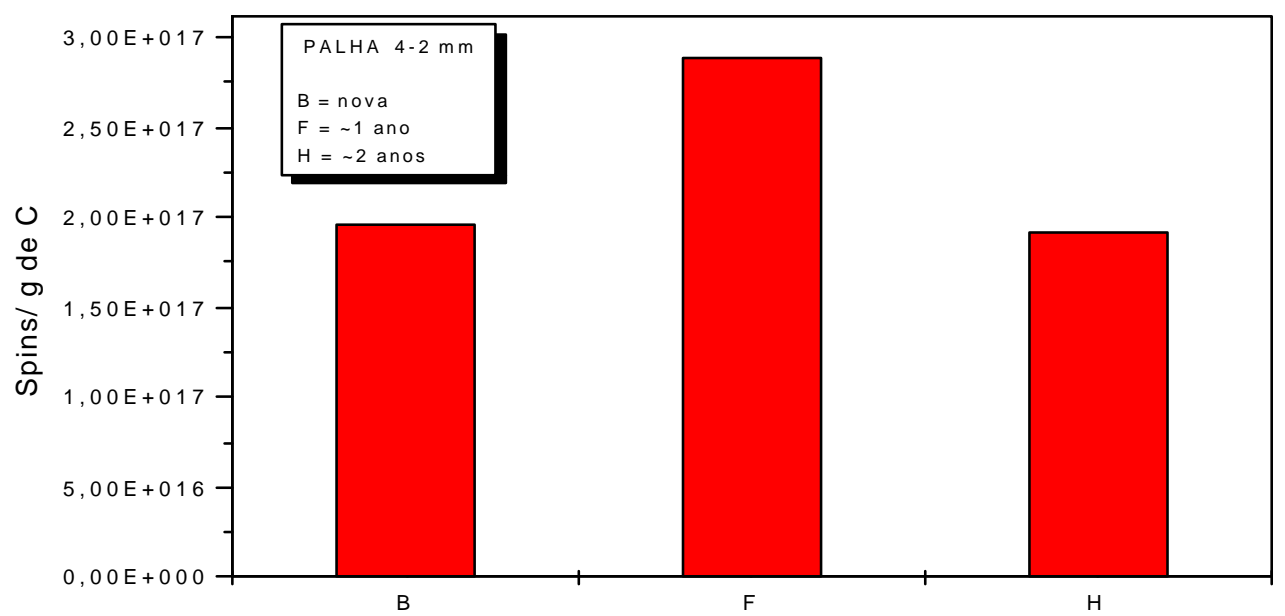

Figura 10 - Número de spins na fração 4-2 mm nas diferentes fases de decomposição.

$\mathrm{Na}$ fração 2-1mm só foram obtidos resultados para a palhada nova e para a palhada com 2 anos de decomposição. Observa-se na figura 11, que o número de spins foram próximos para as duas frações, variando entre $1,75.10^{17}$ spins g C para a palhada nova e $2,25.10^{17}$ spins g C para a palhada com 2 anos. O efeito da contaminação com solo se torna mais pronunciado nas frações menores. 


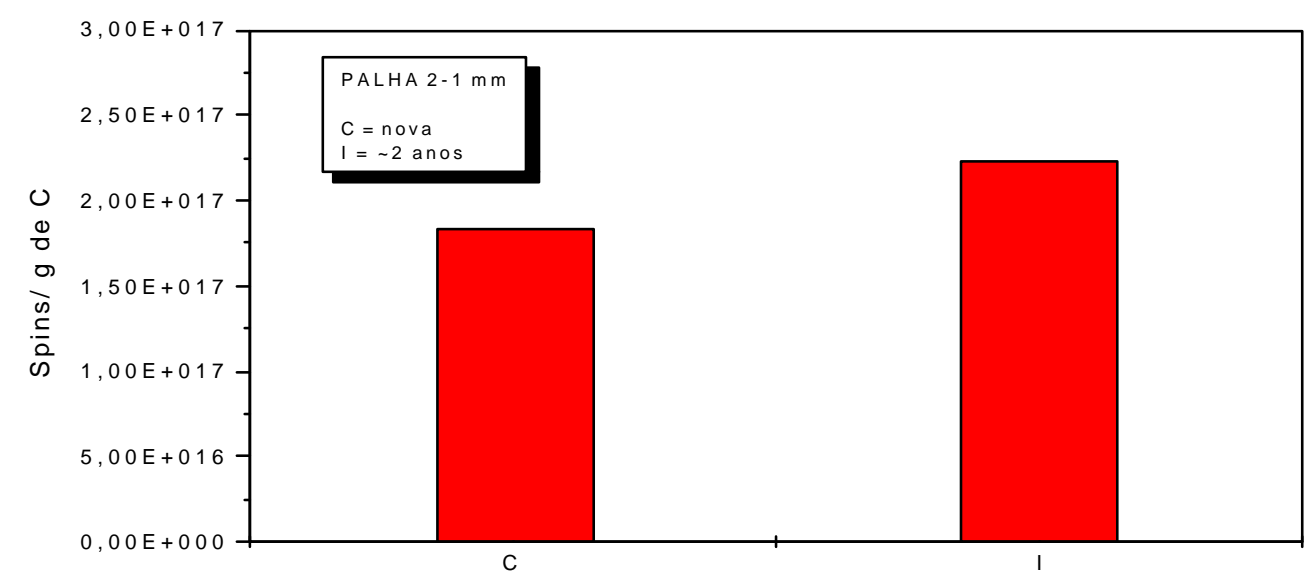

Figura 11 - Número de spins na fração 2-1 mm nas diferentes fases de decomposição.

$\mathrm{Na}$ fração 1-0,5 mm (figura 12) também só foram obtidos resultados para a palhada nova e com 2 anos de decomposição. Observa-se que a diferença é de pelo menos 6 vezes entra as palhadas, e que o efeito do tempo foi influenciado pela contaminação por solo. Nesta fração, a influência é a mais marcante, já que não ocorre contato da palhada nova com o solo, enquanto que a palhada com 2 anos já é difícil distinguir palhada/solo.

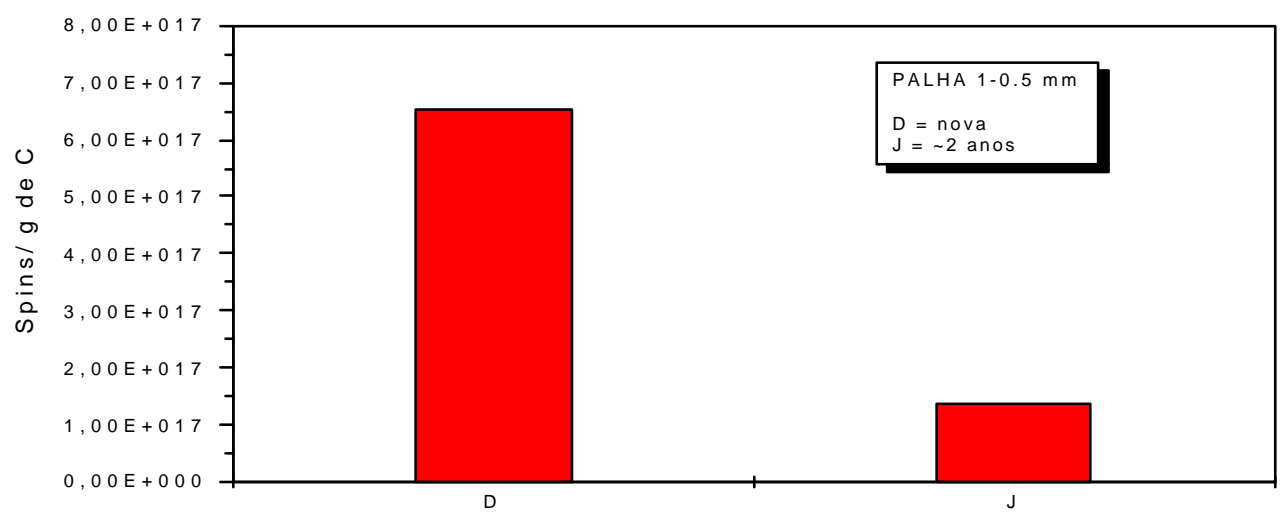

Figura 12 - Número de spins na fração 1-0,5 mm nas diferentes fases da decomposição. 
Serão apresentados os gráficos comparativos do efeito das diferentes frações dentro de cada estágio de decomposição.

$\mathrm{Na}$ figura 13, observa-se o efeito do tamanho da fração na determinação do número de spins. Encontrou-se menos de $1.10^{17}$ spins $\mathrm{gC}$ na fração $>4 \mathrm{~mm}$ e a medida que diminui o tamanho da fração, esse número aumentou até $6,510^{17}$ spins $\mathrm{gC}$ na fração $1-0,5 \mathrm{~mm}$.

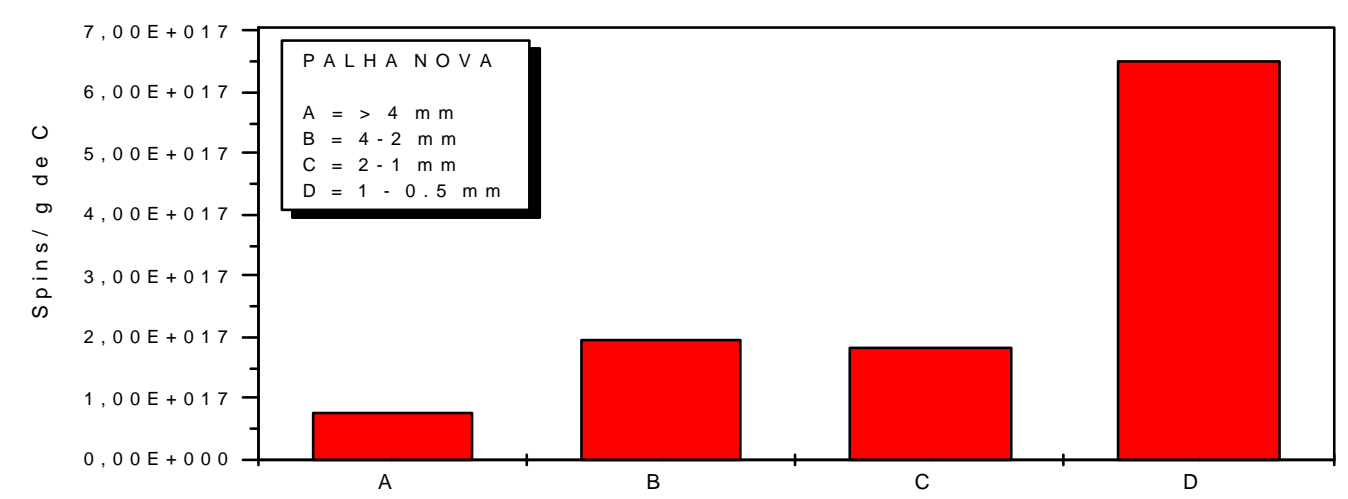

Figura 13 - Número de spins nas frações da palhada nova.

É possível notar o aumento do número de spins a medida que diminui o tamanho das frações, sendo mais de seis vezes maior na fração 1- 0,5 mm. Exceção feita para a fração 2-1mm, onde não se observou a tendência de aumento. Isto pode estar relacionado à contaminação da amostra por solo, o que teria influenciado na leitura por espectrometria desta fração. Cabe ressaltar que, como já demonstrado anteriormente, na palhada nova, a fração $>4 \mathrm{~mm}$ corresponde a mais de $65 \%$ da distribuição, enquanto que as frações menores que $1 \mathrm{~mm}$ representam cerca de $10 \%$ somente.

Na palhada com 1 ano de decomposição, só foi possível fazer a determinação nas fração < $4 \mathrm{~mm}$ e $42 \mathrm{~mm}$. Nas frações menores esta determinação não foi possível pela grande quantidade de solo que estava contaminando as amostras, o que tornou inviável a leitura espectroscópica, uma vez que, como demosntrado anteriormente, o ferro contido no solo, interfere no sinal espectroscópico. 
Pode-se notar, na figura 14 , que ocorreu um aumento no número de spins das frações analisadas, passando de 2,0.1 $10^{17}$ spins g $\mathrm{C}$ na fração $>4 \mathrm{~mm}$, para 3,0.1017 spins g C. Como na palhada nova, a diferença entre essas frações é marcante, demonstrando bem a influência do tamanho das frações.

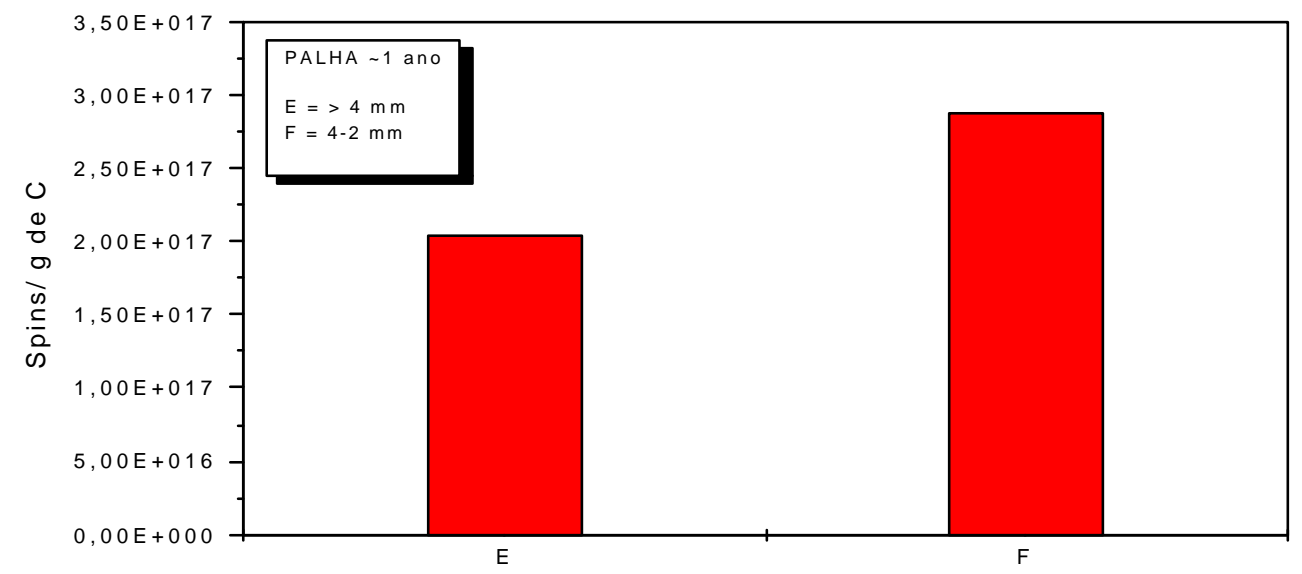

Figura 14 - Número de spins nas frações da palhada de 1 ano.

Na palhada com pelo menos dois anos de decomposição, apresentada na figura 15 , é possível observar bem o efeito do tamanho da fração, passando de $1,4.10^{17}$ spins $g$ $\mathrm{C}$ na fração > $4 \mathrm{~mm}$, para $1,9.10^{17}$ spins g C na fração $42 \mathrm{~mm}$ e $2,25 \cdot 10^{17}$ spins g C na fração $2-1 \mathrm{~mm}$. Na fração 1-0,5 mm foi encontrado praticamente o mesmo da fração > 4 $\mathrm{mm}$.

Nesta palhada, observa-se nitidamente a influência do solo nas amostras, quando da realização da análise. Pois, apesar da palhada estar muito mais decomposta que a palhada nova, os valores encontrados foram menores, exceção feita na fração $>4$ mm que foi mais elevado na palhada 2 anos, em relação a palhada nova. A maior diferença foi observada na fração 1-0,5 mm, sendo 4 vezes menor na palhada 2 anos. 


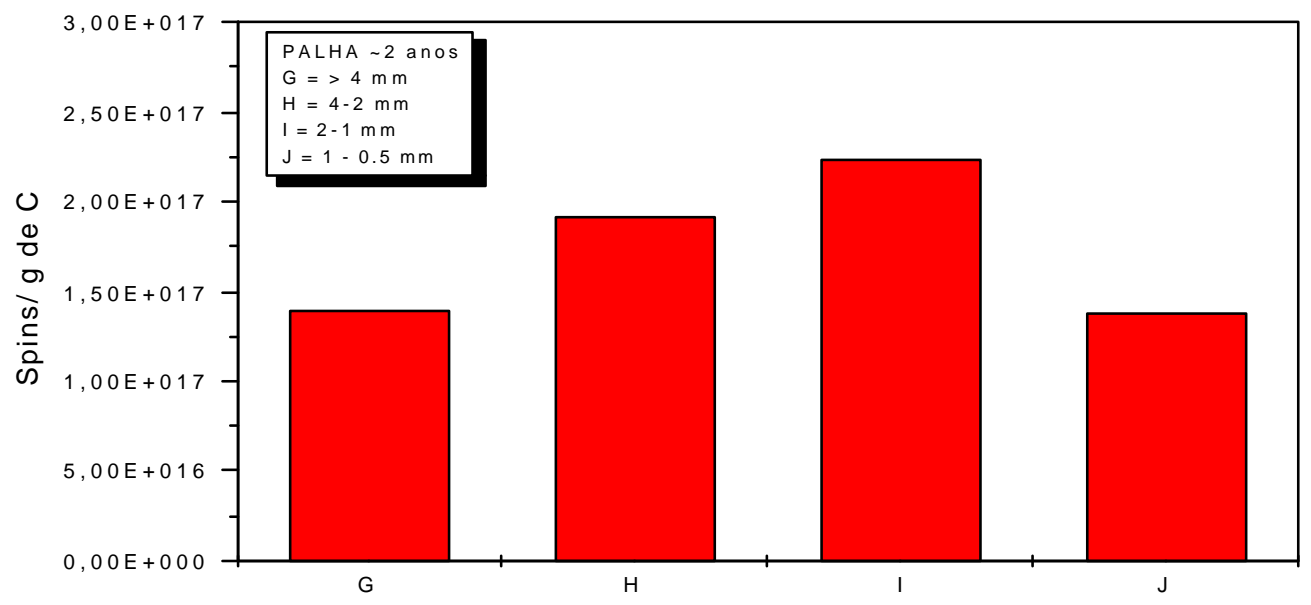

Figura 15 - Número de spins nas frações da palhada de 2 anos.

A análise EPR pode ser uma importante ferramenta para acompanhar a dinâmica da decomposição da palhada depositada sobre o solo no sistema de colheita sem queima da cana-de-açúcar. Contudo, é necessário que a coleta do material seja feita de maneira que impeça a contaminação da palhada por partículas de solo.

\subsection{Conclus ões}

- As variações microscópicas, químicas e bioquímicas observadas no material analisado podem ser consideradas como resultantes do processo de decomposição da MO;

- A palhada nova e a palhada velha, em relação à palhada inicial seguem as mesmas tendências: aumento da relação $\mathrm{C} / \mathrm{N}$ para FDN e declínio para FDA e LDA. O aumento é devido às perda do conteúdo celular (CC), rico em nitrogênio. Os declínios seguintes indicam a extração de compostos solúveis (hemicelulose e celulose) com razões $\mathrm{C} / \mathrm{N}$ altas; 
- $\quad$ Para a palhada muito velha (MV), exceto para LDA, as variações seguem as mesmas tendências, mas com amplitudes menores. Para LDA, com razão $\mathrm{C} / \mathrm{N}$ maior que FDA, tem que se lembrar que a chamada lignina é, na verdade, um complexo humo-ligninoso com compostos húmicos solúveis pelo $\mathrm{H}_{2} \mathrm{SO}_{4}$ e de razões $\mathrm{C} / \mathrm{N}$ baixas;

- A análise de EPR, apesar de ser exploratória, demonstrou que foram obtidos resultados bastante significativos, que puderam comprovar os resultados obtidos pelas outras análises realizadas. 


\section{COLHEITA DE CANA-DE-AÇÚCAR SEM A QUEIMA PRÉVIA DO CANAVIAL, E A EMISSÃO DOS GASES DO EFEITO ESTUFA}

\section{Resumo}

O presente trabalho foi conduzido em área experimental instalada pela COPERSUCAR, sobre Latossolo vermelho (Usina São Martinho) na região de Kbeirão Preto (SP). O objetivo foi analisar a influência da palhada depositada sobre o solo na dinâmica do carbono no agrossistema cana-de-açúcar, já que atualmente buscam-se alternativas para a diminuição da emissão de carbono para o ambiente. Comparou-se o sistema tradicional de queima e colheita manual da cana-de-açúcar, com o sistema de colheita mecanizada, sem a queima do canavial. Analisando a influência na emissão de gases do efeito estufa. As coletas foram realizadas entre agosto de 1999 e julho de 2000. As emissões de gases ocorridas durante a queimada da palhada antes do corte no manejo com queima da cana-de-açúcar foram calculadas a partir de dados da literatura. Foi mostrado que a emissão de $\mathrm{N}_{2} \mathrm{O}$ durante a queimada liberou uma importante quantidade

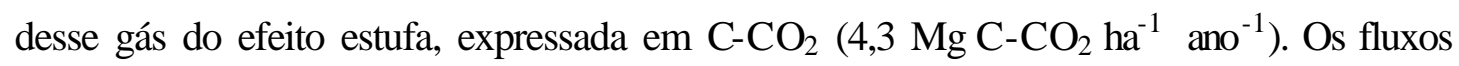
de gases na superfície do solo foram medidos ao longo de um ano nos manejos com e sem queima no Latossolo vermelho. Durante o período estudado, observourse que o manejo sem queima provocou uma emissão maior de $\mathrm{CO}_{2}$ do que o manejo com queima, e emissão de $\mathrm{CH}_{4}$, enquanto que com o manejo com queima ocorreu uma fixação desse gás. Quanto ao $\mathrm{N}_{2} \mathrm{O}$, não houve diferença nas emissões pelos dois manejos. Considerando todos os compartimentos de estoque de carbono (planta, palhada e solo) e de fluxos de gases do efeito estufa, estabelecemos um balanço do carbono em equivalente de $\mathrm{C}-\mathrm{CO}_{2}$ emitido ou sequiestrado pelo manejo sem queima, em comparação ao manejo tradicional com queima. $\mathrm{O}$ resultado final para o Latossolo vermelho, em um 
período de 3 anos, foi uma mitigação das emissões dos gases do efeito estufa de cerca de $5 \mathrm{MgC}-\mathrm{CO}_{2} \mathrm{ha}^{-1}$ ano $^{-1}$.

\section{Summary}

The present work was led in experimental area installed by COPERSUCAR, on Haplodux (Usina São Martinho) in the area of Ribeirão Preto (SP). THE objective was to analyze the influence of the trash deposited on the soil in the dynamics of the carbon in the agrosystem sugarcane, since now alternatives are looked for for the decrease of the emission of carbon for the atmosphere. The traditional system was compared of it burns and manual crop of the sugar-cane, with the system of automated crop, without it burns her/it of the sugar cane plantation. Analyzing the influence in the emission of gases of the effect stews. The collections were accomplished between August of 1999 and July of 2000. The emissions of gases happened during the burned of the trash before the cut in the handling with it burns of the sugar-cane they were calculated starting from data of the literature. The emissions of gases happened during burning of the trash before the cut of the sugar-cane they were calculated by data of literature. It was shown that the emission of $\mathrm{N}_{2} \mathrm{O}$ during the burning liberated an important amount of this greenhouse gas, expressed in $\mathrm{C}-\mathrm{CO}_{2}\left(4,3 \mathrm{MgC}-\mathrm{CO}_{2}\right.$ have-1 year-1). The flows of gases on the soil surface were measured along one year with burning and without it burning on Hapludox. It was shown that the management without burning provoked a larger emission of $\mathrm{CO}_{2}$ and $\mathrm{CH}_{4}$ than the management with burning due to gas fixation. According to $\mathrm{N}_{2} \mathrm{O}$, there was no difference on the emissions for the two management system. Due to the carbon stock compartments (plants, trash and soil) and the flows of the greenhouse gases, we established a balance of carbon in equivalent of emitted $\mathrm{C}-\mathrm{CO}_{2}$ or sequestrated kidnapped by the management without burning, in comparison with the traditional burning system. The final result for Hapludox, in a period of 3 years, revealed a mitigation of greenhouse gases of about $5 \mathrm{MgC}-\mathrm{CO}_{2} \mathrm{ha}^{-1}$ year $^{-1}$. 


\subsection{Introdução}

A queimada do canavial, que tem por finalidade facilitar o corte da cana-deaçúcar, que na maioria das áreas é feito manualmente, libera grande quantidade de cinzas ("carvãozinho") para o ambiente e podem causar doenças respiratórias, constituindo-se, assim, um problema de ordem social.

A maior preocupação, no entanto, não está no incômodo provocado nas cidades próximas às áreas cultivadas com cana-de-açúcar, mas sim no fato de que a queimada de resíduos agrícolas, libera para a atmosfera grande quantidade de gases ligados ao efeito estufa, principalmente $\mathrm{CO}_{2}, \mathrm{~N}_{2} \mathrm{O}$ e $\mathrm{CH}_{4}$.

O aumento do efeito estufa que é causado pela elevação das concentrações desses gases na atmosfera, é um dos principais problemas ambientais atuais. A elevação das concentrações vem ocorrendo principalmente pela queima de combustíveis fósseis, pelo desflorestamento e conversão de área de mata nativa em áreas cultivadas e da queima de resíduos agrícolas.

Paralelo às discussões visando a diminuição da emissão dos gases do efeito estufa, a extinção da queima de resíduos agrícolas, configura uma alternativa bastante viável para o processo chamado de "mitigação", no qual se evita a emissão de carbono para o ambiente.

A agroindústria da cana-de-açúcar desempenha um papel positivo importante no contexto da emissão de gases do efeito estufa para a atmosfera. Segundo Macedo ${ }^{2}$ a utilização do álcool (etanol) como combustível, em substituição à gasolina e do bagaço de cana em substituição ao óleo combustível em processos industriais (geração de energia), diminuiu em cerca de $20 \%$ as emissões anuais de $\mathrm{CO}_{2}$ devido ao uso de combustíveis fósseis no Brasil.

É importante ressaltar que a cana-de-açúcar é responsável por cerca de $98 \%$ das emissões de gases provenientes da queima de resíduos agrícolas no Brasil (Lima, 1999). Entretanto o balanço entre a emissão de $\mathrm{CO}_{2}$ durante as queimadas e a retirada de

\footnotetext{
${ }^{2}$ MACEDO, I. de C. Emissão de gases do efeito estufa e a produção/utilização de etanol da cana-de-açúcar no Brasil. Piracicaba: Centro de Tecnologia Copersucar, 1997. 10p. (Relatório interno CTC-05/97)
} 
$\mathrm{CO}_{2}$ do ambiente, pelo processo fotossintético é nulo, um avez que a cultura reabsorve o equivalente ao $\mathrm{CO}_{2}$ emitido (Silva, 1996)

As discussões levaram o poder público a criar leis que têm por finalidade, eliminar gradativamente a prática da colheita com a queima prévia do canavial, no Estado de São Paulo. Desta forma, o Decreto de Lei Estadual n 47.700 de 11 de março de 2003, que regulamenta a Lei no 11.241, de 19 de setembro de 2002, que dispõe sobre a eliminação gradativa da queima da palha da cana-de-açúcar e dá providências correlatas (Brasil, 2003), é de grande interesse agrícola e ecológico, estabelecem prazos, procedimentos, regras e proibições que visam regulamentar as queimadas em práticas agrícolas.

A adoção do manejo da colheita sem a queima prévia do canavial torna positivo o balanço do $\mathrm{CO}_{2}$, uma vez que o carbono que seria emitido imediatamente durante a queimada, pode permanecer no sistema.

Outro aspecto que deve ser levado em conta, é que a palhada pode funcionar como um mitigador de carbono para o ambiente, á que mesmo ocorrendo liberação de $\mathrm{CO}_{2}$ durante o processo de decomposição, parte do carbono que seria liberado durante a queimada é incorporada ao solo.

A utilização da cana-de-açúcar como mitigador de carbono, ainda demanda estudos para analisar a aplicabilidade e a viabilidade, representaria uma alternativa econômica para os produtores.

O objetivo desse trabalho foi comparar o balanço do carbono nos dois sistemas de colheita da cana-de-açúcar (com e sem queima prévia do canavial); bem como sobre a emissão de gases do efeito estufa para a atmosfera.

\subsection{Material e métodos}

\subsection{1 Área de estudos}

O acompanhamento da emissão dos gases do efeito estufa foi feita nas parcelas do experimento instalado pela COPERSUCAR sobre Latossolo vermelho (Usina São Martinho) na região de Ribeirão Preto (SP), onde foram comparados os sistemas de colheita com e sem queima durante o período de agosto de 1999 até agosto de 2000. 
Desta forma foi acompanhado um ciclo completo da cultura do corte ocorrido em 1999 até o novo corte ocorrido em 2000.

As amostragens foram feitas nas parcelas com queima e corte manual da cana e sem queima e corte mecanizado, tendo ocorrido no mês de agosto de 1999, duas semanas após o corte da cana e nos meses de novembro, março, maio, julho e agosto de 2000 uma semana após o corte da cana-de-açúcar daquele ano. Foram coletadas também, amostras de gás nas câmaras instaladas nas parcelas sem queima, após a retirada da palhada.

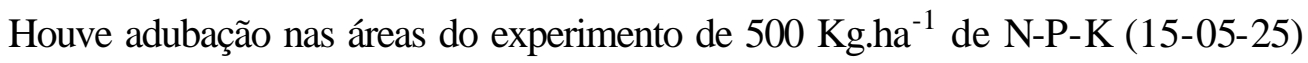
nas áreas SQ o adubo foi lançado sobre a palhada, enquanto que nas áreas CQ foi incorporado ao solo. A adubação ocorreu após o corte na reinstalação do experimento.

\subsubsection{Amostragem}

\subsubsection{Amostragem dos gases do solo e da palhada}

Foram instaladas seis câmaras para cada área, sendo uma câmara por parcela, e em cada câmara foram coletadas amostras nos tempos: tempo zero, cinco minutos após o fechamento das câmaras, dez minutos e quinze minutos.

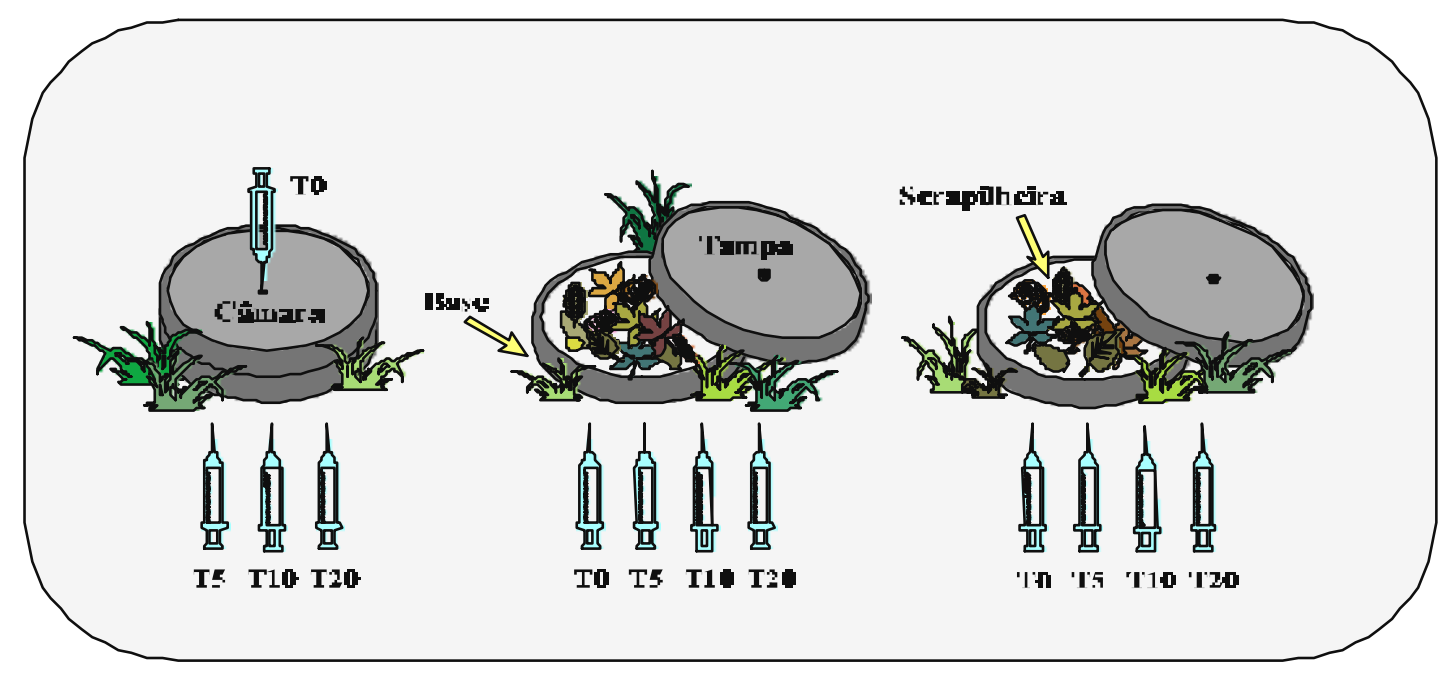

Figura 1 - Esquema das câmaras para coleta dos gases provenientes do solo da palhada. 
As câmaras foram instaladas na parte central de cada parcela, sendo instaladas três nas linhas e três nas entre-linhas de plantio, cada câmara era composta de duas partes, a primeira que media cerca de $5 \mathrm{~cm}$ de altura, por $32 \mathrm{~cm}$ de largura, com $29 \mathrm{~cm}$ de abertura interna, foi enterrada $2 \mathrm{~cm}$ no solo e fixada por três ganchos para uma maior sustentação; em seguida foi colocada sobre a base, a tampa da câmara, que possui o mesmo tamanho desta, a diferença é que a tampa possui uma altura interna de quatro centímetros e um orifício por onde é coletado o gás, esse orifício, a cada coleta, é aberto e posteriormente fechado por um dispositivo tipo torneira.

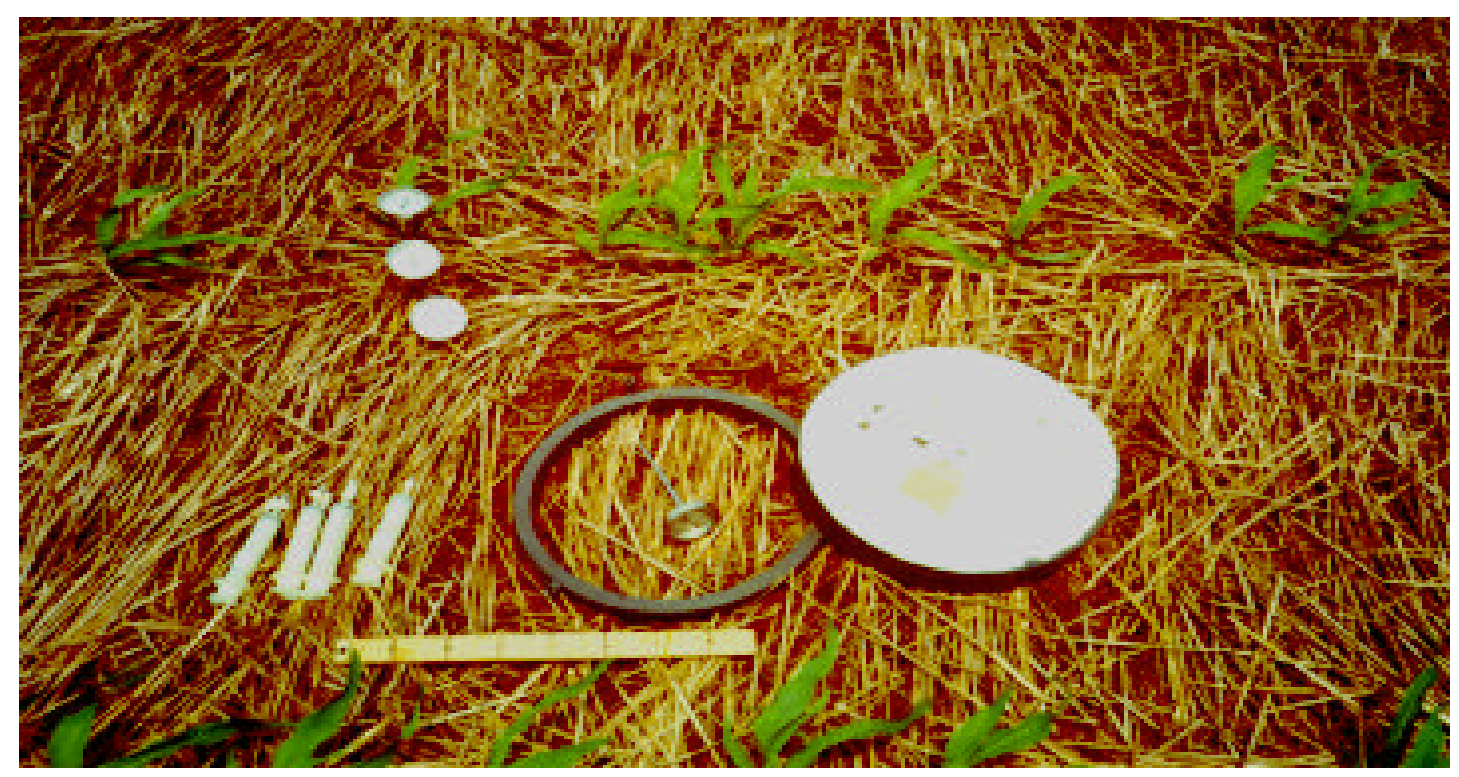

Figura 2 - Câmara de coleta dos gases provenientes do solo e da palhada.

Os horários das coletas foram às 7 horas, 12 horas e às 17 horas. Esses horários se justificam, por se tratarem, teoricamente, dos horários cujas temperaturas seriam, a mais baixa, a mais alta e a intermediária entre as duas primeiras. A cada horário de coleta foram medidas as temperaturas no interior da câmara, as temperaturas ambiente, e nas profundidades de $2 \mathrm{~cm}, 5 \mathrm{~cm}$ e $10 \mathrm{~cm}$ do solo, no início e no final das coletas.

A retirada dos gases do interior das câmaras foi feita por seringas próprias para este tipo de coleta, em cada seringa foram retirados cerca de $20 \mathrm{~cm}^{3}$ de gás (Bowden et 
al., 1990; Feigl et al., 1995), cada seringa foi devidamente identificada quanto à câmara e o horário da coleta, bem como a área a coletada.

Após a coleta dos gases, as seringas foram fechadas por dispositivo próprio tipo torneira, e presas com elásticos o dispositivo de fechamento com o embolo, para evitar contaminação com gases externos.

As seringas foram levadas para o laboratório de Biogeoquímica Ambiental do CENA/USP, onde foram analisadas as presenças dos gases $\mathrm{CO}_{2}, \mathrm{~N}_{2} \mathrm{O}$ e $\mathrm{CH}_{4}$, em cromatógrafo da marca Shimadzu, modelo CR 501.

Foram determinadas as concentrações dos gases em cada amostra, que serviram de base para a quantificação do fluxo de cada gás, permitindo fazer uma avaliação do fluxo que é calculado em função de uma área e do tempo $\left(\mathrm{m}^{2} \mathrm{~h}^{-1}\right)$.

\subsubsection{Amostragem da palhada}

Foram coletadas amostras da palhada do interior da câmara para a quantificação da massa seca remanescente $\left(\mathrm{Mg} \mathrm{ha}^{-1}\right)$ e das concentrações e estoques de carbono e nitrogênio na palhada, além da razão $\mathrm{C} / \mathrm{N}$.

\subsection{Resultados e discussão}

Neste capítulo serão apresentados os resultados das emissões dos gases para que seja possível fazer o balanço do carbono no sistema cana-de-açúcar.

\subsubsection{Fluxo de $\mathrm{CO}_{2}$}

$\mathrm{Na}$ Figura 3 observa-se que os fluxos médios anuais de $\mathrm{CO}_{2}$ medidos para as áreas com queima (129 $\mathrm{mg} \mathrm{C} \mathrm{m}^{-2} \mathrm{~h}^{-1}$ ) e sem queima (140 $\mathrm{mg} \mathrm{C} \mathrm{m}^{-2} \mathrm{~h}^{-1}$ ), foram próximos, não apresentando diferenças estatisticamente significativas. Pode-se observar que, com exceção das coletas realizadas em março e em julho de 2000, a emissão foi mais elevado para o sistema sem queima. 


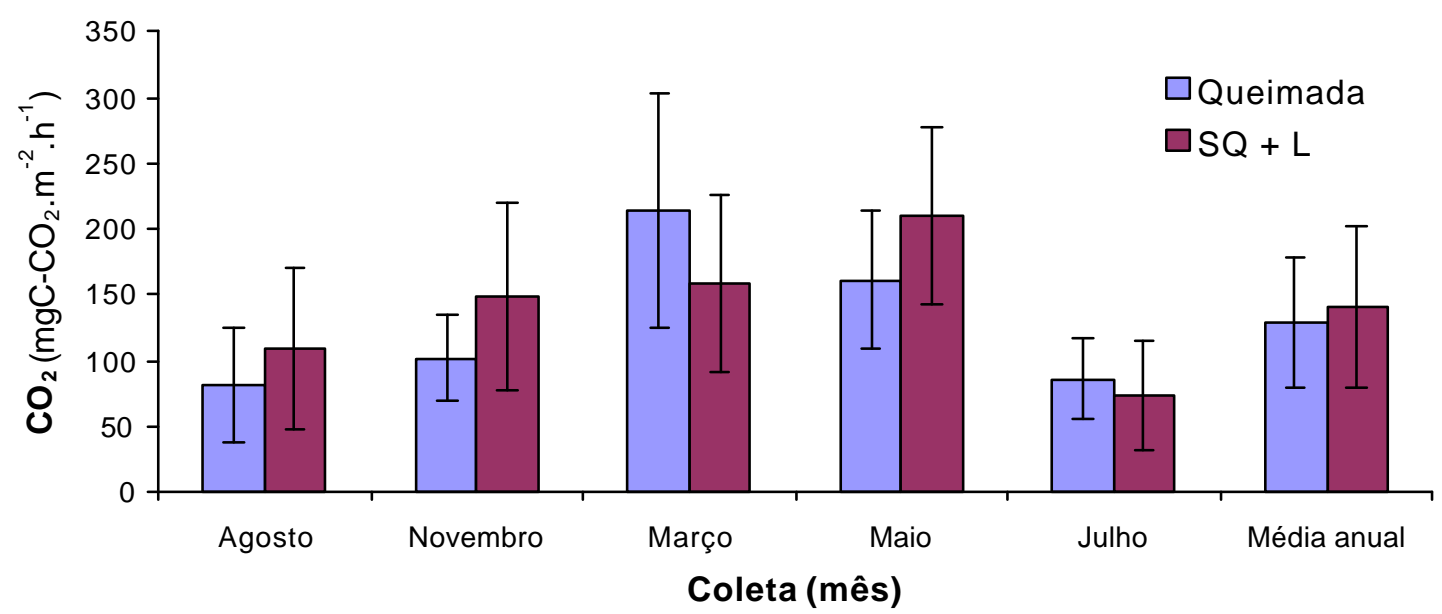

Figura 3 - Fluxos de $\mathrm{CO}_{2}\left(\mathrm{mgC}-\mathrm{CO}_{2} \mathrm{~m}^{-2} \mathrm{~h}^{-1}\right)$ nas duas situações analisadas durante os anos de 1999 a 2000.

Nas parcelas do tratamento com queima, o fluxo aumentou até o mês de março, atingindo o máximo de emissão $\left(213 \mathrm{mg} \mathrm{C} \mathrm{m}^{2} \mathrm{~h}^{-1}\right)$. Em seguida, ocorreu diminuição da emissão até atingir os níveis mais baixos em julho de 2000 (cerca de $85 \mathrm{mg} \mathrm{C} \mathrm{m}^{2} \mathrm{~h}^{-1}$ ). apresentando, inclusive, diferença estatisticamente significativa em relação a maior emissão.

Nas parcelas sem queima, ocorreu aumento no fluxo de $\mathrm{CO}_{2}$ até o mês de maio, com o máximo de emissão (cerca de $210 \mathrm{mg} \mathrm{C} \mathrm{m}^{2} \cdot \mathrm{h}^{-1}$ ), com diferença estatisticamente significativa em relação às demais coletas, em seguida diminuiu rapidamente alcançando em julho um fluxo mais baixo (aproximadamente $73 \mathrm{mg} \mathrm{C} \mathrm{m}^{2} \cdot \mathrm{h}^{-1}$ ).

De um modo geral não houve diferença estatisticamente significativa quando analisamos a média anual nas duas situações, ocorrendo uma emissão um pouco maior para a área sem queima da ordem de $11 \mathrm{mg} \mathrm{C} \mathrm{m}^{2} \mathrm{~h}^{-1}$.

Com exceção do mês de julho, as variações de $\mathrm{CO}_{2}$ acompanham a variação da umidade, que está representada na figura 4. 
Os fluxos quantificados foram próximos aos encontrados por Feigl et al. (1995) estudando pastagens em Rondônia e não sofreram influência da adubação que ocorreu nas áreas, já que segundo Weier (1998) a adubação nitrogenada diminui o fluxo de $\mathrm{CO}_{2}$.

\subsubsection{Fluxo de $\mathrm{CH}_{4}$}

$\mathrm{Na}$ figura 4 pode-se observar que a área com queima funcionou como sumidouro de $\mathrm{CH}_{4}$, enquanto que a área sem queima emitiu $\mathrm{CH}_{4}$ durante o período estudado. A média anual de seqüestro da área com queima foi da ordem de $66 \mu \mathrm{gCH}_{4} \mathrm{e}$, no mês de março ocorreu o maior seqüestro de $\mathrm{CH}_{4}$ do ambiente, com cerca de 174 $\mu \mathrm{gCH}$.

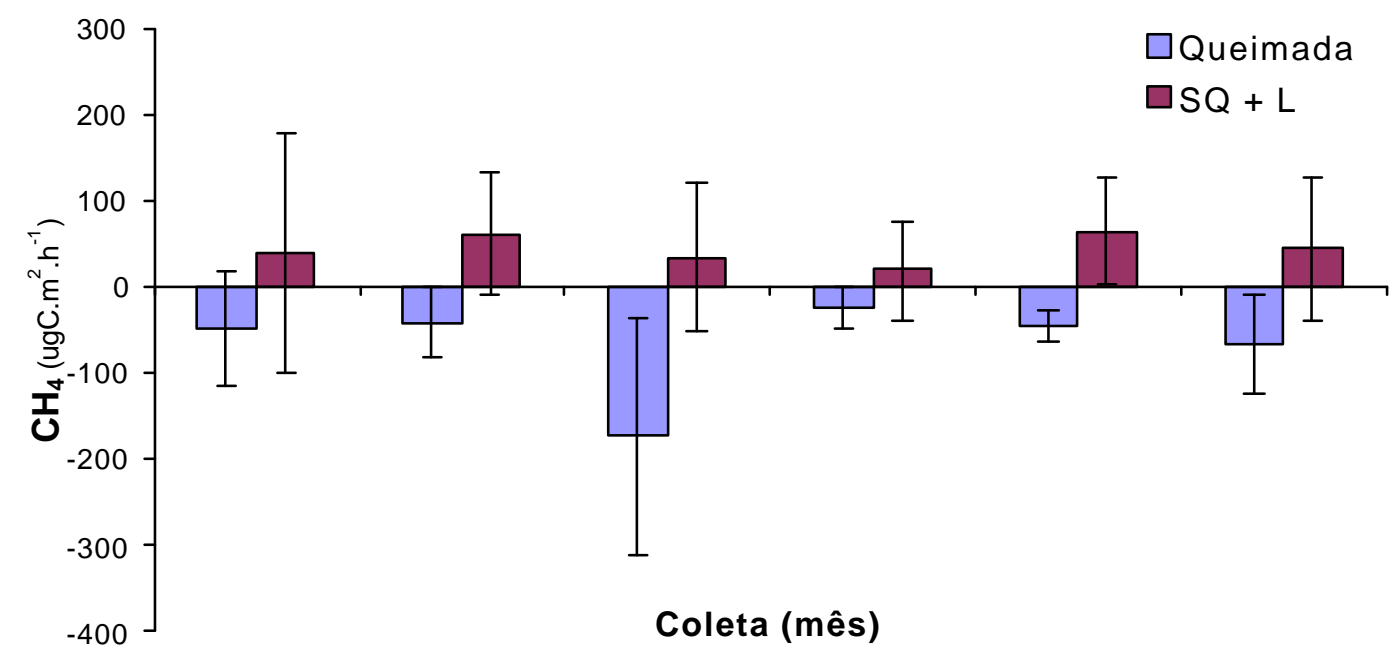

Figura 4 - Fluxo de $\mathrm{CH}_{4}\left(\mu \mathrm{gC} \cdot \mathrm{m}^{2} \cdot \mathrm{h}^{-1}\right)$ ao longo de um ano no experimento sistema de colheita com e sem queima da cana-de-açúcar.

$\mathrm{Na}$ área sem queima, a emissão média foi da ordem de $43 \mu \mathrm{gCH}_{4}$, sendo que as maiores emissões ocorreram nos meses de novembro $\left(61 \mu \mathrm{gCH}_{4}\right)$ e no mês de julho (64 $\left.\mu \mathrm{gCH}_{4}\right)$. 


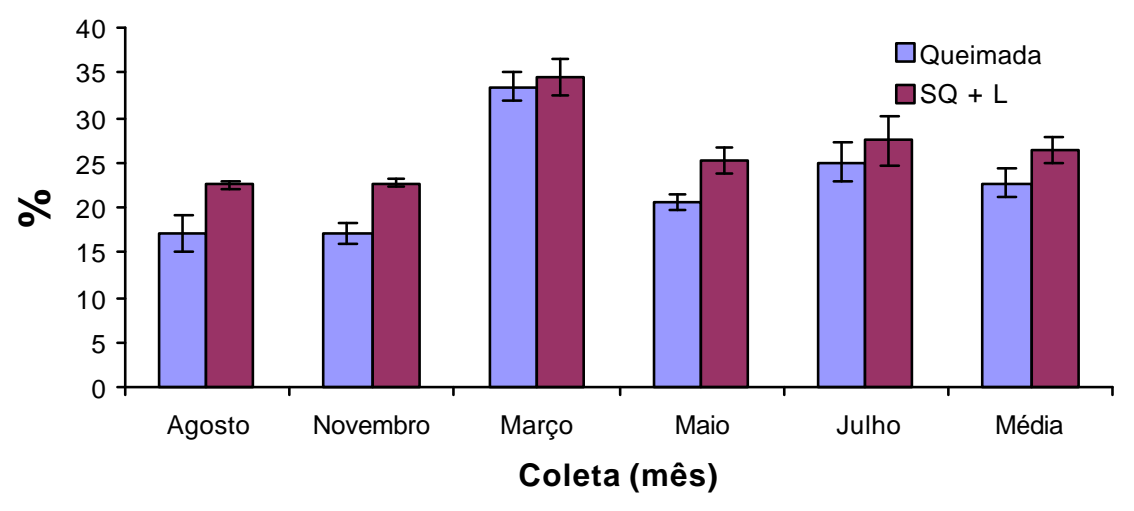

Figura 5 - Teor de água (\%) no solo (camada $010 \mathrm{~cm}$ ) durante o período de coleta (19992000) .

As variações dos fluxos de $\mathrm{CH}_{4}$ durante o ano para os tratamentos Q e $\mathrm{SQ}$, não parecem estar ligados às variações da umidade do solo (Figura 5). Portanto, as emissões de $\mathrm{CH}_{4}$ para SQ devem estar ligadas a um processo incompleto de oxidação do carbono da palhada.

\subsubsection{Fluxo de $\mathrm{N}_{2} \mathrm{O}$}

Nas duas áreas as emissões médias anuais foram muito próximas, sem apresentar diferença estatisticamente significativa. $\mathrm{Na}$ área sem queima a emissão foi de $38 \mu \mathrm{gN}_{2} \mathrm{O} \mathrm{m}^{2} \mathrm{~h}^{-1}$, enquanto que na área com queima a emissão média foi da ordem de 35 $\mu \mathrm{gN}_{2} \mathrm{O} \mathrm{m}_{2} \mathrm{~h}^{-1}$.

$\mathrm{Na}$ figura 6 pode-se observar que na área com queima ocorreu um aumento da emissão até o mês de março quando ocorreu a maior emissão $60 \mu \mathrm{gN}_{2} \mathrm{O} \mathrm{m}^{2} \mathrm{~h}^{-1}$ para SQ.

$\mathrm{Na}$ área sem queima, no início das coletas ocorreram as maiores emissões, com cerca de $85 \mu_{\mathrm{gN}_{2}} \mathrm{O} \mathrm{m}^{2} \mathrm{~h}^{-1}$ no mês de agosto e depois diminuiu até a última coleta em julho, sendo que as emissões de maio e julho foram bem próximas da média anual. A maior emissão de $\mathrm{N}_{2} \mathrm{O}$ na coleta realizada após o corte pode estar associada ao fato de ser feita a fertilização da área, sendo que o fertilizante $(75 \mathrm{~kg} \mathrm{~N}$ na forma de nitrato de 
amônio), é distribuído sobre a palhada na área SQ enquanto que em CQ, o fertilizante é incorporado ao solo

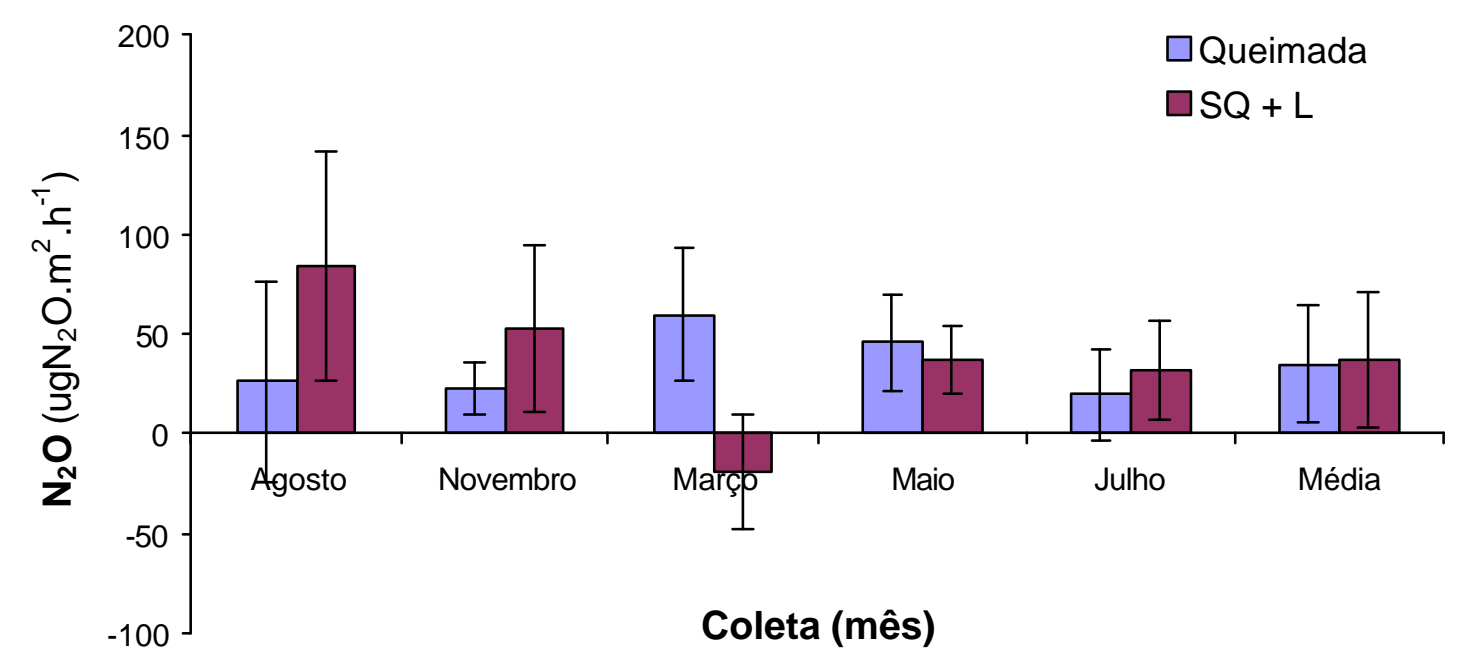

Figura 6 - Fluxo de $\mathrm{N}_{2} \mathrm{O}\left(\mu \mathrm{gN}_{2} \mathrm{O} \mathrm{m}^{2} \mathrm{~h}^{-1}\right)$ ao longo de um ano no experimento sistema de colheita com e sem queima da cana-de-açúcar.

Os dados de literatura indicam que os fluxos dos gases são fortemente influenciados pela presença da palhada da cana-de-açúcar (Weier 1996) e pela variação da temperatura e da umidade, como Rocha (2000) relatou num estudo realizado na mesma região deste estudo. Verchot et al. (2000) trabalhando em áreas de pastagem próximas a Paragominas (Pará), encontraram fluxos próximos aos deste estudo e, também observaram que a umidade do solo influenciou o fluxo de $\mathrm{N}_{2} \mathrm{O}$, já que nos meses mais secos, ocorreu um fluxo menor.

Os fluxos de $\mathrm{N}_{2} \mathrm{O}$ foi também influenciado pela adubação nitrogenada que ocorreu nas parcelas após o corte da cana com $75 \mathrm{kgN}$ na forma de nitrato de amônio que foram depositados sobre a palhada nas parcelas SQ e incorporados ao solo nas parcelas CQ. 
De um modo geral, podemos observar que o sistema sem queima, libera mais $\mathrm{CO}_{2}$ e $\mathrm{N}_{2} \mathrm{O}$, que o sistema com queima, em relação ao $\mathrm{CH}_{4}$ o sistema sem queima libera para o ambiente, enquanto que o sistema com queima absorve $\mathrm{CH}_{4}$. Entretanto, como poderá ser visto a seguir o balanço geral de emissões e mitigações é amplamente favorável ao sistema sem queima.

\subsection{Balanço do carbono em equivalente de $\mathrm{C}-\mathrm{CO}_{2}$}

Para finalizar o trabalho foi feito o balanço geral do carbono, considerando todas as variáveis envolvidas. Desta forma foram consideradas as diferenças entre os parâmetros e determinações encontradas nos sistema com e sem queima.

No balanço global foram considerados:

o rendimento, através da determinação da retirada de $\mathrm{C}$ do sistema pela fotossíntese;

a emissão de gases devido à queimada do canavial;

o fluxo dos gases durante o período de um ano;

o estoque de carbono na palhada e no solo.

Para o cálculo da emissão de gases devido à queimada utilizamos os dados fornecidos por Lima et al (1999), onde consta que a eficiência da queimada é da ordem de $79 \%$ e apresenta uma tabela de conversão (tabela1), para se calcular o equivalente em $\mathrm{C}-\mathrm{CO}_{2}$ de emissão dos gases.

Tabela 1. Taxa de emissão de gases liberados durante a queima de resíduos agrícolas e fatores de conversão para o cálculo das emissões.

\begin{tabular}{ccc}
\hline Gás & Taxa de Emissão & Fator de Conversão \\
\cline { 2 - 3 } $\mathrm{CH}_{4}$ & $0,005(\mathrm{C})$ & $16 / 12$ \\
$\mathrm{~N}_{2} \mathrm{O}$ & $0,007(\mathrm{~N})$ & $44 / 28$ \\
\hline
\end{tabular}

Fonte: IPCC (1996) 
Como as taxas de emissões se encontram em unidades de carbono (C) ou nitrogênio $(\mathrm{N})$, é necessário se empregar fatores de conversão, que consideram o peso molecular dos gases emitidos. A emissão desses gases é calculada como segue:

Emissão de $\mathrm{CH}_{4}=$ carbono liberado $\mathrm{x}$ taxa de emissão $\mathrm{x}$ fator de conversão

Emissão de $\mathrm{N}_{2} \mathrm{O}=$ carbono liberado $\mathrm{x}$ razão $\mathrm{N} / \mathrm{C} \times$ taxa de emissão $\mathrm{x}$ fator de conversão (10).

Para o cálculo do carbono liberado utilizou-se a fórmula (1): remanescente de palhada, menos o que sobra após a queimada (13,9 Mg MS ha- ${ }^{-1}$ 2,0 $\mathrm{Mg} \mathrm{MS} \mathrm{ha}^{-1}$ ) e multiplicamos pela concentração de carbono na palhada (40 $\mathrm{mg} \mathrm{Cg}^{-1} \mathrm{MS}$ ). Totalizando cerca de $4.700 \mathrm{kgC} \mathrm{ha}^{-1} \mathrm{ano}^{-1}$

A tabela 2 apresenta os valores em equivalente $\mathrm{C}-\mathrm{CO}_{2}$ nos sistemas com e sem queima, que são retirados do sistema através da fotossíntese, e o carbono que deixa de ser liberado para a atmosfera e fica retido no ambiente, na palhada remanescente sobre o solo, ou incorporado a MOS.

Como a produtividade foi um pouco maior no sistema $\mathrm{CQ}$, ocorreu uma retirado maior de carbono via fotossíntese nesse sistema com $5838 \mathrm{~kg} \mathrm{Cha}^{-1}$, enquanto que no sistema SQ, a retirada foi de $5560 \mathrm{~kg} \mathrm{C} \mathrm{ha}^{-1}$.

Em relação à estocagem de carbono na palhada e no solo, só ocorre no sistema SQ e foi da ordem de $1500 \mathrm{~kg} \mathrm{C.ha}{ }^{-1}$.

Tabela 2. Retirada do ambiente e retenção de carbono nos sistemas de colheita em com e sem queima.

\begin{tabular}{cccc}
\hline & \multicolumn{3}{c}{ Retirada do carbono do ambiente } \\
\cline { 2 - 4 } & Com queima (CQ) & Sem queima (SQ) & CQ-SQ \\
\hline \multirow{2}{*}{ Fotossíntese } & -5838 & Kg ha $^{-1}$ \\
& & -5560 & 278 \\
Solo & 0 & Retenção do carbono no sistema & \\
Palhada & 0 & -1033 & -1033 \\
Total & -5838 & -536 & -536 \\
& & -7129 & -1291 \\
\hline
\end{tabular}


Após relacionar os valores obtidos fazendo a relação entre os dois sistemas de colheita, o sistema sem queima proporciona que $1291 \mathrm{~kg} \mathrm{C}$ deixem de ser liberados para o ambiente.

Na tabela 3 estão demonstrados os valores de carbono em equivalente $\mathrm{CCO}_{2}$, que são liberados para o ambiente nos sistemas com e sem queima.

Tabela 3. Liberação de carbono para o ambiente em equivalente $\mathrm{CCO}_{2}$ nos sistemas com e sem queima.

\begin{tabular}{lccc}
\hline & \multicolumn{3}{c}{ Emissões de gases (queimada ou decomposição) } \\
\cline { 2 - 4 } $\mathrm{CO}_{2}$ & $\mathrm{CQ}$ & $\mathrm{SQ}$ & $\mathrm{CQ}-\mathrm{SQ}$ \\
$\mathrm{CH}_{4}$ & 4700 & 4527 & -173 \\
$\mathrm{~N}_{2} \mathrm{O}$ & 180 & 0 & -180 \\
$\mathrm{Soma}$ & 4369 & 0 & -4369 \\
& 9249 & 4527 & -4722 \\
& \multicolumn{2}{c}{ Fluxo dos gases durante o ano } & \\
$\mathrm{CO}_{2}$ & $\mathrm{CQ}$ & $\mathrm{SQ}$ & $\mathrm{CQ}-\mathrm{SQ}$ \\
$\mathrm{CH}_{4}$ & 11265 & 12247 & 982 \\
$\mathrm{~N}_{2} \mathrm{O}$ & $-44,4$ & 29,1 & 73,5 \\
Soma & 408 & 438,9 & 30,9 \\
Total & 11628,6 & 12715 & 1086,4 \\
\hline
\end{tabular}

A emissão de gases foi muito maior em $C Q$ do que em SQ, influenciada principalmente pela queimada que ocasionou uma liberação de 180 em eq C-CO $\mathrm{CO}_{2}$, oriundos do $\mathrm{CH}_{4}$ e 4369 em eq $\mathrm{C}-\mathrm{CO}_{2}$ advindos do $\mathrm{N}_{2} \mathrm{O}$. Nesta ponto está a maior diferença entre os sistemas, já que ocorre uma liberação pela queimada de mais de 4500 em eq $\mathrm{C}-\mathrm{CO}_{2}$ graças a esses dois gases. 
O fluxo de gases já foi comentado anteriormente, só ressaltando que ocorreu diferença entre os sistemas apenas para as emissões de $\mathrm{CH}_{4}$, onde o sistema CQ funcionou como um sumidouro de $\mathrm{CH}_{4}$, enquanto que em SQ houve liberação de $\mathrm{CH}_{4}$.

Para se fazer o balanço de carbono entre os dois sistemas de colheita, foi feita a relação entre as entradas e saídas de carbono do ambiente, conforme apresentado na tabela 4.

Tabela 4. Balanço anual do $\mathrm{C}$ em equivalente $\mathrm{C}-\mathrm{CO}_{2}$ nos sistemas com e sem queima.

\begin{tabular}{cccc}
\hline \multirow{2}{*}{ Balanço } & Com queima (CQ) & Sem queima (SQ) & CQ-SQ \\
\cline { 2 - 3 } & & Kg ha $^{-1}$ \\
\hline Retirada de C & 5838 & 7129 & 1291 \\
Liberação de C & 20877,6 & 17242 & 3635,6 \\
TOTAL & 15039,6 & 10113 & 4926,6 \\
\hline
\end{tabular}

De um modo geral com o sistema SQ, cerca de $5000 \mathrm{~kg}$ em eq $-\mathrm{CO}_{2} \cdot \mathrm{ha}^{-1} \cdot \mathrm{ano}^{-1}$ deixam de ser liberados para a atmosfera.

As figuras 6 e 7 ilustram o balanço do carbono comparando os dois sistemas

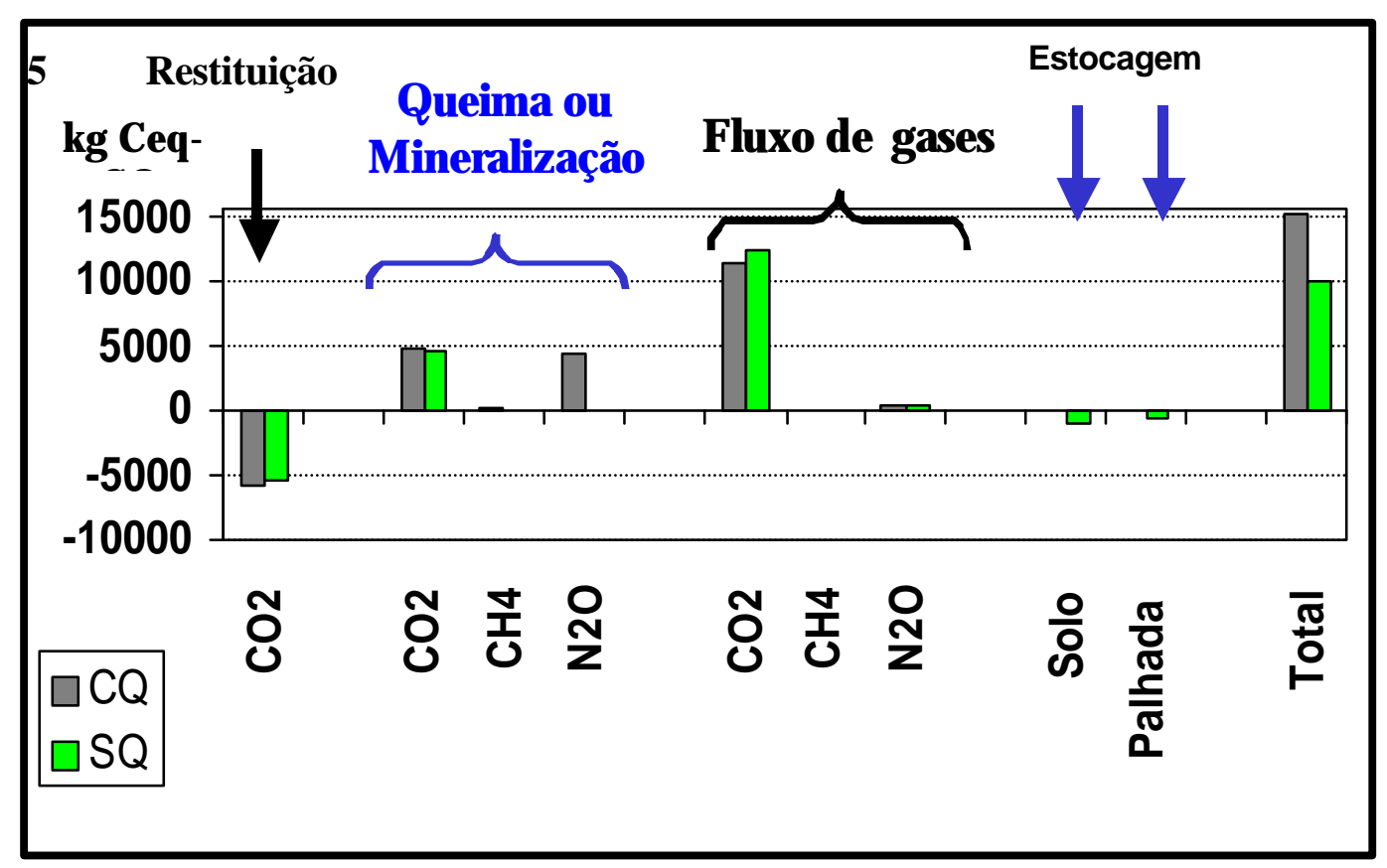

Figura 6 - Comparativo entre os dois sistemas. 


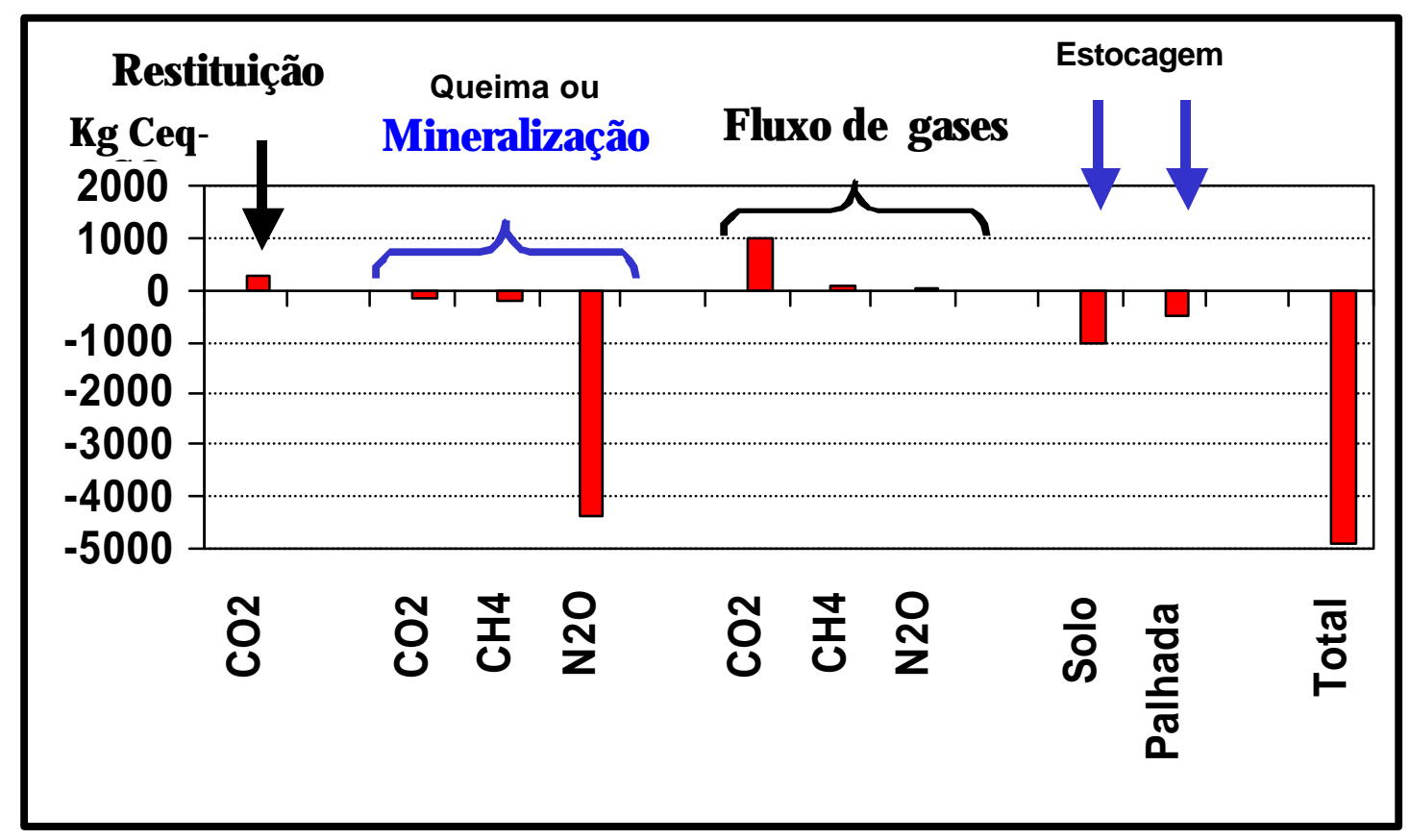

Figura 7 - Diferenças entre sistemas (SQ - CQ).

\subsection{Conclusões}

- Cálculos da emissão de gases do efeito estufa durante a queimada, realizados à partir de dados de literatura, demonstraram que a emissão de № O, expressa em C$\mathrm{CO}_{2}$ foi bastante elevada, da ordem de 4,3 $\mathrm{Mg} \mathrm{C}-\mathrm{CO}_{2} \mathrm{ha}^{-1}$ ano $^{-1}$;

- No manejo sem queima houve maior emissão de $\mathrm{CO}_{2}$ e emissão de $\mathrm{CH}_{4}$, enquanto que no manejo com queima, a emissão de $\mathrm{CO}_{2}$ foi menor, e ocorreu fixação de $\mathrm{CH}_{4}$. Quanto ao $\mathrm{N}_{2} \mathrm{O}$, não houve diferença entre as emissões nos dois sistemas;

- Considerando todos os compartimentos de estoque de carbono (planta, palhada e solo) e de fluxos de gases do efeito estufa, foi estabelecido um balanço do carbono em equivalente $\mathrm{C}-\mathrm{CO}_{2}$, emitido ou seqüestrado pelo manejo sem queima, em comparação ao manejo tradicional com queima. $\mathrm{O}$ resultado final para o Latossolo vermelho, em um período de três anos, foi uma mitigação das emissões dos gases do efeito estufa de cerca de $5 \mathrm{MgC}-\mathrm{CO}_{2} \mathrm{ha}^{-1} \mathrm{ano}^{-1}$. 


\section{CONCLUSÕES GERAIS}

Atualmente o manejo da cana-de-açúcar é caracterizado pelo uso ou não da queimada do canavial previamente à colheita. Com a queimada quase a totalidade da parte foliar da cultura é perdida por gaseificação e o restante que sobra é formado por materiais grosseiros e semicarbonizados. No manejo sem queima, a colheita é realizada geralmente por máquinas, ao contrário da colheita manual do manejo com queima, a parte foliar (cerca de $15 \mathrm{Mgha}^{-1}$ ano $^{-1}$ em matéria seca, ou $7 \mathrm{MgC} \mathrm{ha}^{-1}$ ano $^{-1}$ ) pode ser então depositada anualmente sobre o solo.

Nas condições desse estudo se constatou que a produtividade de cana-de-açúcar sob manejo com queima foi $5 \%$ maior do que sob manejo sem queima.

Após quatro anos de manejo sem queima observou-se a formação de uma camada de palhada, com diferentes níveis de decomposição. Puderam ser distinguidas, visualmente, três camadas diferentes: uma camada nova, mais recente; uma camada velha, entre um ano e dois anos após a deposição e uma camada muito velha, com pelo menos três anos. Os tecidos vegetais das camadas velha e muito velha foram alterados particularmente pelos fungos com diminuição da celulose, um pequeno aumento de lignina e diminuição da razão $\mathrm{C} / \mathrm{N}$.

A distribuição granulométrica da palhada demonstrou que a maior parte desta se encontra na fração > 4mm, com valores superiores a $50 \%$ nesta fração, e que a razão $\mathrm{C} / \mathrm{N}$ diminuiu com a diminuição do tamanho das frações.

A massa de material seco acumulada na palhada após quatro anos foi de 4,5 $\mathrm{Mg}$ $\mathrm{ha}^{-1}$, ou 1,1 $\mathrm{Mg} \mathrm{ha}^{-1}$ ano $^{-1}$ sobre um Latossolo Vermelho e de 3,6 $\mathrm{Mgha}^{-1}$, ou 0,9 $\mathrm{Mg} \mathrm{ha}^{-1}$ ano $^{-1}$ sobre um Neossolo Quartzarênico. Os fatores solo e variedade de cana-de-açúcar não influenciaram a decomposição da palhada. Mas houve um efeito positivo da 
quantidade depositada ao solo sobre a quantidade acumulada ao longo dos anos, tanto para o Latossolo Vermelho como para o Neossolo Quartzarênico.

Um total de $1,5 \mathrm{MgC} \mathrm{ha}^{-1}$ ano $^{-1}$ foram estocados no compartimento palhada $\left(0,5 \mathrm{MgC} \mathrm{ha}^{-1} \mathrm{ano}^{-1}\right)$ e solo $\left(1 \mathrm{Mg} \mathrm{C} \mathrm{ha}^{-1} \mathrm{ano}^{-1}\right)$. As emissões de gases ocorridas durante a queimada da palhada antes do corte no manejo com queima da cana-de-açúcar foram calculadas a partir de dados da literatura. A emissão de $\mathrm{N}_{2} \mathrm{O}$ durante a queimada liberou uma importante quantidade desse gás do efeito estufa, expressada em ${\mathrm{C}-\mathrm{CO}_{2}}_{2}(4,3 \mathrm{MgC}$ $\mathrm{CO}_{2} \mathrm{ha}^{-1} \mathrm{ano}^{-1}$ ). Os fluxos de gases na superfície do solo foram medidos ao longo de um ano nos manejos com e sem queima no Latossolo Vermelho. O manejo sem queima provocou uma emissão um pouco maior de $\mathrm{CO}_{2}$ do que o manejo com queima, e emissão de $\mathrm{CH}_{4}$, enquanto que com o manejo com queima ocorreu uma fixação desse gás. Quanto ao $\mathrm{N}_{2} \mathrm{O}$, não houve diferença nas emissões pelos dois manejos.

Considerando todos os compartimentos de estoque de carbono (planta, palhada e solo) e de fluxos de gases do efeito estufa, foi estabelecido um balanço do carbono em equivalente de $\mathrm{C}-\mathrm{CO}_{2}$ emitido ou seqüestrado pelo manejo sem queima, em comparação ao manejo tradicional com queima. Em um período de 3 anos no Latossolo Vermelho ocorreu uma mitigação das emissões dos gases do efeito estufa de cerca de $5 \mathrm{Mg} \mathrm{C}-\mathrm{CO}_{2}$ $\mathrm{ha}^{-1}$ ano $^{-1}$.

Desta forma pode-se concluir que o sistema de manejo de colheita sem a queima prévia do canavial, pode atuar de maneira significativa no seqüestro de carbono, aumentando a eficiência do agrossistema cana-de-açúcar. 


\section{REFERÊNCIAS BIBLIOGRÁFICAS}

ABRAMO FILHO, J.; MATSUOKA, S.; SPERANDIO, M.L.; RODRIGUES, R.C.D.; MARCHETTI, L.L. Resíduos da colheita mecanizada de cana crua. Álcool \& Açúcar, n.67, p.23-25, abr./jun. 1993.

ABRAMO FILHO, J. Decomposição da palha da cana-de-açúcar em canavial colhido sem queima, mecanicamente. Rio Claro, 1995. 91p. Dissertação (M.S.) - Instituto de Biociências, Universidade Estadual Paulista.

AUDE, M.I.S.; MARCHEZAN; DARIVA, T.; PIGNATARO, L.H.B. Manejo do palhiço da cana-de-açúcar: efeito na produção de colmos industrializáveis e outras características agronômicas. Ciência Rural, v.23, n.3, p.281-286, 1993.

BARBOSA, V. Cultivo de soqueira, adubação e reforma de canaviais sob sistema de cana crua. In: SEMANA DA CANA DE PIRACICABA - SECAPI, 2., Piracicaba, 1997. Anais. Piracicaba: Comissão organizadora, 1997. p.52-54.

BEUNARD, D. Essai de caractérisation biochimique de quelques sous-produits (agroalimentaires, agricoles) et fertilisants organiques: application de la méthode de Van Soest. In: Sciences et technique du languedoc. Montpellier, 1999. 49p.

BOWDEN, R.D.; STEUDLER, P.A.; MELILLO, J.M. Annual nitrous oxide fluxes from temperate forest soils in the northeastern United States. Journal of Geophysical Research, v.95, p.13997-14005, 1990.

CRUTZEN, P.J.; ANDRADE, M.O. Biomass burning in the tropics: impact on atmospheric chemistry and biological cycles. Science, v.250, p.1669-1678, 1990.

DEEPCHAND, K. A note on the pyrolysis behaviour of sugar cane fibrous products. Biological Wastes, v.20, p.203-208, 1987. 
FEIGL, B.J.; STEUDLER, P.A.; CERRI, C.C. Effects of pasture introduction on soil $\mathrm{CO}_{2}$ emissions during the dry season in the state of Rondônia, Brazil. Biogeochemistry, v.31, p.1-14, 1995.

FURLANI NETO, V.L. Colheita mecanizada da cana-de-açúcar. STAB: Açúcar, Álcool e Subprodutos, v.94, n.3, p.8-9, 1994.

FURLANI NETO, V.L.; RIPOLI, T.C.; VILA NOVA, N.A. Biomassa de cana-deaçúcar: energia contida no palhiço remanescente de colheita mecânica. STAB: Açúcar, Álcool e Subprodutos, v.15, n.4. p.24-27, mar./abr. 1997.

GALVÃO, F.; ZILLER, S.R.; BUFREM, A.M. Decomposição foliar de algumas espécies arbóreas. Revista Setor Ciências Agrárias, v.11, n.1-2, p.161-168, 1989/1991.

INTERGOVERNMENTAL PANEL ON CLIMATE CHANGE - IPCC. Climate change in 1994: radiactive forcing of climate change. Cambridge: Cambridge University Press, 1995. 339p.

INTERGOVERNMENTAL PANEL ON CLIMATE CHANGE - IPCC. Guidelines for national greenhouse gas inventories: reference manual. Paris: OECD, 1996. 572p.

JALLOW, B.P. Emissions of the greenhouse gases from agriculture, land-use change and forestry in the Gambia. Environmental Monitoring and Assessment, v.38, p.301-312, 1995.

KNOWLES, P.F.; MARSH, D.; RATTLE, H.W.E. Magnetic resonance of biomolecules. New York: John Wiley, 1976. 147p.

LAL, R.; KIMBLE, J.; FOLLETT, R.F. (Ed.). Soil properties and their management for carbon sequestration. Lincoln: USDA, National Soil Survey Center, 1997. $150 \mathrm{p}$.

LIMA, M.A.; LIGO, M.A.; CABRAL, M.R.; BOEIRA, R.C.; PESSOA, M.C.P.Y.; NEVES, M.C. Emissão de gases do efeito estufa provenientes da queima de resíduos agrícolas no Brasil. Jaguariúna: Embrapa Meio Ambiente, 1999. 60p. (Documentos, 7) 
LUCA, E.F. Matéria orgânica e atributos do solo em sistemas de colheita com e sem queima da cana-de-açúcar. Piracicaba, 2002. 101p. Tese (Doutorado) - Centro de Energia Nuclear na Agricultura, Universidade de São Paulo.

LYNCH, J.M. Biotecnologia de solo: fatores microbiológicos na produtividade agrônoma. São Paulo: Manote, 1986. 209p

MARTIN-NETO, L.; ROSSEL, R.; SPOSITO, G. Correlation of spectroscopic indicators of humification with mean annual rainfull along a temperature grassland climosequence. Geoderma, v.81, p.305-311, 1998.

MELILLO, J.M.; ABER, J.D.; MURATORE, J.F. Nitrogen and lignin control of hardwood leaf litter decomposition dynamics. Ecology, v.63, n.3, p.621-626, 1982.

NG KEE KWONG, K.F.; DEVILLE, J. Residual fertilizer nitrogen as influenced by timing and nitrogen forms in a silty clay soil under surgacane Mauritus. Fertilizer Research, v.14, p.219-226, 1987.

OLIVEIRA, M.W. de; TRIVELIN, P.C.O.; GAVA, G.J. de C.; PENATTI, C.P. Degradação da palhada de cana-de-açúcar. Scientia Agricola, v.56, n.4, p.803-09, out./dez. 1999.

PAGE, R.E.; GLANVILLE, T.J.; TRUONG, P.N. The significance of trash retention trials in the Isis an Maryborought mill areas. In: CONFERENCE OF THE AUSTRALIAN SOCIETY OF SUGAR TECHNOLOGISTS, 8., Townville, 1986. Proceedings. Brisbane: Watson Ferguson, 1986. p.95-101.

PRIMAVESI, A. A matéria orgânica. In: Manejo ecológico do solo. São Paulo: Nobel, 1987. p.108-135.

POOLE, C.P.; FARACH, H.A. Theory of magnetic resonance. New York: John Wiley/Interscience, 1972. 117p.

RAVEN, P.H.; EVERT, R.F.; EICHHORN, SE. Biologia vegetal. 5.ed. Rio de Janeiro: Guanabara Koogan, 1996. 728p.

RIPOLI, T.C.; MIALHE, L.G.; BRITO, J.O. Queima de canavial, o desperdício não mais admissível. Álcool \& Açúcar, v.10, n.54, p.18-23, 1990. 
RIPOLI, T.C.; MOLINA JÚNIOR, W.F.; STUPIELLO, J.P.; NOUEIRA, M.C.; SACCOMANO, J.B. Potencial energético de resíduos de casecha de la caña verde. STAB: Açúcar, Álcool e Subprodutos, v.10, n.1, p.22-28, 1991.

RÍPOLI, T.C.; TILLMAN, C.A. de C.; MILAN, M.O. O corte manual da cana verde. Álcool \& Açúcar, v.77, p.28-30, 1995.

ROBIN, D. Intérêt de la caractérisation biochimique pour li évaluation de la proportion de matère organique stable après décomposition dans le sol et la classification des produits organominéraux. Agronomie, v.17, p.157-171, 1997.

ROCHA, H.R. da. Atmospheric $\mathrm{CO}_{2}$ fluxes and soil respiration measurements over sugarcane in southeast Brazil. In: LAL, R.;. KIMBLE, J.M.; STEWART, B.A. Global climate change and a tropical ecossystems. Lincoln: USDA, 1999. p.405414.

SALLAWAY, M.M. Trash retention as a soil conservation technique. In: CONFERENCE OF THE AUSTRALIAN SOCIETY OF SUGAR TECHNOLOGIST, Mackay, 1979. Proceedings. Brisbane: BSES, 1979. p.133-137.

SANG, S.L.; YEH, C.S.; CHEN, C.H.; LEE, L.J.; KE, L.J.; CHEN, W.S.; HSIAO, Y.C.

A study on deterioration of chopped burnt and chopped unburnt cane in Taiwan.

Taiwan Sugar, v.34, n.2, p.37-49, 1987.

SANGER, L.J.; COX, P.; SPLATT, P.; WHELAN, M.J.; ANDERSON, J.M. Variability in the quality of Pinus Sylvestris needles and liter from sites with different soil characteristics: lignin and phenylpropanoid signature. Soil Biology \& Biochemistry, v.28, n.7, p.829-835, 1996.

SÃO PAULO (Estado). Leis, decretos, etc. Decreto n $n^{0}$ 47.700, de 11 de março de 2003.

Diário Oficial do Estado de São Paulo, 12 mar. 2003. Seção I, v.113, n.46, p.1-2. Regulamenta a Lei nº 11.241 de 19 de setembro de 2002 que dispõe sobre a eliminação gradativa da queima da palha da cana-de-açúcar e dá providências correlatas. 
SAS INSTITUTE. SAS/STAT guide for personal computers: version 6 (software). Cary, 1987.

SILVA, L.L. Álcool e a nova ordem econômica mundial: frente parlamentar sucroalcooleira. São Paulo: Segmento, 1996. p.60-63.

SINGER, L.S. Synthetic ruby as a secondary standard for the measurement of intensities in Electron Paramagnetic Resonance. Journal of Physical Application, v.30, p.1463-1464, 1959.

SPAIN, A.V.; HODGEN, M.J. Changes in the composition of sugarcane harvest residues during decomposition as a surface mulch. Biology Fertility Soils, v.17, p.225-231, 1994.

SPAROVEK, G. Informações geográficas para a identificação de áreas com potencialidade para colheita de cana crua. In: SEMANA DA CANA DE PIRACICABA - SECAPI, 2., Piracicaba, 1997. Anais. Piracicaba: Comissão organizadora, 1997. p.58-60.

STUPIELLO, J.P. Alguns aspectos de qualidade da matéria prima. STAB: Açúcar, Álcool e Subprodutos, v.7, n.3-5, p.52-54, 1989.

TRIVELIN, P.C.O.; VICTORIA, R.L.; RODRIGUES, J.C. Aproveitamento por soqueira de cana-de-açúcar de final de safra do nitrogênio da aquamônia- ${ }^{15} \mathrm{~N}$ e aplicado ao solo em complemento à vinhaça. Pesquisa Agropecuária Brasileira, v.30, n.12, p.1375-1385, 1995.

UNIÃO DA AGROINDÚSTRIA CANAVIEIRA DE SÃO PAULO - UNICA.

Produtos : cana-de-açúcar: estatísticas. http://www.única.com.br (15 mar. 2003)

VAN SOEST, P.J. Use of detergent in the analysis of fibrous feed. II. A rapid method for the determination of fibber and lignin. Journal of Analytical Official Agriculture Chemistry, v.46, p.829-835, 1963.

VERCHOT, L.V.; DAVIDSON, E.A.; CATTÂNIO, J.H.; ACKERMAN, I.L. Land-use and biogeochemical controls of methane fluxes in soils of eastern Amazonia. Ecosystems, v.3, p.41-56, 2000. 
WEIER, K.L. Trace gas emission from a trash blanketed sugarcane field in tropical Australia. In: WILSON, J.R.; HOGART, D.M; CAMPBELL, J.A.; GARSIDE, A.L. (Ed.). Sugarcane: research towards efficient and sustainable production. Brisbane: CSIRO, Division of Tropical Crops and Pastures, 1996. p.271-272.

WEIER, K.L. Sugarcane fields: sources or sinks for greenhouse gas emissions ? Australian Journal Agricultural Research, v.49, p.1-9, 1998. 